\title{
5-Hydroxymethylfurfural (HMF) in organic synthesis: a review of its recent applications towards fine chemicals
}

\author{
Weigang Fan, Charlie Verrier, * Yves Queneau, Florence Popowycz* \\ Université de Lyon, UMR 5246, CNRS, Université Lyon 1, INSA Lyon, CPE Lyon, ICBMS, \\ Bâtiment Edgar Lederer, F-69622 Villeurbanne Cedex, France. \\ E-mail: charlie.verrier@insa-lyon.fr; florence.popowycz@insa-lyon.fr
}

\begin{abstract}
Hydroxymethylfurfural (HMF) is a platform molecule produced from renewable carbohydrate sources such as fructose, glucose, sucrose, cellulose or inulin. Its interest as building block for accessing chemicals of industrial relevance such as monomers or biofuels has resulted in intense research on cleaner and more efficient processes for its manufacture. Its increased availability has also attracted many studies exploring its use towards value-added fine chemicals, thus widening the scope of its applications. The aim of this review is to bring an updated overview on the use of 5-HMF in fine organic synthesis, to the exclusion of already well documented platform molecules and intermediates such as 2,5-diformylfuran, 2,5-furandicarboxylic acid, 2,5dihydroxymethylfuran, 2,5-dimethylfuran and so on.
\end{abstract}

\section{Table of contents}

1. Introduction 1

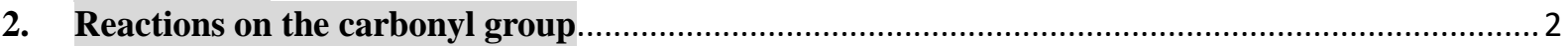

2.1 Carbon-carbon bond formation reactions.............................................................. 2

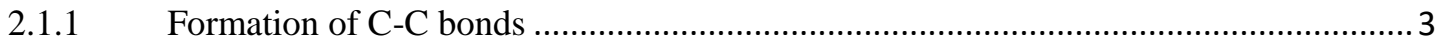

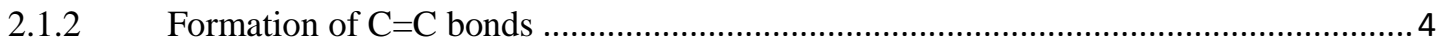

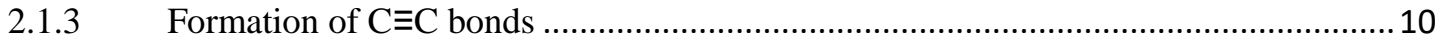

2.1.4 Oxidative transformations .......................................................................... 10

2.2 Carbon-nitrogen bond formation reactions .................................................... 11

2.2.1 Synthesis of imines, hydrazones, oximes, nitrones and their applications.................11

2.2.2 Preparation of amines ................................................................................ 13

2.2.3 Synthesis of nitrogen-containing heterocycles............................................. 14

2.2.4 Oxidative transformations ............................................................................ 16

2.3 Carbon-oxygen and carbon-sulfur bond formation reactions ....................................... 16

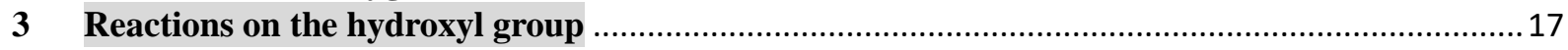

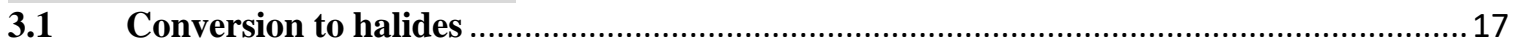

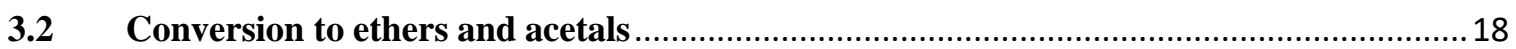

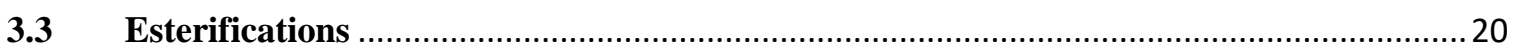

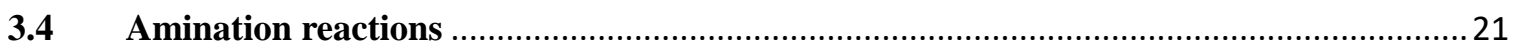

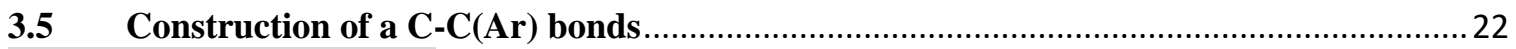

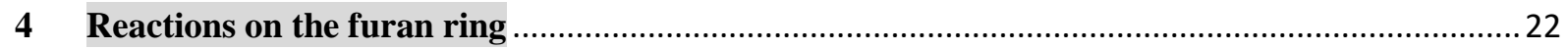

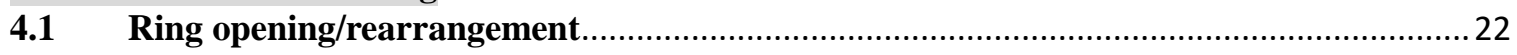

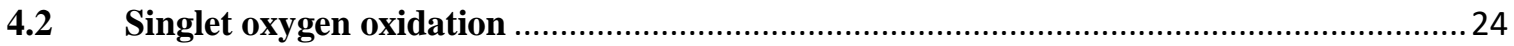

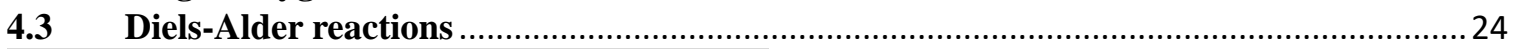

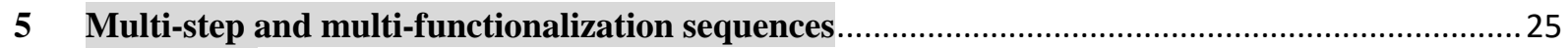

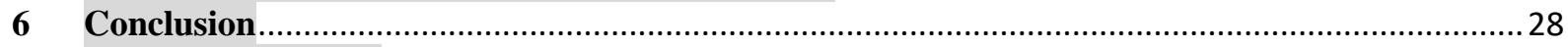

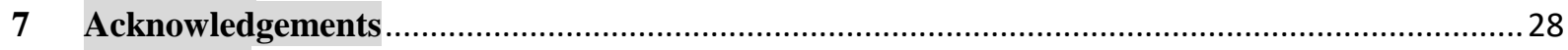

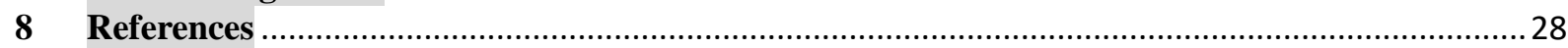

\section{Introduction}

The exploitation of biomass-derived platform molecules is an increasingly developed strategy for replacing building blocks arising from petrochemicals. However, their use can be limited due to low-tonnage productions and rather high prices. In the past decades, the obvious interest of bio-based platform molecules for developing 
novel chemicals, notably in the field of polymer chemistry, has generated intensive efforts for improving their manufacture processes, therefore increasing their availability due to higher scale industrial production and lower cost. A consequence of this increased availability has been a renewed interest of the chemical community to apply these bio-based building blocks in strategies towards fine chemicals also.

Among platform molecules, 5-hydroxymethylfurfural (5-HMF) appears as one of the most promising. This apparently simple molecule, obtained by dehydration of hexoses (as monosaccharides or included in oligo- or polysaccharides), incorporates an aldehyde group at the $\mathrm{C} 2$ position, a hydroxymethyl group at the $\mathrm{C} 5$ position, as well as a reactive furan ring, offering a wide range of possible functionalizations and chemical transformations. Whereas the first reports related to the formation and uses of 5-HMF appeared at the end of the $19^{\text {th }}$ century, it is only in the past decades that this area has entered a boom stage, consistently with the increasing awareness of environmental concerns in the chemical community and the development of biobased chemistry. A specific character of HMF is its relative limited stability, which is a drawback both at the level of its manufacture and of its utilizations. This sensitivity to both heat and acids leads to the occurrence of degradation and undesired reactions such as dimerization or oligomerization. ${ }^{[1-3]}$ Taking into account the high potential of 5-HMF, some methods aiming at improving its stability start to appear, such as the recently reported use of sodium dithionite. ${ }^{[4]}$

Several comprehensive recent reviews by Afonso, ${ }^{[5]}$ de Vries ${ }^{[6-7]}$ and Ananikov, ${ }^{[8]}$ extensively cover the synthesis and manufacture of HMF, and/or its catalytic conversion to simple molecules such as 2,5-diformylfuran (DFF) or 2,5-difurandicarboxylic acid (FDCA). They illustrate most immediate industrial relevance and economic interests of HMF and, in a less detailed manner, its applications towards fine chemicals. The purpose of the present review article, as a complementary account to the extensive reviews previously published, is to provide an exhaustive and updated overview describing the synthetic methodologies developed around 5-HMF chemistry, in the context of fine chemicals synthesis, including multi-step and total synthesis. It illustrates the importance of the HMF scaffold as a building block in all areas of synthetic organic chemistry.

The review is organized with respect to the different chemical functions present in HMF and their reactivity. First, transformations of the aldehydic moiety of 5-HMF will be discussed, then the transformations of the hydroxymethyl group, and the modifications of the furan ring (Scheme 1). Finally, multistep and multifunctionalization sequences involving 5-HMF are shown, giving a complete exemplification of the incorporation of this platform molecule into complex chemical architectures.

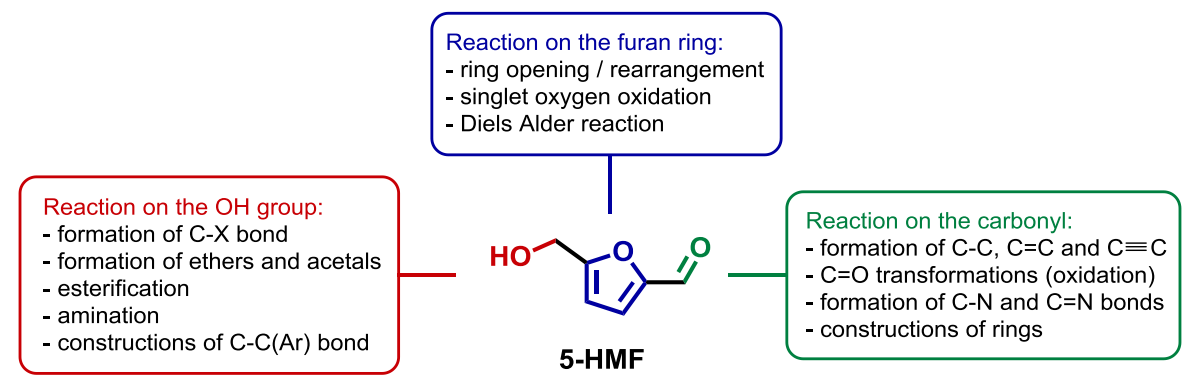

Scheme 1. Overview of 5-HMF chemistry

\section{Reactions on the carbonyl group}

Aldehydes are essential building blocks in organic synthesis. Their high electrophilicity makes them appropriate partners for reactions with a variety of nucleophiles, allowing the formation of single, double or triple carboncarbon bonds, but also the construction of carbon-heteroatom bonds through condensation reactions. Consequently, most of the direct transformations of 5-HMF toward high value-added chemicals take advantage of its aromatic aldehyde group.

\subsection{Carbon-carbon bond formation reactions}

Carbon-carbon bonds are among the strongest bonds of organic chemistry, and their construction constitutes the basis of most synthetic routes toward organic molecules. Many strategies have been developed to generate new $\mathrm{C}-\mathrm{C}$ bonds using the aldehydic moiety of 5-HMF, offering accesses to new bio-based compounds with various properties. 


\subsubsection{Formation of C-C bonds}

The benzoin condensation is an efficient method to upgrade HMF to $\mathrm{C}_{12}$ furoins as potential fuel intermediates. During the course of a study on the degradation of HMF in ionic liquids such as 1-ethyl-3-methylimidazolium acetate ([EMIM]OAc), Chen found that 1-ethyl-3-methylimidazolin-2-ylidene carbene could catalyze the selfcondensation of HMF to form 5,5'-dihydroxymethylfuroin 1 with high conversion and selectivity (Table 1). ${ }^{[9]}$ Since this pioneering work, several NHC catalysts derived from ILs and discrete catalysts proved their efficiency for the benzoin condensation of HMF. ${ }^{[10-14]}$ Benzaldehyde lyase could also be used as a biocatalyst for this umpolung condensation. ${ }^{[15]}$ However, under those conditions, a partial spontaneous oxidation to the corresponding diketone was observed.

Table 1. Organocatalysts and biocatalyst for HMF benzoin condensation

Entry

Afonso and coworkers reported the preparation of a highly functionalized furan skeleton via a novel reaction pathway from 5-HMF or $O$-protected HMF and a secondary amine. ${ }^{[16]}$ HMF could react with morpholine to provide the iminium intermediate $\mathbf{2}$, which is in equilibrium with the trienamine $\mathbf{3}$ under acidic catalysis (Scheme 2). The two intermediates reacted together, releasing a molecule of amine to yield the coupling product 4.

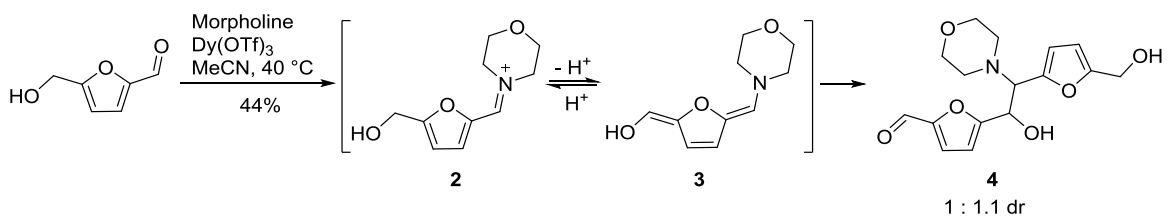

Scheme 2. Homo-bis-vinylogous Mannich-type reaction on 5-HMF

The synthesis of the symmetric triarylmethane 5 was achieved by reaction of a secondary aniline on 5-HMF in the presence of $\mathrm{Yb}(\mathrm{OTf})_{3}$ as acidic catalyst, following a double Friedel-Crafts pathway (Scheme 3). ${ }^{[17]}$ The scope of the reaction was successfully extended to $O$-substituted hydroxymethylfurfurals. The reaction was found to be significantly accelerated by applying high pressure, especially in the case of less reactive anilines. The authors considered that the first Friedel-Crafts reaction proceeded first via the addition of the aniline onto the iminium ion formed by condensation of the secondary aniline on the aldehyde. Then a second Friedel-Crafts reaction took place in a non-concerted mechanism suggesting a secondary carbocation as the transient intermediate for this step. 


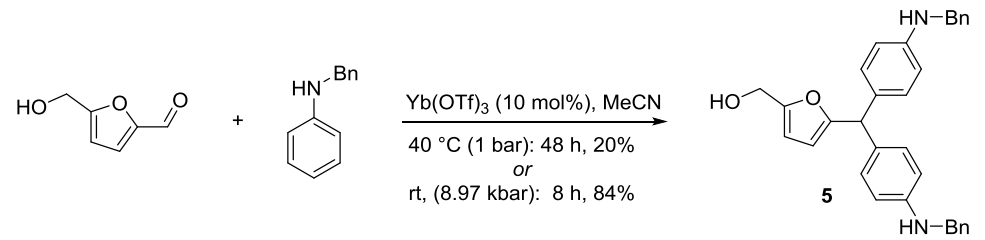

Scheme 3. Synthesis of symmetric triarylmethanes via Friedel-Crafts mechanism

A last type of C-C bond forming reaction with carbonyl derivatives exploiting the Morita-Baylis-Hillman reaction has been reported. The use of electron-deficient alkenes such as methyl acrylate ${ }^{[18]}$ and acrylamide ${ }^{[19]}$ in combination with $\mathrm{DABCO}$ in a dioxane/water mixture at room temperature gave access to the conjugated compounds 6 (Scheme 4). Our group more recently extended this reactivity to other solvent mixtures, including bio-based solvent, and to glycosylated derivatives of HMF. ${ }^{[20-21]}$

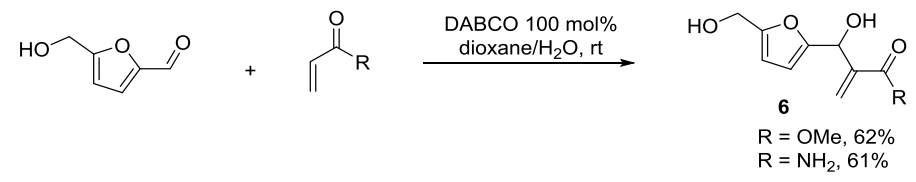

Scheme 4. Morita-Baylis-Hillman reaction of 5-HMF

\subsubsection{Formation of $\mathrm{C}=\mathrm{C}$ bonds}

Aldol- and Knoevenagel type condensations are classical transformations of the chemistry of the carbonyl group. Aromatic aldehydes, such as HMF, are very good substrates for such reactions, due to the absence of proton on the carbon adjacent to the carbonyl (no competition possibly arising from self-condensation).

Different research groups have explored the reaction of acetone with 5-HMF under basic conditions. This transformation provides a straightforward access to the natural products rhemanones $\mathrm{A}, \mathrm{B}$ and $\mathrm{C}$, owning interesting biological activities such as blood platelet aggregation inhibitors or immunostimulant. The challenge relies on the control of the mono- or bis-condensation of the ketone on 5-HMF, as the monoadduct leads to rhemanone $\mathrm{B}$ and $\mathrm{C}$, whereas bis-condensation would give an advanced intermediate for the preparation of rhemanone A (Table 2). The group of Tamariz used sodium hydroxide to promote the reaction, and a good control of the selectivity (ratio 7 vs $\mathbf{8}$ ) was obtained by tuning the quantity of acetone used. ${ }^{[22]}$ The yield of mono adduct 7 reached $91 \%$ when acetone was used in excess, whereas the di-adduct 8 was obtained in a $60 \%$ yield when HMF was used in excess. Palkovits described a quite selective mono-condensation mediated by mesoporous magnesium aluminate as the base. ${ }^{[23]}$ Roman-Leshkov reported the use of hafnium- $\beta$ zeolite providing compound 7 with $>99 \%$ selectively and $73 \%$ conversion. ${ }^{[24]}$ Another selective mono-condensation, promoted by $\mathrm{CO}_{2}$ under elevated pressure with a high yield, was reported by Jessop. ${ }^{[25]}$ A similar yield of the mono-adduct 7 could be obtained under heterogeneous catalysis conditions using amine-grafted Faujasite (FAU) zeolite nanosheets (Table 2). ${ }^{[26]}$ Zirconium carbonate was also used to promote the same condensation under mild conditions. ${ }^{[27]}$

Table 2. Synthesis of the precursors of rhemanones

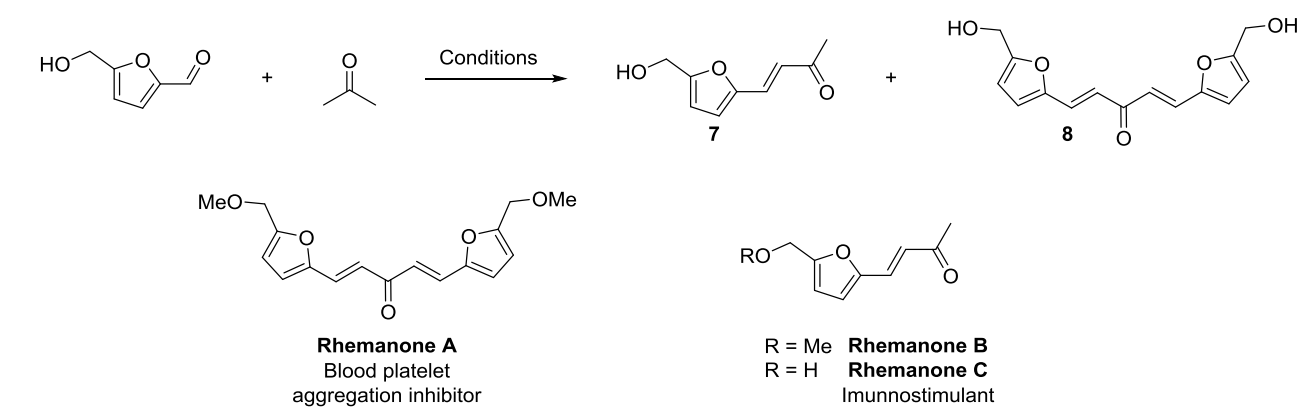

\begin{tabular}{cccc}
\hline Entry & Conditions & Product (yield) & Ref \\
\hline 1 & Acetone (2 eq.), $\mathrm{NaOH}(\mathrm{aq}), \mathrm{EtOH}, \mathrm{rt}$ & $\mathbf{7}(91 \%)$ & ${ }^{[22]}$ \\
2 & Acetone (0.5 eq.), $\mathrm{NaOH}(\mathrm{aq}), \mathrm{EtOH}, \mathrm{rt}$ & $\mathbf{8}(60 \%)$ & ${ }^{[22]}$ \\
\hline
\end{tabular}




\begin{tabular}{rccc}
\hline 3 & Acetone (as solvent), $\mathrm{MgAl}_{2} \mathrm{O}_{4}, 140{ }^{\circ} \mathrm{C}$ & $\mathbf{7}(81 \%)+\mathbf{8}(11 \%)$ & ${ }^{[23]}$ \\
4 & Acetone (3 eq.), Hf-Beta zeolite, toluene, $90{ }^{\circ} \mathrm{C}$ & $\mathbf{7}(73 \%$ conv) & ${ }^{[24]}$ \\
5 & Acetone (solvent), $\mathrm{H}_{2} \mathrm{O}, 2.5 \mathrm{MPa} \mathrm{CO}, 200{ }^{\circ} \mathrm{C}, 20 \mathrm{~h}$ & $\mathbf{7}(95 \%)$ & ${ }^{[25]}$ \\
6 & Acetone (solvent), amine-grafted FAU nanosheets, $130{ }^{\circ} \mathrm{C}$ & $\mathbf{7}(92 \%$ conv) & ${ }^{[26]}$ \\
7 & Acetone (20 eq.), zirconium carbonate, $\mathrm{H}_{2} \mathrm{O}, 54{ }^{\circ} \mathrm{C}$ & $\mathbf{7}(92 \%)$ & ${ }^{[27]}$ \\
\hline
\end{tabular}

Skowronski ${ }^{[28]}$ and Corma $^{[29]}$ independently reported the efficient condensation of acetophenone derivatives with HMF. The reaction, promoted by potassium hydroxide in methanol, produced 5-hydroxymethyl-furfurylideneacetophenone 9, later named furanochalcone, in $82 \%$ yield (Scheme 5). The same transformation was also performed with almost quantitative yield in the presence of a catalytic amount of $\mathrm{Mg}$ - $\mathrm{Al}$ mixed oxide ( $\mathrm{HTc}$ ). Different 5-hydroxymethyl-furanochalcones have then been prepared following similar strategies, and evaluated for diverse biological activities such as phosphatase inhibitor ${ }^{[30]}$ or synergistic antifungal. ${ }^{[31]}$ The group of Surwayanshi described the preparation of enone $\mathbf{1 1}$ by condensation of the dihydro- $\alpha$-ionone $\mathbf{1 0}$ with HMF under microwave irradiation using $\mathrm{KF}$ and aluminate as heterogeneous base. ${ }^{[32]}$ The product $\mathbf{1 1}$ was then evaluated for its antileshmanial properties. A condensation with 1-C-( $\beta$-D-galactopyranosyl)-propan-2-one in the presence of lithium hydroxide was performed to prepare galactose derivative $\mathbf{1 2}$ in $65 \%$ yield, which proved to be an effective antimycobacterial agent (Scheme 5). ${ }^{[33]}$ A $C$-4 epimer of 12 could also be prepared from 1-C- $\beta$ glucosylacetone in dichloromethane in the presence of pyrrolidine in $87 \%$ yield. $^{[34]}$

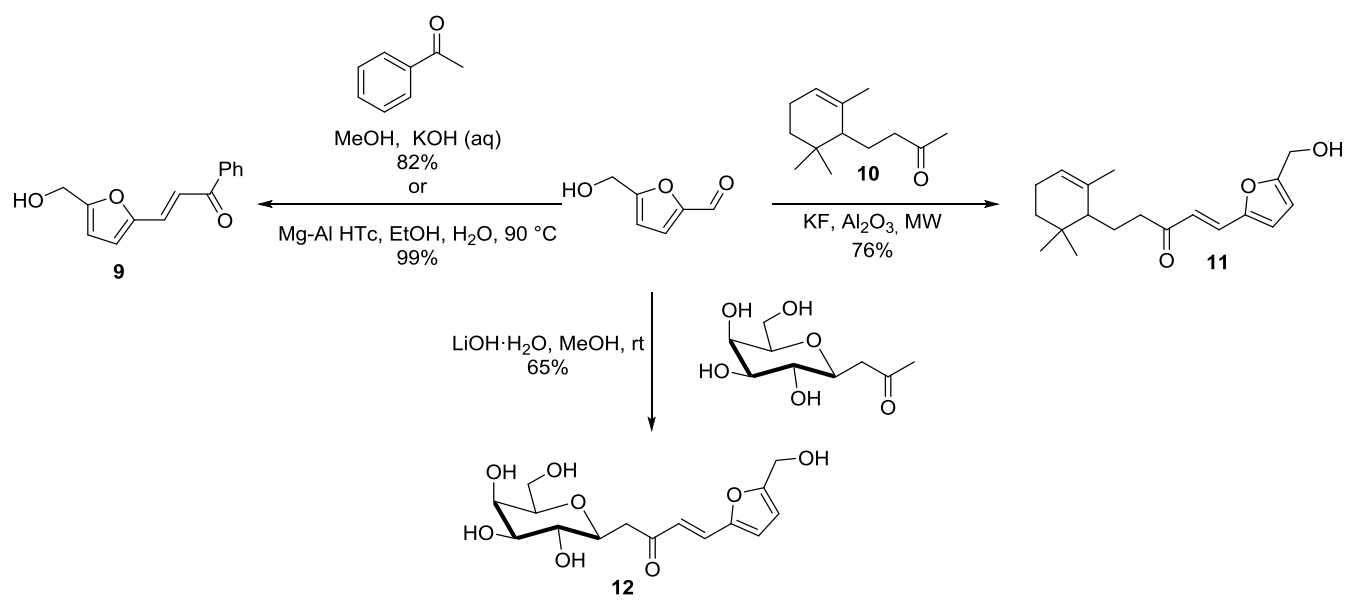

Scheme 5. Condensation with ketones

Some more elaborated ketones have been employed in aldol condensations with 5-HMF to produce molecules with high added-value. One example relies on its condensation with cyclooctanone to generate the intermediate 13, which can be further converted into the thieno[2,3-b]pyridine 14, found to be active against the elongation factor-2 kinase (eEF2-K) (Scheme 6). ${ }^{[35]}$ Some benzofuran-3-ones were also condensed with 5-HMF to prepare furanic analogues $\mathbf{1 5}$ of aurone. The $\mathrm{KOH}$-mediated aldol condensation of di-hydroxybenzofuranone with HMF provided 15 in 53\% yield. ${ }^{[36]}$ The microwave activation carried out in a deep eutectic solvent did not bring any improvement in terms of yield. ${ }^{[37]}$ Finally, a base-catalyzed aldol condensation between dihydrolevoglucosenone and HMF was described by Witczak and Bielski. ${ }^{[38]}$ Piperidine gave superior efficiency when the reaction was conducted in refluxing ethanol, providing the chiral building block 16 in $86 \%$ yield. The base-mediated double condensation of cyclopentanone on 5-HMF proved to be an efficient route toward molecule 17. The latter has been studied as a synergistic antifungal compound, ${ }^{[39]}$ but also constituted a valuable intermediate in the preparation of long-chain cycloalkanes from bio-renewable resources. ${ }^{[40]}$ 

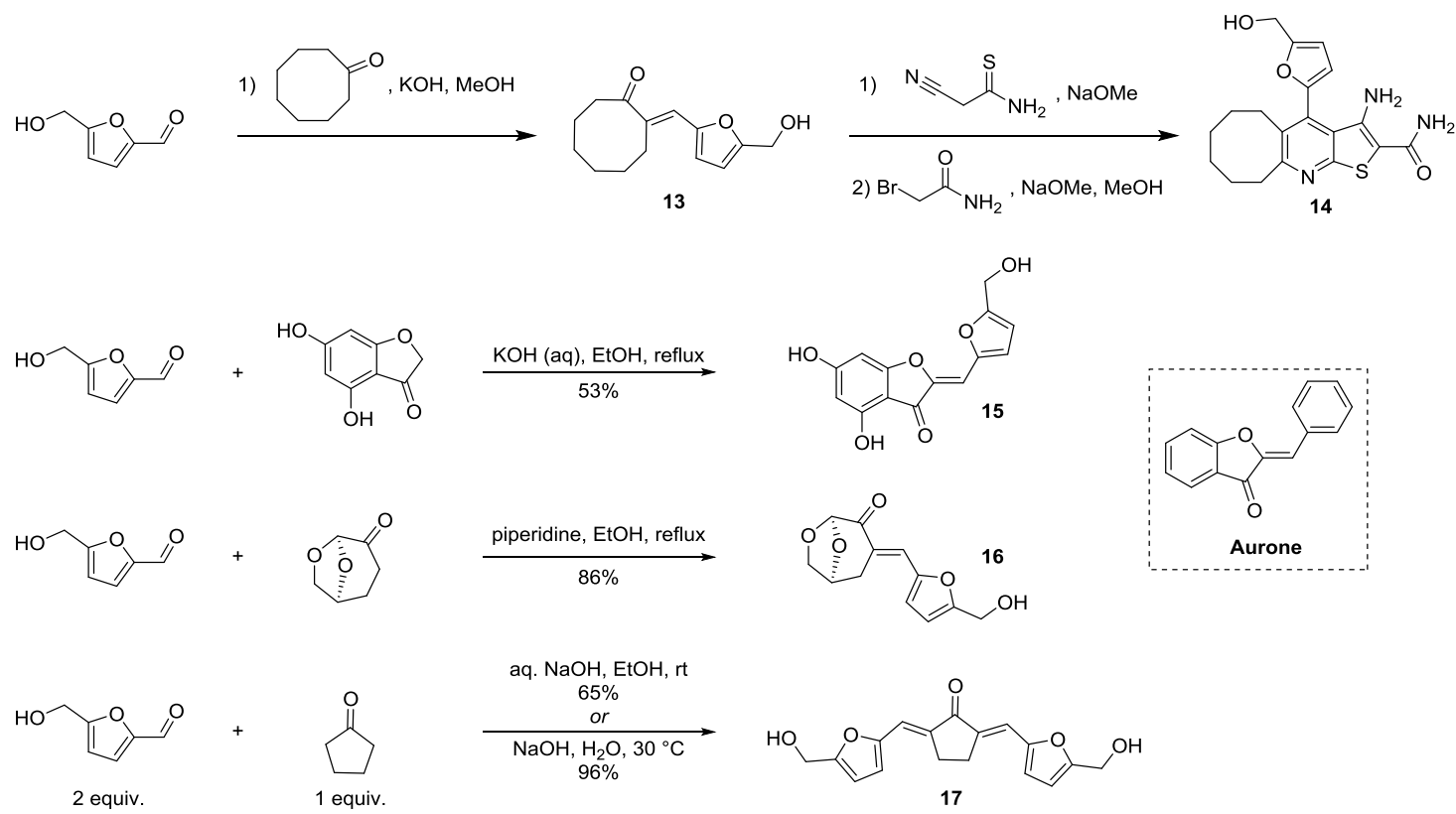

Scheme 6. Condensation on more elaborated ketones as targets in medicinal chemistry

The condensation of unsymmetrically substituted ketones bearing two enolizable positions with 5-HMF raises a problem of regioselectivity. Aqueous sodium hydroxide was employed by Amarasekara and coworkers to condense levulinic acid on 5-HMF. ${ }^{[4]}$ The reaction produced a mixture of kinetic and thermodynamic products (respectively 18 and 19) in a 2.5:1 ratio and $82 \%$ total yield (Scheme 7). This problem could be avoided by performing the reaction under pyridine/DCM conditions. ${ }^{[34]}$ The condensation of 5-HMF with methyl isobutyl ketone (MIBK) in the presence of $\mathrm{NaOH}$, led selectively to the corresponding kinetic enone in $95 \%$ GC yield. ${ }^{[42]}$

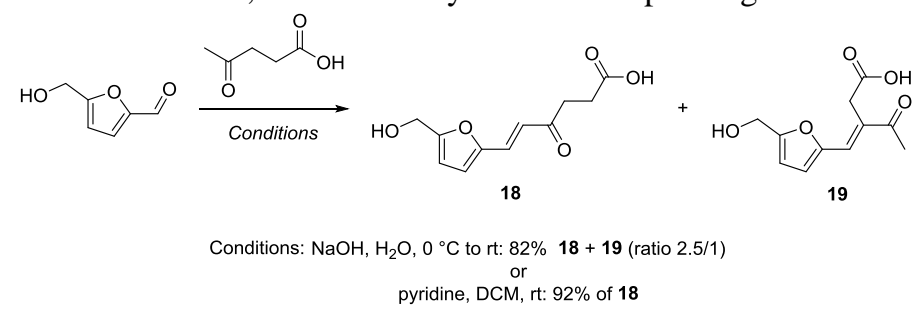

Scheme 7. Regioselective condensation on levulinic acid

The regioselective condensation of acetylacetone with 5-HMF was also studied. Acetylacetone bearing highly acidic protons at $\mathrm{C} 3$ position, the selective condensation at $\mathrm{C} 1$ and/or $\mathrm{C} 5$ without the formation of the Knoevenagel adduct (C3 condensation) represented a synthetic challenge and could lead to curcumin analogs (Scheme 8). A solution emerged from Lee's group ${ }^{[43]}$ through a double $\mathrm{C} 1$ and $\mathrm{C} 5$ enolization in the presence of boric anhydride, tributylborate, butylamine and an excess of 5-HMF, giving the symmetrical double condensation product $\mathbf{2 0}$ in $12 \%$ yield. When the same reaction was carried out with an excess of diketone, the Knoevenagel adduct 21, arising from the functionalization at C3, was obtained in 51\% yield (Scheme 8). ${ }^{[44]}$

The most efficient alternative reported to date for the synthesis of unsymmetrical HMF-derived curcumin analogues such as 22, consisted in a solid-phase synthesis strategy. Supporting HMF on a 2-chlorotrityl resin led to a significant improvement of the yield ${ }^{[45]}$ After completion of the reaction, the resin was cleaved by treatment with a mixture of DCM/TFA/MeOH, releasing the final product $\mathbf{2 2}$ in excellent yield (Scheme 8). 


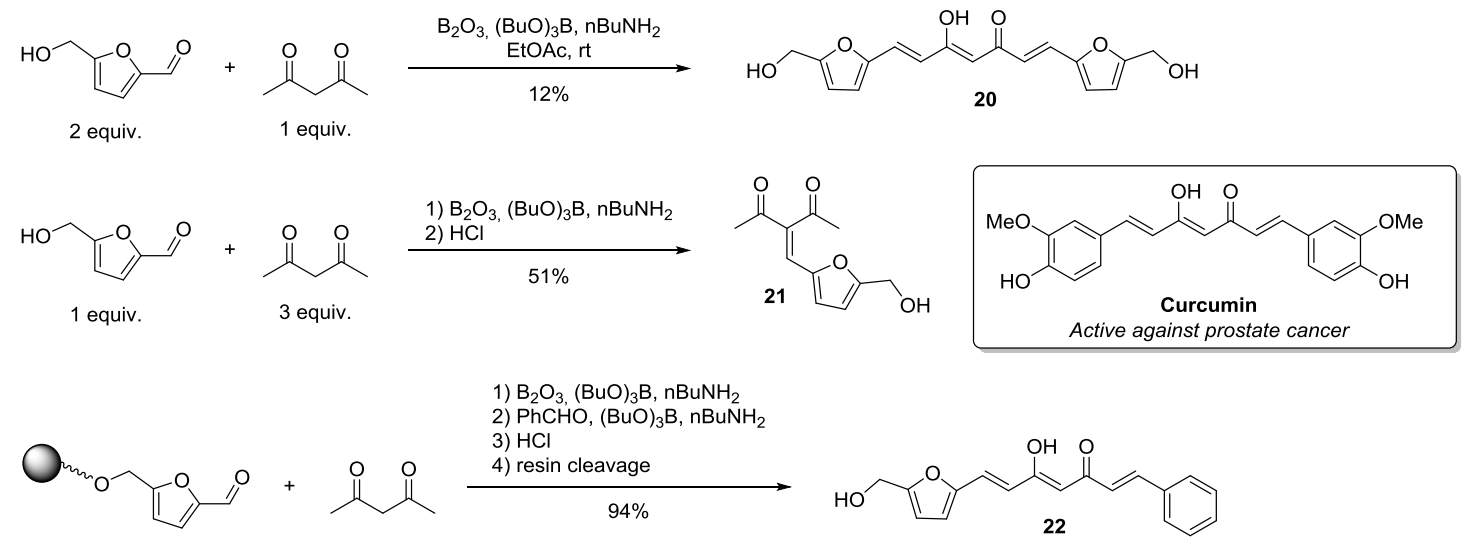

Scheme 8. Strategies for regioselective aldolisation of HMF with acetylacetone

The cyanoamide $\mathbf{2 3}$ was reacted with HMF to produce the cyano-acrylamide $\mathbf{2 4}$ under microwave irradiation in a modest $45 \%$ yield (Scheme 9). ${ }^{[46]}$ McCluskey reported the reaction of dichlorophenylacetonitrile with 5-HMF under phase transfer catalysis which provided the acrylonitrile $\mathbf{2 5}$ in $78 \%$ yield. ${ }^{[47]}$ In parallel to compound $\mathbf{2 5}$, evaluated for its antitumoral properties, the two other derivatives $\mathbf{2 6}$ and $\mathbf{2 7}$ (supposed to exhibit significant antisenile dementia activities) were prepared by condensation with the corresponding activated methylene substrates (Scheme 9). ${ }^{[48]}$

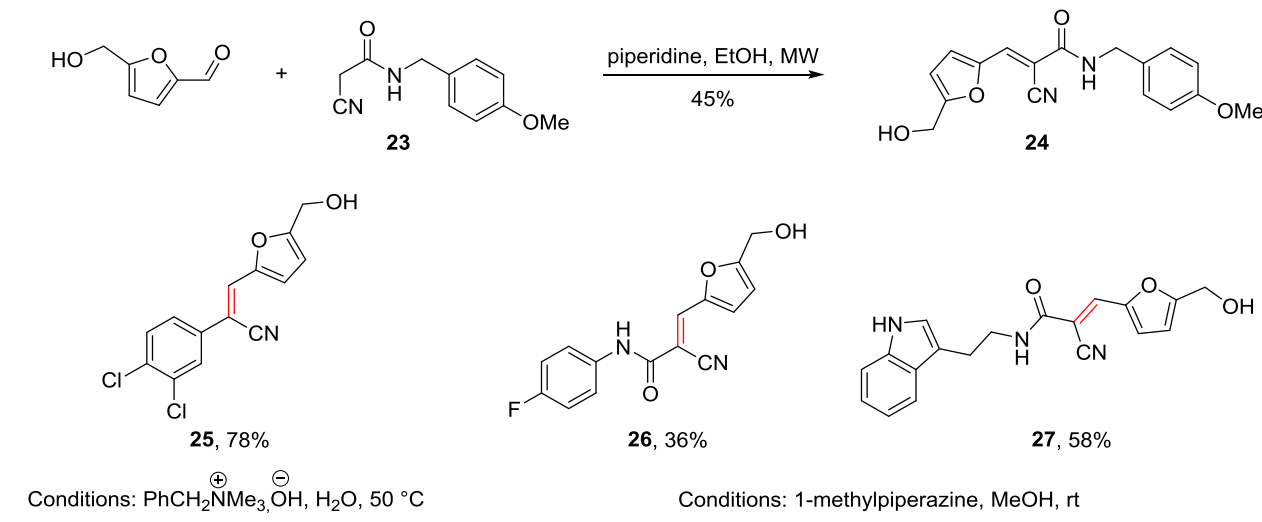

Scheme 9. Condensation of cyanoamides and nitriles derivatives with 5-HMF

Cyclic amides such as rhodanine $28{ }^{[49]}$ and thiohydantoins $30^{[50]}$ have been employed for the preparation of 5hydroxymethylfurfurylidene-substituted heterocycles, designed for pharmacological tests (Scheme 10). The furfurylidene-rhodanine $\mathbf{2 9}$ was obtained in the presence of ethylenediammonium diacetate with $73 \%$ yield whereas the thiohydantoin $\mathbf{3 1}$ was formed in the presence of pyrrolidine and indium triflate as Lewis acid.

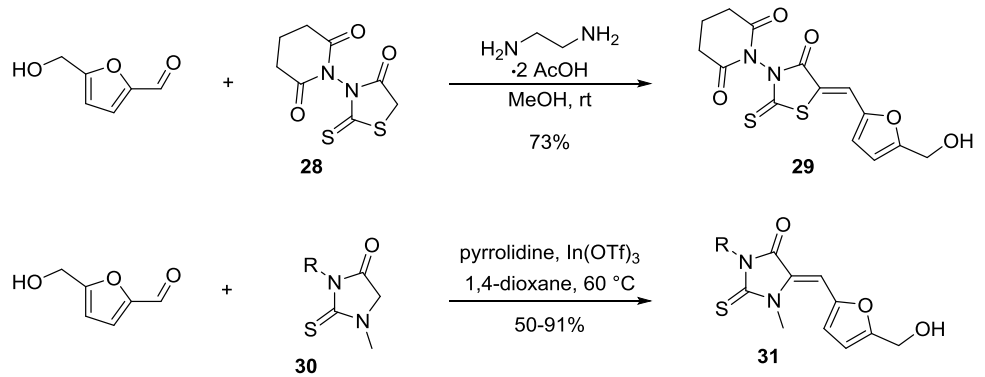

Scheme 10. Cyclic amides in the condensation with 5-HMF

Several activated methylene compounds have been used in Knoevenagel type condensations with HMF yielding push-pull olefins which could be further used as building blocks or directly studied for their biological properties. Highly acidic cyclic 1,3-dicarbonyl derivatives such as Meldrum's acid and barbituric acid proved their efficiency, reacting with HMF smoothly. The condensation with Meldrum's acid using a mixture of piperidine and acetic acid in benzene afforded compound $\mathbf{3 2}$ in $72 \%$ yield, and its antitumoral and psychotropic activities 
were evaluated (Scheme 11). ${ }^{[51]}$ Another experimental procedure reported by Afonso referred to the use of water with $1 \mathrm{wt} \% \mathrm{Na}_{2} \mathrm{~S}_{2} \mathrm{O}_{4}$ leading to $96 \%$ of yield of the same compound 32. ${ }^{[4]}$ The authors also reported an interesting transformation of $\mathbf{3 2}$ to lactone-fused cyclopentenones by treatment with various amines. ${ }^{[52]}$ Nikolov carried out the condensation between HMF and barbituric acid in refluxing water, and assessed the photochemical properties of the product $33 .{ }^{[53]}$ Finally, 4-hydroxycoumarin reacted in catalyst-free conditions to produce the dimeric compound 34 in $55 \%$ yield. ${ }^{[54]}$ The mono-addition led to a Knoevenagel intermediate exhibiting structural analogy with the ortho-quinone methide skeleton, facilitating the addition of a second molecule of 4-hydroxycoumarin (Scheme 11).

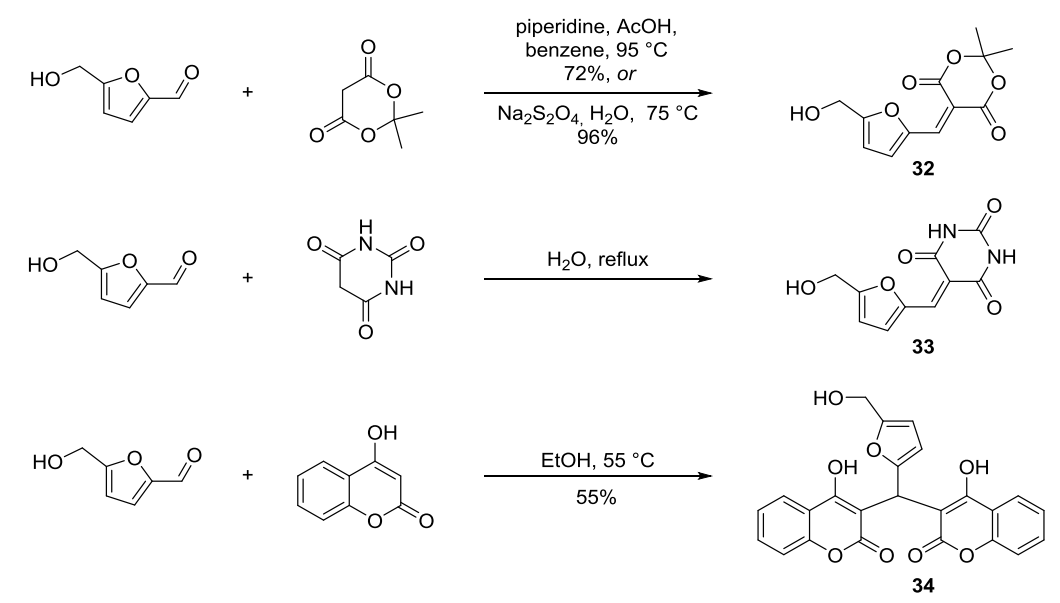

Scheme 11. Condensation of cyclic activated methylene derivatives with 5-HMF

Acyclic activated methylene compounds are also possible nucleophiles for condensation with 5-HMF. For example, the reaction of 5-HMF with malonic acid in the presence of ammonium bicarbonate without solvent at $50{ }^{\circ} \mathrm{C}$ afforded the product 35 in $93 \%$ yield. ${ }^{[55]}$ Decarboxylation took place at a higher temperature in pyridine, leading to the acrylic acid $\mathbf{3 6}$ up to $88 \%$ yield. ${ }^{\left[28,{ }^{34]}\right.}$ Finally, Knoevenagel condensation of the dione $\mathbf{3 7}$ promoted by piperidine allowed the preparation of the dihydrochromone $\mathbf{3 8}$ which could be rapidly converted into the chromone 39, a photo-activable fluorophore (Scheme 12). ${ }^{[56]}$

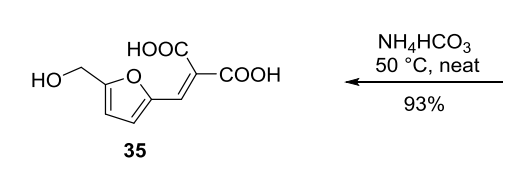<smiles>O=Cc1ccc(CO)o1</smiles>
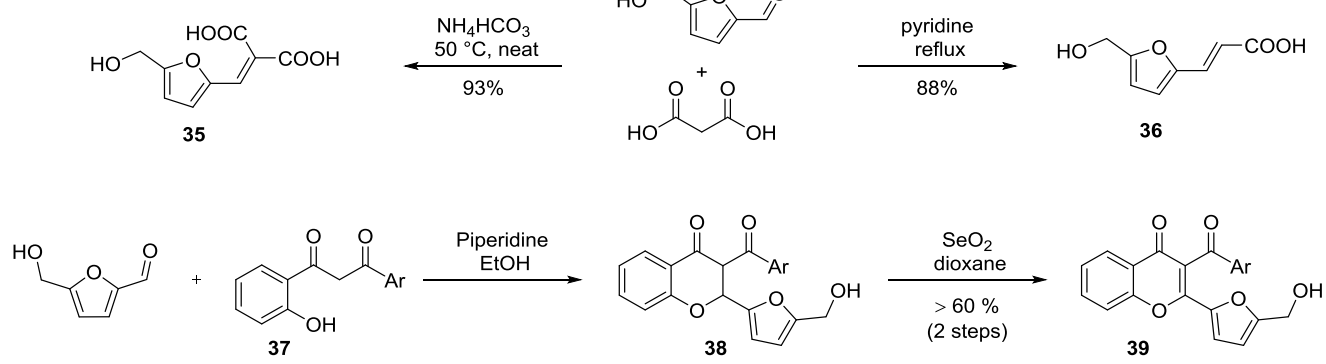

Scheme 12. Condensation of acyclic activated methylene compounds

Compound 41 was identified as a side product of the reaction between D-glucose and L-lysine under acidic conditions. In order to support the mechanism explaining its formation, a larger amount of compound $\mathbf{4 1}$ was successfully prepared by reaction of 5-HMF on the cyclic imine $\mathbf{4 0}$ (obtained from piperidine, $\mathrm{N}$ chlorosuccinimide and potassium hydroxide) in $64 \%$ yield (Scheme 13$).{ }^{[57]}$

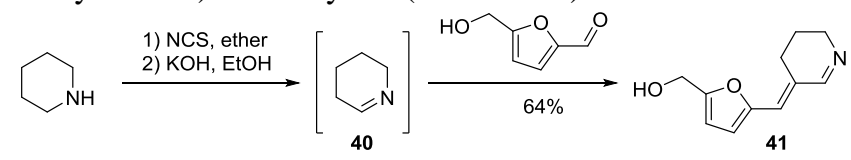

Scheme 13. Condensation of 5-HMF with compound 40

Condensation of the diaminonitroalkene $\mathbf{4 2}$ on 5-HMF provided the new neonicotinoid $\mathbf{4 3}$ with insecticidal potency against Nephotettix bipunctatus, higher than imidacloprid (Scheme 14). ${ }^{[58]}$ 


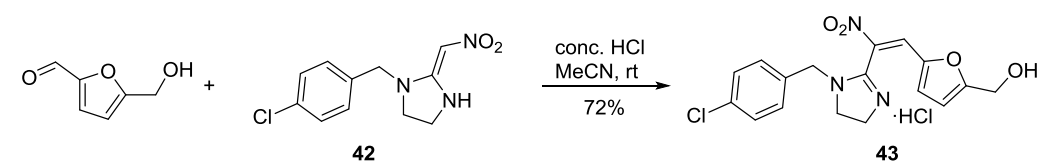

Scheme 14. Condensation of 5-HMF with enediamine 42

The HMF-modified boron-dipyrromethene (BODIPY) 44 was prepared via an aldol-like condensation between HMF and 1,3-dimethyl-BODIPY in the presence of pyrrolidine under microwave irradiation (Scheme 15). ${ }^{[59]}$

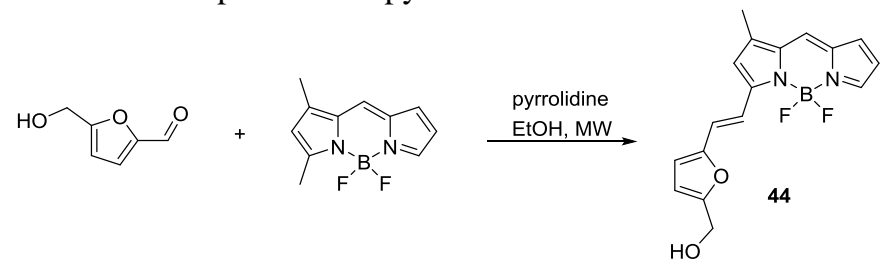

Scheme 15. Synthesis of a BODIPY molecule for bio-imaging application

The indene-derivative $\mathbf{4 5}$ was prepared as a mixture of isomers by the condensation of 2-methylindene-3-acetic acid with $\mathrm{HMF}^{[60]}$, and its sodium salt displayed anti-proliferative activities (Scheme 16).
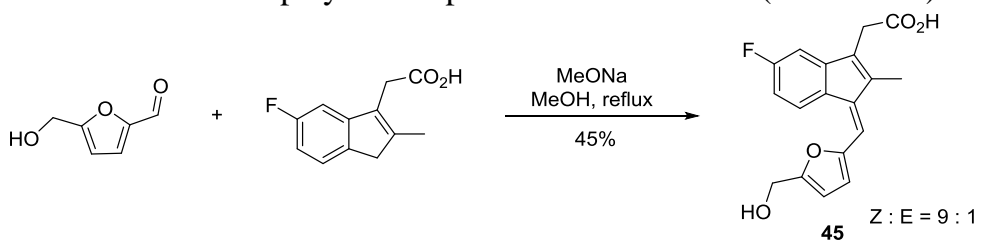

Scheme 16. Condensation with 2-methylindene-3-acetic acid

In 1984, the first Horner-Wadsworth-Emmons reaction of HMF was reported by Delmas. Reaction with triethylphosphonoacetate using potassium carbonate in a mixture of 1,4-dioxane and water afforded $\alpha, \beta$ unsaturated ester 46 as $E$ isomer exclusively in $90 \%$ yield (Scheme 17). ${ }^{[61]}$ When the reaction was performed in alcoholic medium such as $n$-octanol, further transesterification occurred. ${ }^{[62]}$ A DBU-mediated HornerWadsworth-Emmons reaction on HMF was performed to synthesize $\alpha, \beta$-unsaturated imide 47, which was obtained as a single diastereoisomer in $87 \%$ yield, and might further serve as a precursor of $\beta$-amino acids. ${ }^{\text {[63] }}$ The Horner-Wadsworth-Emmons reaction of HMF was also reported as the key step in a one-pot preparation of substituted pyrazoles. ${ }^{[64]}$ HMF or $O$-protected derivatives reacted with diethoxyphosphorylacetaldehyde tosylhydrazone in the presence of $\mathrm{NaH}$ in $\mathrm{THF}$, yielding $\alpha, \beta$-unsaturated tosylhydrazones sodium salts 48, which in refluxing THF provided the pyrazoles 49 in $60-78 \%$ yield for 2 steps (Scheme 17).
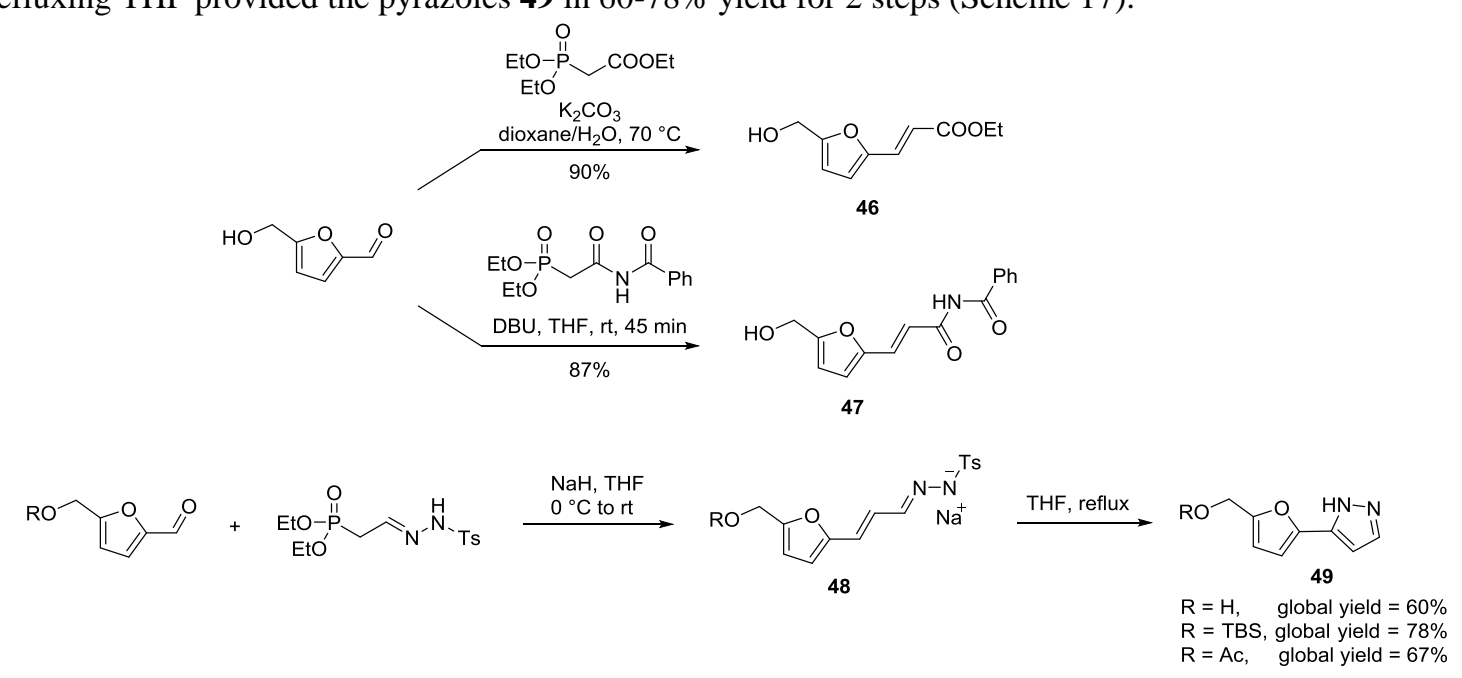

Scheme 17. Horner-Wadsworth-Emmons reaction on 5-HMF

The $\alpha, \beta$-unsaturated ester 46 could also be prepared by one-pot Wittig reaction. The in situ formed Wittig reagent reacted with 5 -HMF in the presence of tetra- $n$-butylammonium fluoride (TBAF) providing 46 with $81 \%$ yield and $85 \%$ selectivity in favor of $E$ isomer (Scheme 18). ${ }^{[65]}$ 


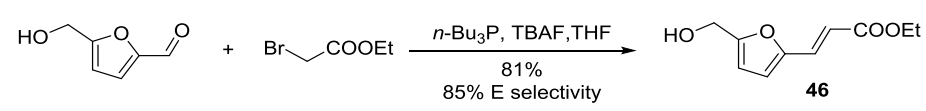

Scheme 18. One-pot Wittig reaction on 5-HMF

The monomer 5-hydroxymethyl-2-vinylfuran (HMVF) was synthesized using methyltriphenylphosphonium bromide and potassium carbonate in $67 \%$ yield, as an adaptation of a procedure used on furfural (Scheme 19). ${ }^{[66]}$ The resulting HMVF could be efficiently polymerized by AIBN-initiated radical polymerization. Recently, Ji demonstrated that HMVF itself exhibits strong adhesion to metals via in-situ polymerization and crosslinking after either heating or acid treatment, concluding that HMVF could serve as a bio-based adhesive. ${ }^{[67]}$

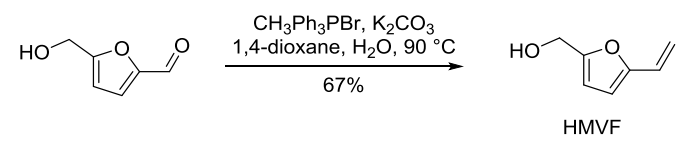

Scheme 19. Direct alkenylation of 5-HMF

\subsubsection{Formation of $\mathrm{C} \equiv \mathrm{C}$ bonds}

Direct alkynylation of 5-HMF was performed in $97 \%$ yield using Ohira-Bestmann reagent in $\mathrm{MeOH}$ in the presence of $\mathrm{K}_{2} \mathrm{CO}_{3}$ (Scheme 20). 2-Hydroxymethyl-5-ethynylfuran $\mathbf{5 0}$ was used as a platform to conduct various chemical transformations targeting furanic pharmaceuticals as well as conjugated polymers. ${ }^{[68]}$

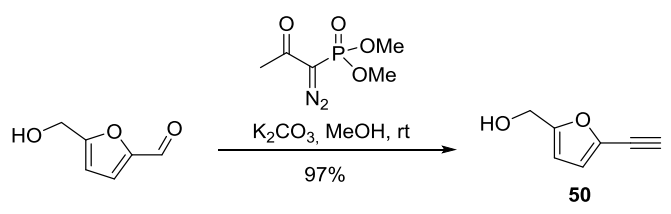

Scheme 20. Direct alkynylation of 5-HMF

\subsubsection{Oxidative transformations}

Van der Eycken and Noël reported an acylation protocol at $C 2$ of $N$-pyrimidylindoles using a range of aldehydes as acylating reagents via dual photoredox/transition-metal catalysis in flow conditions (Scheme 21 ). ${ }^{[69]}$ In this work, HMF also showed certain reactivity leading to compound 51, but with a low isolated yield of $34 \%$ in comparison with furfural (85\%). This important difference of yield between similar substrates suggests detrimental effect of the hydroxymethyl group, moderately compatible with oxidative SET pathways.

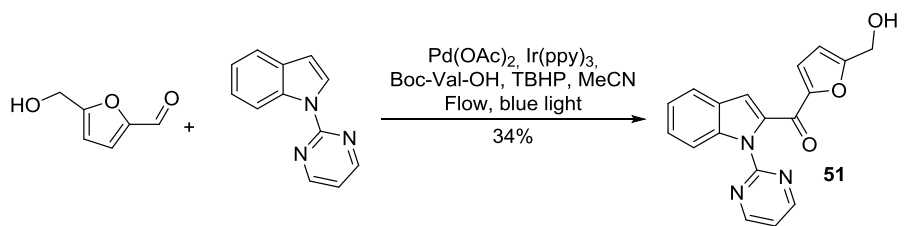

Scheme 21. Acylation of indole using HMF in a photoredox strategy

Following a Büchner-Curtius-Schlotterbeck reaction, HMF was reacted with diazomethane yielding 1-(5(hydroxymethyl)furan-2-yl)ethan-1-one (52) in 40\% yield after 14 days (Scheme 22). ${ }^{[0]}$
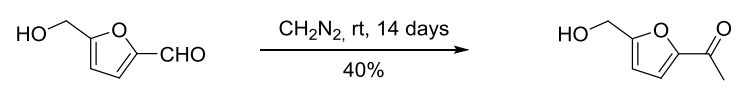

52

Scheme 22. Reaction between 5-HMF and diazomethane

A ruthenium dihydride complex was employed as a catalyst for the coupling of 5-HMF and isoprene on both $\mathrm{C} 2$ and C5 positions leading to the bis-ketofurane $\mathbf{5 3}$ in $48 \%$ yield (Scheme 23). ${ }^{[71]}$ 


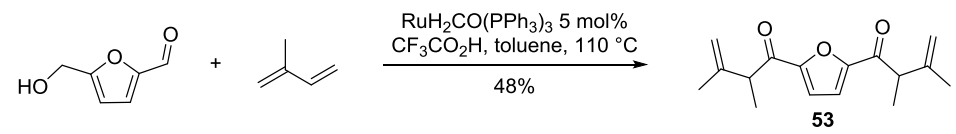

Scheme 23. Coupling of 5-HMF and isoprene

Das reported a novel route to prepare $\alpha$-diketone by performing the NHC-catalyzed HMF self-condensation in DMSO under $\mathrm{CO}_{2}$ atmosphere (Scheme 24). ${ }^{[72]}$ DFT calculations lightened the role of $\mathrm{CO}_{2}$ in the mechanism, by reacting with the hydroxyl of so formed furoin, producing a carboxylate which is a good leaving group. DMSO was prone to therefore act as an oxidation reagent allowing the access to diketone $\mathbf{5 4}$. The non-symmetrical $\alpha$ diketone 55 could also be prepared in good yield employing a 1:1.5 ratio of furfural and HMF, although the formation of the homo $\alpha$-diketone could not be suppressed completely.

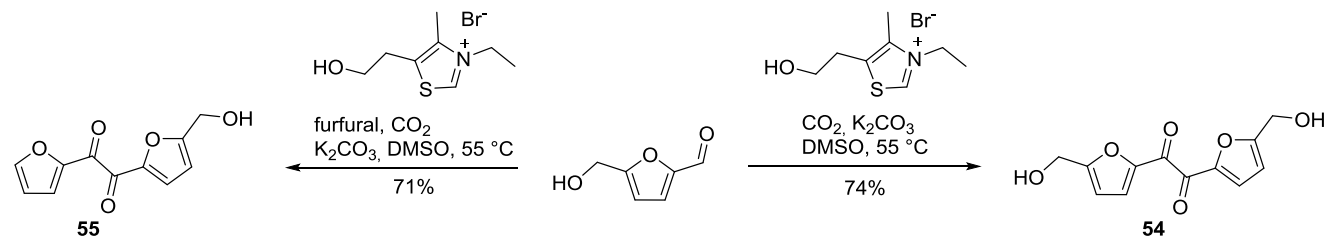

Scheme 24. NHC and $\mathrm{CO}_{2}$-mediated homo and cross-coupling of $\mathrm{HMF}$

\subsection{Carbon-nitrogen bond formation reactions}

The condensation of nitrogen nucleophiles on the aldehyde of HMF is a straightforward way to produce a variety of new molecules with interesting properties, but can also be a step of more complex chemical sequences toward original nitrogen-containing scaffolds, useful for agrochemical and pharmaceutical industries.

\subsubsection{Synthesis of imines, hydrazones, oximes, nitrones and their applications}

In the early stage study on HMF from the end of the $19^{\text {th }}$ century to the beginning of the $20^{\text {th }}$ century, researchers already showed that HMF could react with a range of nitrogen nucleophiles, such as hydroxylamine, arylhydrazine, semioxamazide, semicarbazide and amine to form respectively oxime 56, hydrazone 57, semioxamazone 58, semicarbazone 59 and imine $\mathbf{6 0}^{[73]}$ (Scheme 25). ${ }^{[74]}$ These reactions with nitrogen nucleophiles were carried out mainly for purification and identification purposes because the products are often crystalline and easy to handle.

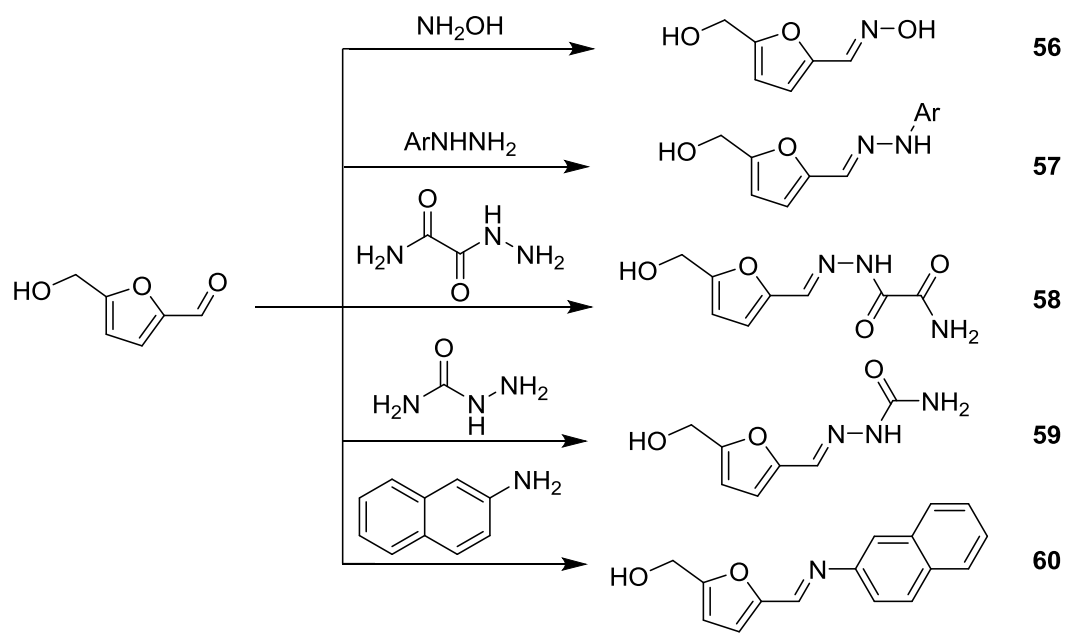

Scheme 25. Reactions between HMF and diverse nitrogen-nucleophiles in early studies

The imines $\mathbf{6 1}$ obtained from HMF were subjected to TFA-catalyzed Pudovik reaction to afford the $\alpha$ aminophosphonates 62 (Scheme 26). ${ }^{[75]}$ In 2018, our group reinvestigated the reaction conditions in a direct 3CR strategy between 5-HMF, amine and dialkylphosphite. This one-pot approach named Kabachnik-Fields reaction was efficient in the presence of mild Lewis acid catalyst $\mathrm{I}_{2}$. ${ }^{[76]}$ 


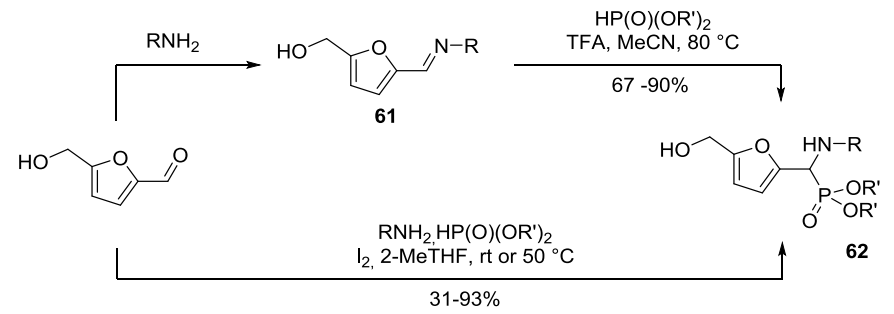

Scheme 26. Synthesis of $\alpha$-aminophosphonates via Pudovik or Kabachnik-Fields reactions

Amarasekara reported an interesting application of the HMF-derived oxime 56. ${ }^{[77]}$ Oxidation of $\mathbf{5 6}$ in aqueous bleach solution provided the nitrile oxide 63, which readily underwent 1,3-dipolar cycloaddition with alkenes or alkynes to give the corresponding dihydro-isoxazoles 64 or isoxazoles 65 depending on the nature of the dipolarophiles (Scheme 27).

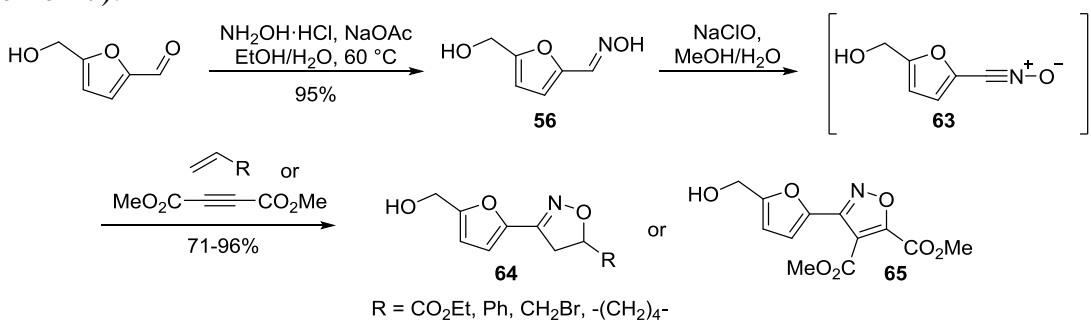

Scheme 27. Application of HMF-derived oxime in 1,3-dipolar cycloaddition

The condensation of HMF with rhodamine B hydrazide delivered hydrazone 66, which could serve as a chemosensor for the detection of $\mathrm{pH}$ and $\mathrm{Cu}^{2+} \cdot{ }^{[78]}$ A couple of HMF-derived $N$-acyl-hydrazones 67 were prepared as nifuroxazide analogues for antimicrobial activity screening. ${ }^{[79]}$ Unfortunately, the HMF-based hydrazones 67 displayed no interesting biological properties. Hydrazone 68 was also prepared to study its activity as a kinase inhibitor, ${ }^{[80]}$ whereas compound 69 (from 1-aminoquinolin-2(1H)-one) was studied as a ligand for making metal complexes (Scheme 28). ${ }^{[81]}$
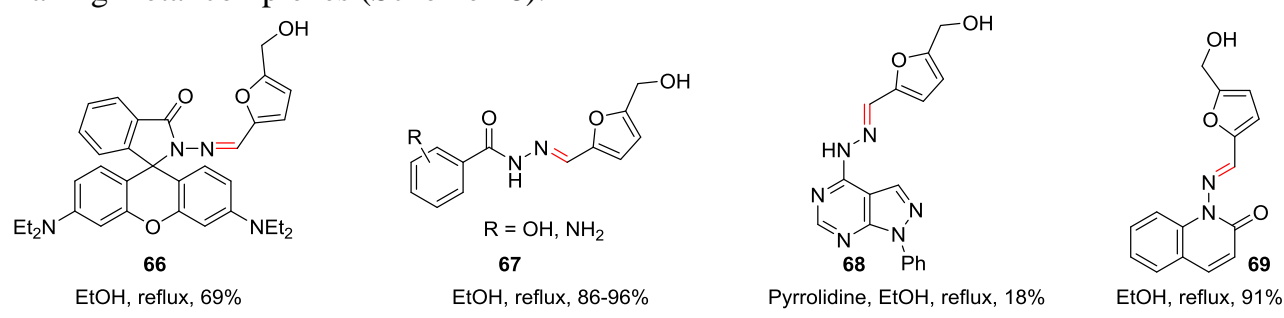

Scheme 28. Examples of valuable HMF-based acylhydrazones and hydrazones

Capon isolated naturally occurring prolinimines from a fish gastrointestinal tract-derived fungus, Trichoderma $s p$. CMB-F563 (Scheme 29). ${ }^{[82]}$ To confirm their structures, the authors performed a biomimetic synthesis of the prolinimine 70 by reacting HMF with $N$-amino-L-Pro methyl ester. Further treatment of prolinimine 70 in acidic conditions led to oligomeric prolinimines $\mathbf{7 1}$ and $\mathbf{7 2}$.

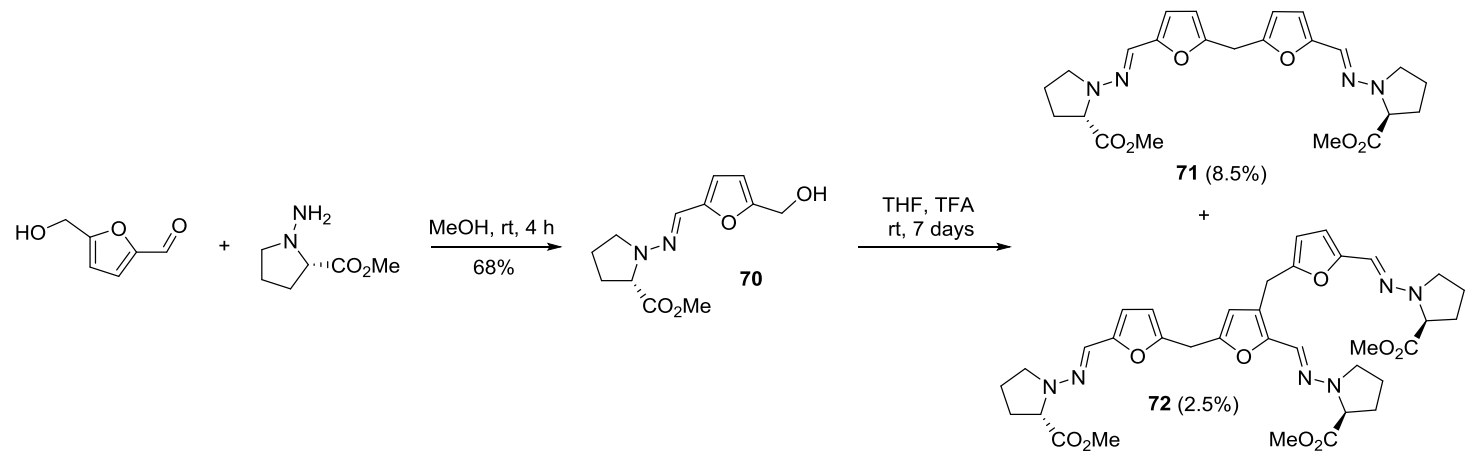

Scheme 29. Synthesis of natural prolinimines from 5-HMF

The preparation of nitrone $\mathbf{7 3}$ was investigated by heterogeneous reductive coupling of nitrobenzene and HMF 
under $\mathrm{H}_{2}$ atmosphere in the presence of platinum nanoparticles (Scheme 30). ${ }^{[83]}$ The conversion was complete and the selectivity was evaluated at $89 \%$ ( $76 \%$ yield) in favor of the nitrone (side products expected: partial reduction into imine, total reduction into secondary amine or reduction of 5-HMF into the corresponding symmetrical diol).

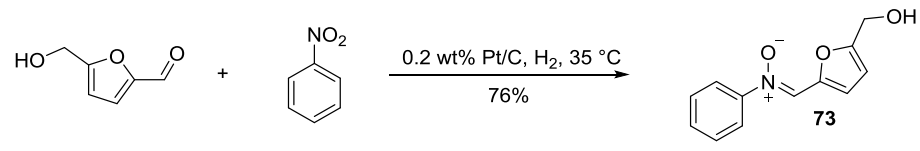

Scheme 30. Preparation of nitrone

The Murai reaction via imine directing group assisted $\mathrm{C}-\mathrm{H}$ activation on the furan ring of HMF derivatives was first reported by Poli, Oble and coworkers (Scheme 31). ${ }^{[84]}$ A diamine reacted with the aldehyde group of $O$ protected HMF derivatives to form products 74 in which the amino-imine moiety served as a $N, N$ '-bidentate directing group. The reaction was performed using a typical ruthenium catalyst and vinylsilanes as olefin partners in toluene at high temperature. The directing group was removed by hydrolysis during the silica gel column chromatography purification to release the $C 3$-functionalized furfurals $\mathbf{7 5}$. More recently, the same group reported the Ru-catalyzed imine-directed $C 3$-arylation of compound $\mathbf{7 6}$ with aryl boronate esters. ${ }^{[85]}$ In this case, a $p$-dimethylaminophenylimine proved to be the best directing group. In contrast to their previous study, the arylated imine $\mathbf{7 7}$ could be isolated by silica gel chromatography, the arylated aldehydes $\mathbf{7 8}$ being further released after hydrolysis with aqueous $\mathrm{HCl}$ (Scheme 31).

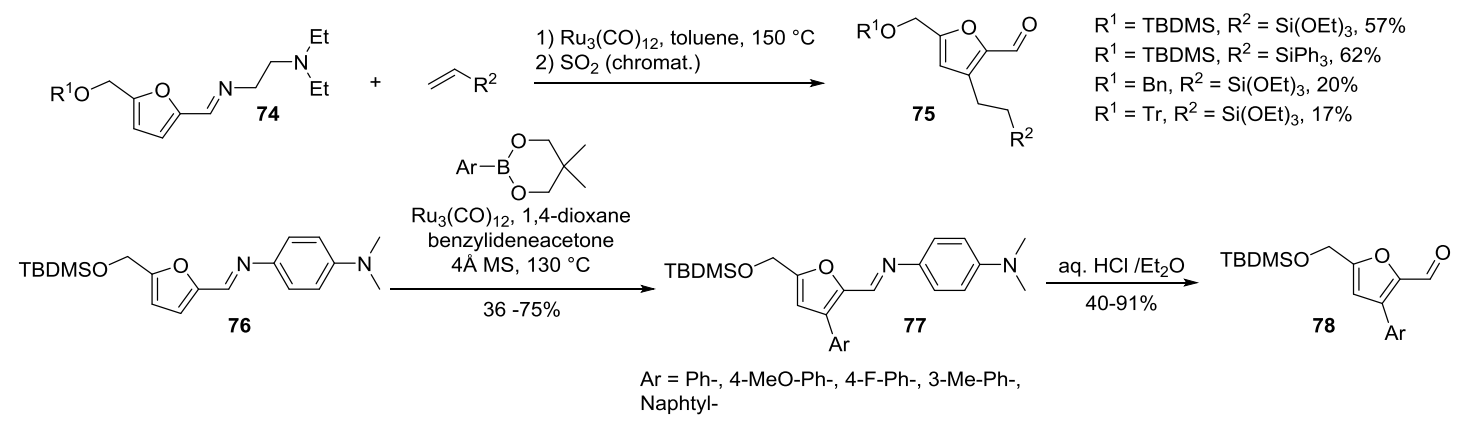

Scheme 31. Imine as directing group for C-H activation

\subsubsection{Preparation of amines}

Many examples of reductive amination of $\mathrm{HMF}$ to target 5-aminomethyl-2-furfuryl alcohols have been reported (Table 3). The utilization of $\mathrm{NaBH}_{4}$ as a reducing agent was proved to be efficient, ${ }^{[86]}$ but many studies describe also the use of $\mathrm{H}_{2}$ together with a wide range of heterogeneous catalysts. Other reducing agents such as water or silanes have also been reported. Throughout these studies, aromatic and aliphatic amines, as well as ammonia, were introduced on the HMF scaffold.

Table 3. Reductive amination with simple amines

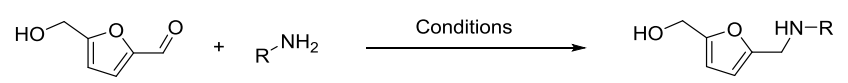

\begin{tabular}{cllcc} 
Entry & \multicolumn{1}{c}{ Conditions } & \multicolumn{1}{c}{$\mathrm{RNH}_{2}$} & Yield & Ref. \\
\hline 1 & $\mathrm{NaBH}_{4}, \mathrm{H}_{2} \mathrm{O}$ or EtOH & aromatic/aliphatic amines & $77-99 \%$ & {$[86]$} \\
2 & $\mathrm{H}_{2}, \mathrm{Raney} \mathrm{Ni}$ & $\mathrm{NH}_{3}$ (liq.) & $72 \%$ & {$[87]$} \\
3 & $\mathrm{H}_{2}(1.2 \mathrm{MPa}), \mathrm{Ru}(\mathrm{DMP})_{2} \mathrm{Cl}_{2}, \mathrm{EtOH}, 60{ }^{\circ} \mathrm{C}$ & aromatic/aliphatic amines & $66-95 \%$ & {$[88]$} \\
4 & $\mathrm{H}_{2}(2 \mathrm{MPa}), \mathrm{Rh} / \mathrm{Al}_{2} \mathrm{O}_{3}, 80{ }^{\circ} \mathrm{C}$ & $\mathrm{NH}_{3}$ (aq.) & $86 \%$ & {$[89]$} \\
5 & $\mathrm{H}_{2}(4 \mathrm{MPa}), \mathrm{Ru} / \mathrm{Nb}_{2} \mathrm{O}_{5}, \mathrm{MeOH}, 90{ }^{\circ} \mathrm{C}$ & $\mathrm{NH}_{3}$ (in $\mathrm{MeOH}$ solution) & $96 \%$ & {$[90]$} \\
6 & $\mathrm{H}_{2}(2 \mathrm{MPa}), \mathrm{RuNPs}, \mathrm{MeOH}, 90{ }^{\circ} \mathrm{C}$ & $\mathrm{NH}_{3}$ (in MeOH solution) & $95 \%$ & {$[91]$} \\
7 & $\mathrm{H}_{2}(4 \mathrm{MPa}), \mathrm{Co} \mathrm{nanoparticles},{ }^{t} \mathrm{BuOH}, 120{ }^{\circ} \mathrm{C}$ & $\mathrm{NH}_{3}$ (gas) & $89 \%$ & {$[92]$} \\
8 & $\mathrm{H}_{2} \mathrm{O} / \mathrm{CO}(2 \mathrm{MPa}) / \mathrm{MeOH}, \mathrm{Au} / \mathrm{TiO}_{2}-\mathrm{R}, 60^{\circ} \mathrm{C}$ & aromatic/aliphatic amines & $60-99 \%$ & {$[93]$}
\end{tabular}


The reductive amination was applied to a phenanthropiperidine derivative using $\mathrm{NaBH}(\mathrm{OAc})_{3}$ as reducing agent, to deliver the $N$-substituted phenanthropiperidine derivative $\mathbf{7 9}$ in $72 \%$ yield (Scheme 32 ). This tylophorine analogue was evaluated with respect to its biological activity and found to inhibit the proliferation of MCF-7 cells but only at micromolar concentration. ${ }^{[95]}$ The indolopyrrolocarbazole derivative $80{ }^{[96]}$ and cytosine derivative $\mathbf{8 1}{ }^{[97]}$ were also synthesized by reductive amination, and their antitumor effect and DNA methylation inhibition activity were respectively studied (Scheme 32).

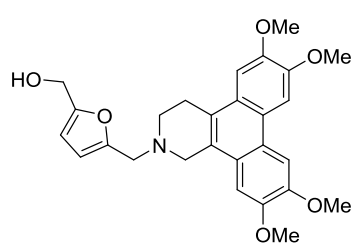

79
$\mathrm{NaBH}(\mathrm{OAc})_{3}, \mathrm{DCE}, \mathrm{rt}$
$72 \%$

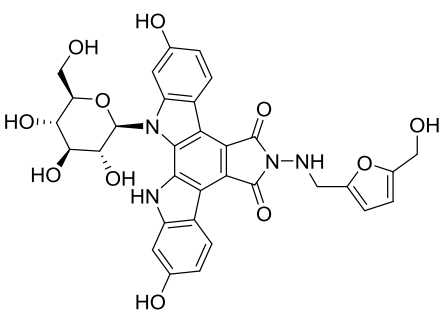

80

1) $\mathrm{AcOH}, \mathrm{EtOH}, 80^{\circ} \mathrm{C}$

2) $\mathrm{NaBH}_{3} \mathrm{CN}, \mathrm{MeOH}-\mathrm{THF}, \mathrm{HCl} / \mathrm{MeOH}$, rt

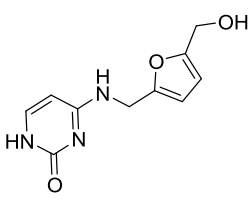

81

1) $\mathrm{Mg}(\mathrm{OMe})_{2}, \mathrm{MeOH}, 55^{\circ} \mathrm{C}$ 2) $\mathrm{NaBH}_{4}, \mathrm{MeOH}, \mathrm{rt}$

Scheme 32. Reductive amination with complex amines and derivatives

By switching the ratio of $\mathrm{HMF}$ and amine, Zhang et al. were able to convert HMF to bis(hydroxylmethylfurfuryl)amines 82 using $\mathrm{Ru}(\mathrm{DMP})_{2} \mathrm{Cl}_{2}$ as catalyst (Scheme 33). ${ }^{[98]}$ The in situ generated secondary amine further reacted with excess of HMF to form an iminium-ion intermediate, followed by hydrogenation to produce bis(hydroxylmethylfurfuryl)amines 82.

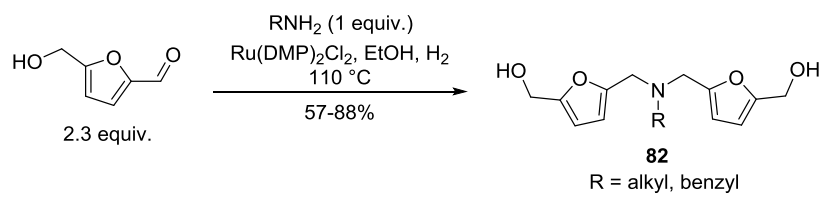

Scheme 33. Double reductive amination

\subsubsection{Synthesis of nitrogen-containing heterocycles}

The condensation of 5-HMF with 2-aminothiophenol took place smoothly in AcOH giving rise to the benzothiazole 83 quantitatively after spontaneous oxidation (Scheme 34). ${ }^{[99]}$ Similarly, the benzo[d]imidazole derivative 84, prepared by reaction of HMF with $o$-phenyldiamine in the presence of DDQ in refluxing EtOH, served as an intermediate for the preparation of molecule $\mathbf{8 5}$, a potential Myc modulator. ${ }^{[100]}$

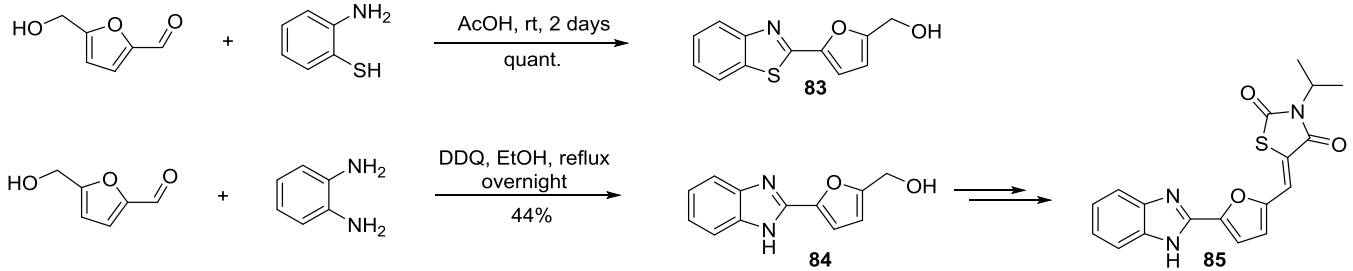

Scheme 34. Synthesis of benzothiazole and benzimidazole derivatives

HMF was often introduced as an aldehyde component in combinatorial chemistry to synthesize libraries of complex heterocyclic derivatives designed for bioactivity screening (Scheme 35). Treatment of HMF with $p$ toluenesulfonylmethyl isocyanide and potassium carbonate in refluxing methanol produced the 5-(5hydroxymethyl-2-furyl)oxazole 86 in $66 \%$ yield. ${ }^{[101]}$ In FM-381, an outstanding JAK3 inhibitor, synthesized by Laufer and coworkers, ${ }^{[102-103]}$ the furan moiety plays a crucial role with respect to the inhibitory activity, as replacement of the furan link by a phenyl one generally induced lower activities. The 5-HMF was condensed on 4,5-diamino-7-azaindole to provide the tricyclic skeleton $\mathbf{8 7}$ as a precursor of FM-381. Sova prepared a range of quinazolinone derivatives such as $\mathbf{8 8}$ to study their antimicrobial activities, among which the HMF-derived product has no significant effect. ${ }^{[104]}$ A fused tetracyclic heterocycle $\mathbf{8 9}$ was prepared in $68 \%$ yield by the TFAcatalyzed condensation of HMF and a 2-(1H-pyrrol-1-yl)aniline derivative. ${ }^{[105]}$ The condensation of HMF with pyrimidinylguanidine furnished the desired pyrimido[1,2-a][1,3,5]triazin-6-one 90 in $38 \%$ yield. ${ }^{[106]}$ 


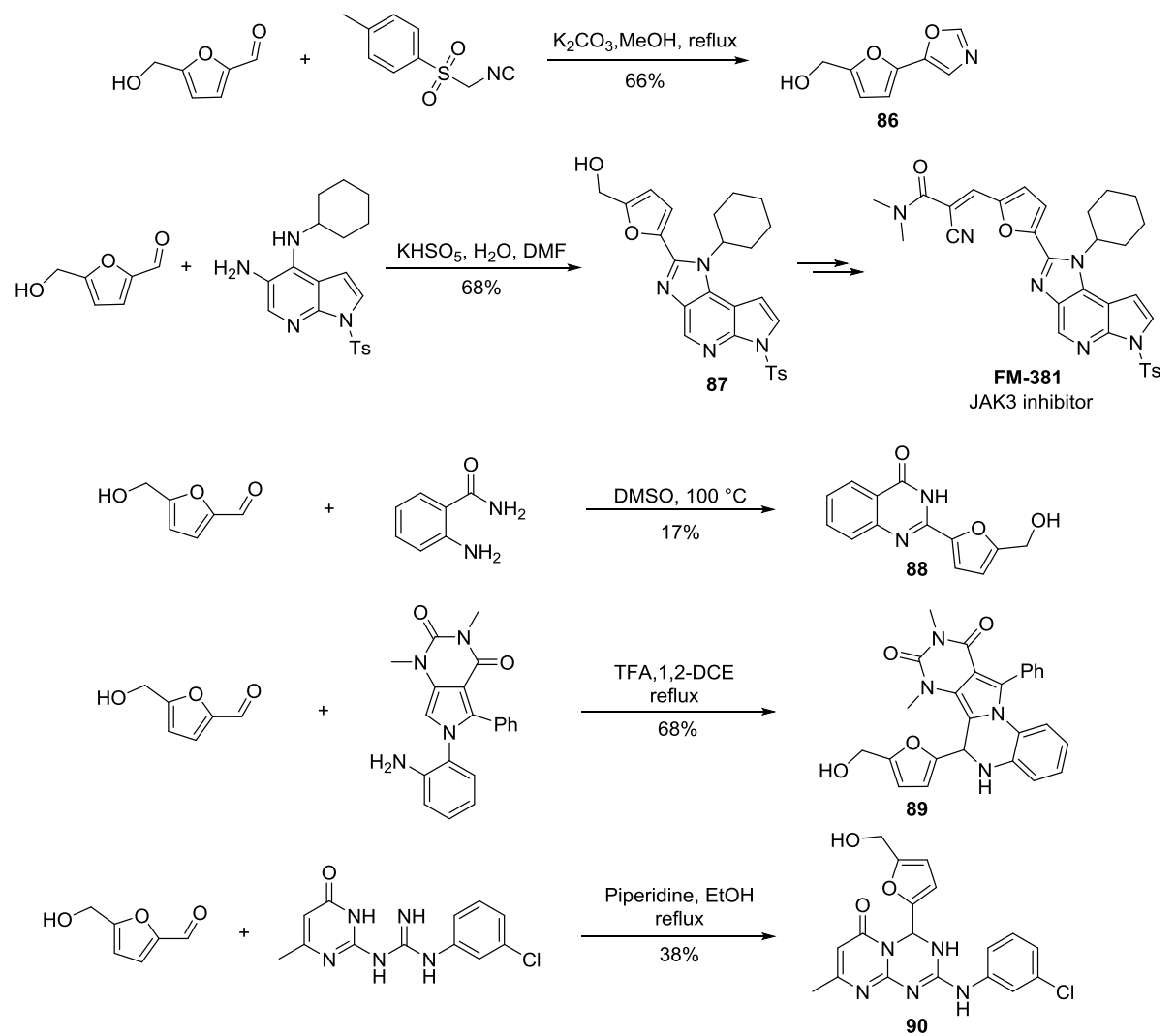

Scheme 35. Synthesis of nitrogen-containing heterocycles

An interesting extension of the scope to access more complex molecules was achieved by using multicomponent reactions (Scheme 36). The 3-component condensation of HMF, indanone and guanidine produced the compound 91, which was found to be a potent $\mathrm{A}_{2 \mathrm{~A}}$ adenosine receptor antagonist. ${ }^{[107]} \mathrm{A}$ montmorillonite $\mathrm{K}-10$ clay-catalyzed condensation of HMF, 2-aminopyridine and isocyanide was performed to generate the 1,8adihydroimidazo[1,2-a]pyridine derivative 92. ${ }^{[108]}$ More recently, our group disclosed the Biginelli reaction of 5HMF using zinc chloride as Lewis acid catalyst, allowing access to furan-based 3,4-dihydropyrimidin-2-ones 93. ${ }^{[109]}$ The urea scope could be extended to thiourea and heterocyclic urea derivatives. Another interesting multicomponent reaction is the coupling of $\mathrm{HMF}$, terminal aromatic alkynes, primary aliphatic amines and carbon dioxide using copper iodide as catalyst, to deliver oxazolidinones $94 .{ }^{[110]}$ In the case of anilines and secondary aliphatic amines, the $\mathrm{A}^{3}$ coupling (aldehyde, amine and alkyne) took place under same conditions providing compounds $\mathbf{9 5}$.

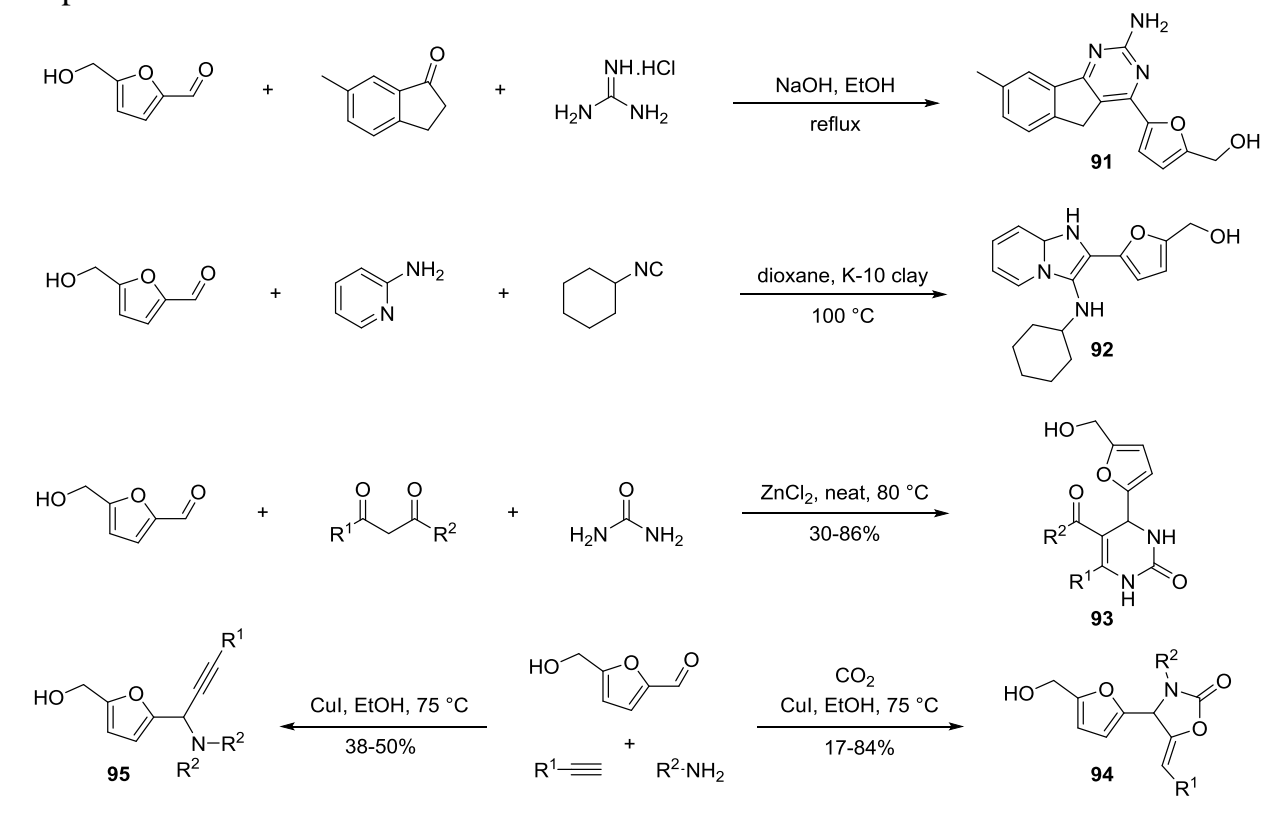


Scheme 36. MCR strategies involving 5-HMF

\subsubsection{Oxidative transformations}

The reaction of diazo derivatives 96 on 5-HMF catalyzed by $N$-heterocyclic carbene (NHC) allowed the preparation of acylhydrazones 97 displaying some antitumoral activity (Scheme 37). ${ }^{[11]}$ An in situ-generated $\mathrm{NHC}$ catalyst (prepared by reacting imidazolidinium SiMes $\mathrm{HCl}$ with $\mathrm{DBU}$ ) was used to reverse the reactivity of the aldehyde group of HMF. The authors observed neither Cannizzaro reaction nor NHC-catalyzed benzoin condensation. In some cases, the expected acylhydrazones were obtained as mixtures of $E / Z$ geometric isomers. The extension of the scope to hydroxymethyl protected substrates pointed out significant differences in terms of reactivity. For example, benzoyl HMF gave only 3\% yield of acylhydrazone, while HMF benzyl and TBDMS ethers afforded $89 \%$ and $99 \%$ yields respectively.

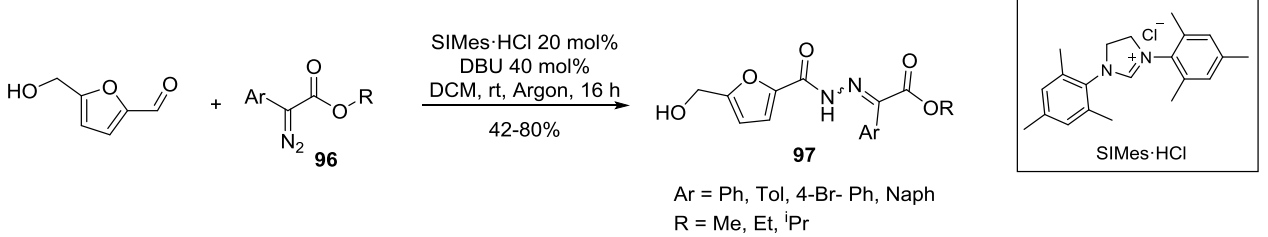

Scheme 37. Reaction between 5-HMF and diazo derivatives

HMF has been converted to the nitrile 98 by treatment with an ammonia solution in the presence of molecular iodine in a mixture of water and THF (Scheme 38$).{ }^{[112]}$ A similar oxidative cyanation was implemented in a onepot procedure for converting HMF into amide $99,{ }^{[13]}$ where the in situ-generated nitrile was hydrolyzed to the corresponding carboxamide under the action of a nitrile hydratase from $R$. rhodochrous IFO 15564. The same transformation could be performed under modified experimental conditions by flow process with hydroxylamine hydrochloride as nitrogen source. ${ }^{[114]}$ The reaction was completed in 5 minutes taking advantage of the flow chemistry technique (Scheme 38$)$.

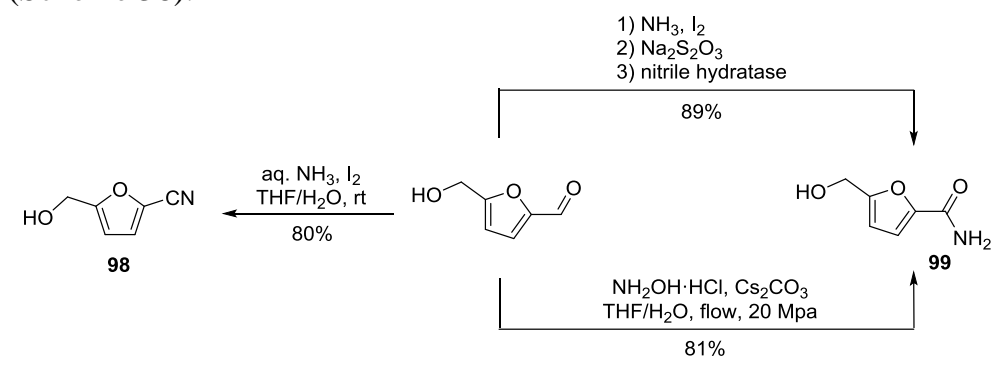

Scheme 38. Conversion 5-HMF to nitrile 98 and amide 99

Catalytic oxidation of 5-HMF in the presence of aqueous ammonia and manganese oxide octahedral molecular sieves (OMS-2) as catalyst afforded the bis-imidate 100 in good yield (Scheme 39). Subsequent treatment with ammonium chloride provided the corresponding bis-amidine 101..$^{[15]}$

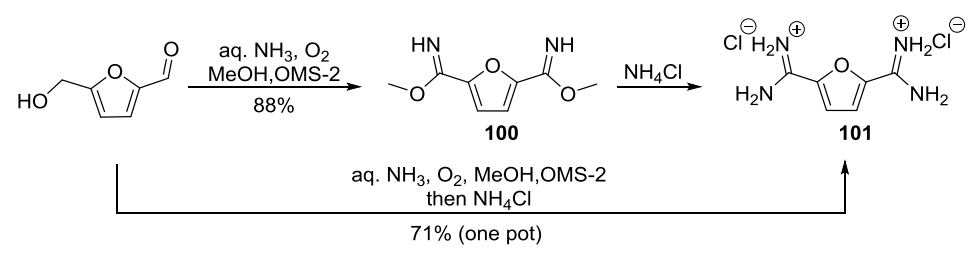

Scheme 39. Transformation of 5-HMF to dicarboximidate and diamidine salt

\subsection{Carbon-oxygen and carbon-sulfur bond formation reactions}

The nucleophilic attack of alcohols on aldehyde groups forms acetals, which are often applied as strategies for carbonyl compounds protection due to the reversibility of the acetal formation. Treatment of HMF with trimethyl orthoformate in the presence of ytterbium sulfate supported on Amberlite 15 gave access to the acetal $\mathbf{1 0 2}$ in $80 \%$ yield (Scheme 40). ${ }^{[16]}$ The same protected HMF was obtained in high yield by Al-beta-Zeolite-catalyzed acetalization in methanol. ${ }^{[117]}$ Using cerium phosphate as a catalyst in alcohols, both cyclic and acyclic acetals have been obtained in good yields. ${ }^{[118]}$ Amberlyst 15 was also found to be an efficient catalyst for the preparation 
of cyclic acetals. ${ }^{[119]}$

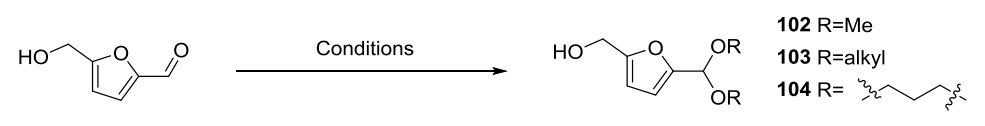

Conditions A : $\mathrm{HC}(\mathrm{OMe})_{3}, \mathrm{MeOH}, \mathrm{Yb}_{2}\left(\mathrm{SO}_{4}\right)_{3} @$ Amberlite $15,0{ }^{\circ} \mathrm{C}$ to $\mathrm{rt}, 80 \%$ (102)

Conditions $\mathrm{B}: \mathrm{MeOH}, \mathrm{Al}-\beta$-zeolite, $65{ }^{\circ} \mathrm{C}, 96 \%$ (102)

Conditions C : Alcohol, $\mathrm{CePO}_{4}$, reflux, $78-80 \%$ (103)

Conditions D : 1,3-propanediol, Amberlyst 15, DCM, rt, 92\% (104)

Scheme 40. Acetalization of HMF with simple alcohols

The acetalization of HMF with glycerol was performed by means of solid acid catalysis, yielding a mixture of 1,3-dioxolane 105 and 1,3-dioxane 106 (Scheme 41). ${ }^{[120-121]}$ The acetalization with glycerol was extended to several in situ formed 5-(alkyloxymethyl)furfurals for the preparation of potential surfactant molecules $\mathbf{1 0 7}$ and 108 in a one-pot process. ${ }^{[122]}$ The resulting compounds with HLB values in the range of 4.9 to 6.6 and good thermal and water stability could be useful for industrial applications as W/O emulsifiers.

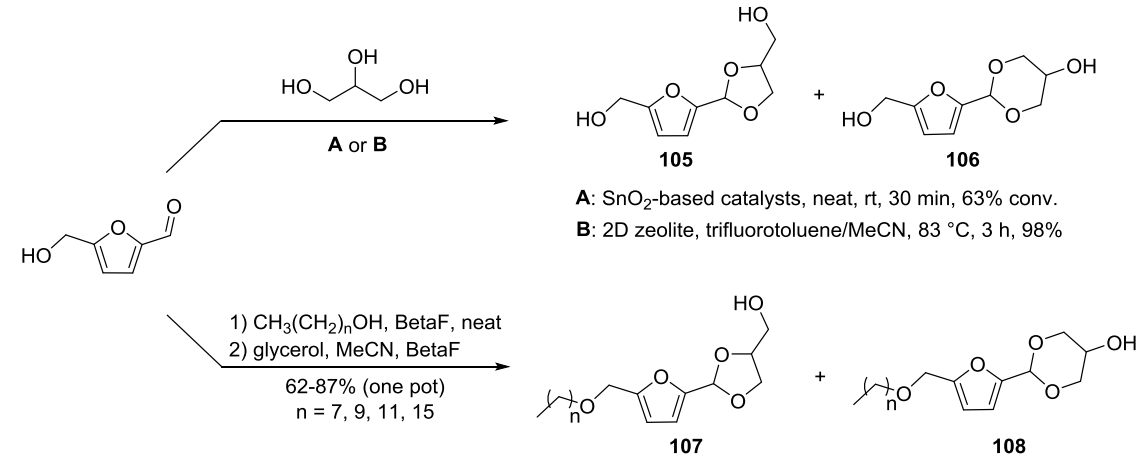

Scheme 41. The acetalization of HMF and its derivative with glycerol

Likewise, thioacetalization of HMF under various catalytic conditions has been also reported. The reaction with ethyl-2-mercaptoacetate in the presence of acidic $\mathrm{H}-\beta$ zeolite and 1-butyl-3-methylimidazolium chloride provided the corresponding dithioacetal $\mathbf{1 0 9}$ in $85 \%$ yield (Scheme 42). ${ }^{[123]}$ Ou prepared dithioacetal 110 by the reaction of $\mathrm{HMF}$ and cysteine in order to evaluate its cytotoxicity because this dithioacetal could be formed during food processing and digestion. ${ }^{[124]}$

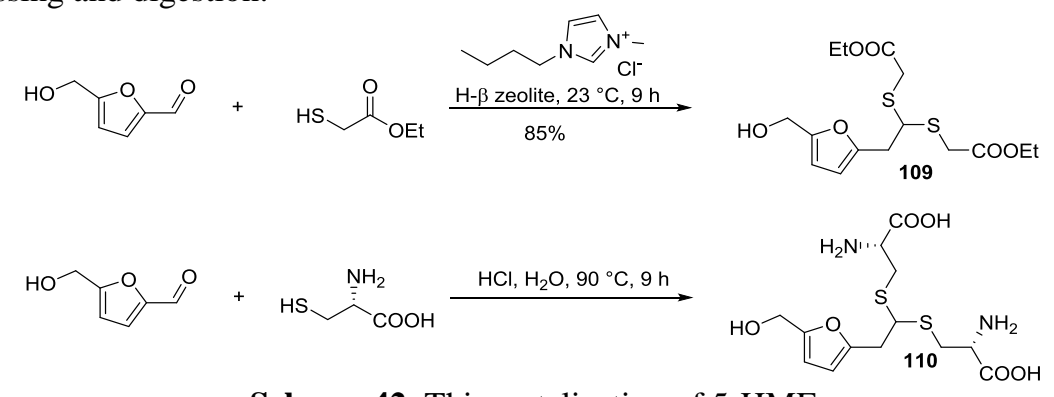

Scheme 42. Thioacetalization of 5-HMF

\section{Reactions on the hydroxyl group}

This section covers the strategies taking advantage of the reactivity of this benzylic alcohol to produce valuable chemicals. Apart from reactions where the hydroxymethyl group of HMF has been exploited for grafting it onto solid supports or polymers, several other transformations involving the $\mathrm{CH}_{2} \mathrm{OH}$ group of HMF were reported, such as conversion to esters, ethers, halides and amines, as well as its reactivity as an alkylating reagent in Friedel-Crafts alkylations.

\subsection{Conversion to halides}

HMF can be easily converted to 5-chloromethylfurfural 111 or 5-bromomethylfurfural 112 via halogen substitution of the hydroxyl group. A range of classical halogenating conditions could be successfully applied to HMF (Table 4). The resulting halogenated HMF derivatives proved to be useful intermediates for the synthesis 
of several valuable furan-based complex compounds. 5-Chloromethylfurfural 111 being easily and directly obtained from sugars is now also claimed as a platform chemical itself. ${ }^{[125]}$

Table 4. Halogenation experimental conditions

\begin{tabular}{|c|c|c|c|c|}
\hline Entry & Product & Conditions & Yield & Ref. \\
\hline 1 & \multirow{5}{*}{$\Xi$} & $\mathrm{HCl}$ (gas), $\mathrm{Et}_{2} \mathrm{O}, 9 \mathrm{~h}$ & $87 \%$ & [126] \\
\hline 2 & & $\mathrm{HCl}(\mathrm{aq}), \mathrm{DCM}$ or DCE, rt, $24 \mathrm{~h}$ & $86-92 \%$ & {$[1,127-128]$} \\
\hline 3 & & $\mathrm{SOCl}_{2}$, pyridine, DCE, $5 \mathrm{~h}$ & $71 \%$ & [126] \\
\hline 4 & & $\mathrm{Me}_{3} \mathrm{SiCl}, \mathrm{CDCl}_{3}, 6 \mathrm{~h}$ & $92 \%$ & [126] \\
\hline 5 & & $\mathrm{POCl}_{3}, \mathrm{DMF}, 5 \mathrm{~h}$ & $77 \%$ & [129] \\
\hline 6 & \multirow{6}{*}{$\cong$} & $\mathrm{HBr}$ (gas), $\mathrm{Et}_{2} \mathrm{O}, 5 \mathrm{~h}$ & $64 \%$ & {$[126,130]$} \\
\hline 7 & & $\mathrm{HBr}(\mathrm{aq}), \mathrm{DCE}, 65^{\circ} \mathrm{C}, 1 \mathrm{~h}$ & $94 \%$ & [127] \\
\hline 8 & & $\mathrm{SOBr}_{2}$, pyridine, DCE, $5 \mathrm{~h}$ & $75 \%$ & [126] \\
\hline 9 & & $\mathrm{PBr}_{3}, \mathrm{CaCO}_{3}, \mathrm{DCE}, 5 \mathrm{~h}$ & $62 \%$ & [126] \\
\hline 10 & & $\mathrm{Me}_{3} \mathrm{SiBr}, \mathrm{CHCl}_{3}$ or $\mathrm{CHCl}_{2} \mathrm{CH}_{2} \mathrm{Cl}, 3 \mathrm{~h}$ & $>98 \%$ & {$[126,131]$} \\
\hline 11 & & $\mathrm{NBS}, \mathrm{PPh}_{3}, \mathrm{DCM},-5^{\circ} \mathrm{C}, 0.5 \mathrm{~h}$ & $87 \%$ & [132] \\
\hline
\end{tabular}

Taking advantage of chlorination of HMF as a key step, Ananikov reported an efficient synthetic route to ranitidine, a medication which decreases stomach acid production (Scheme 43). ${ }^{[1]}$ The synthetic route consisted of the nucleophilic substitution of 5-chloromethylfurfural $\mathbf{1 1 1}$ by $N$-acetylcysteamine. Subsequent transformations of the thioether $\mathbf{1 1 3}$ afforded smoothly ranitidine in 65\% overall yield from HMF. Changing the reagent to an arylisocyanate in the last step provided CAP-1, a novel compound with inhibition of HIV-1 capsid protein assembly activity. ${ }^{[128]}$

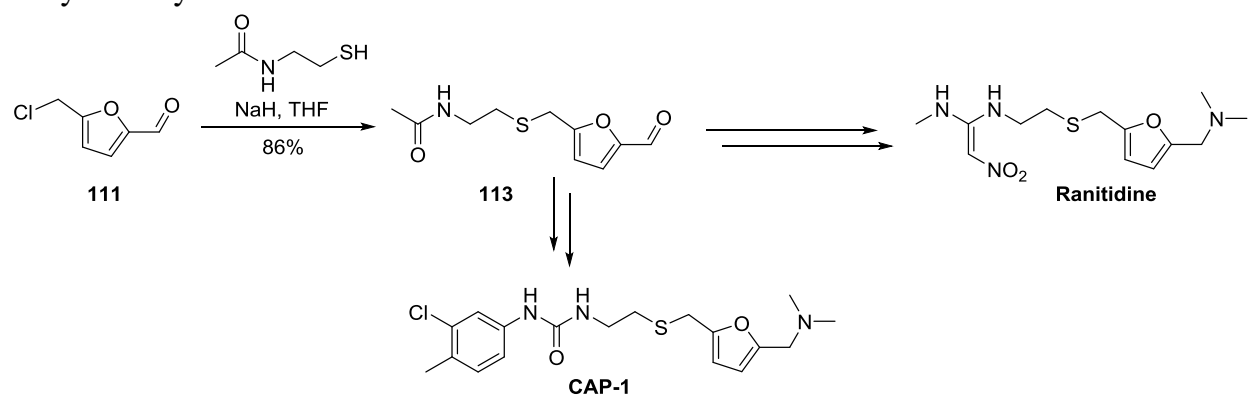

Scheme 43. Synthesis of ranitidine and CAP-1 from 5-HMF

\subsection{Conversion to ethers and acetals}

HMF can undergo self-etherification to yield 5,5'-[oxybis(methylene)]bis-2-furfural (OBMF) 114 under acidic medium (Scheme 44). It is one of the (undesired) processes occurring during degradation of HMF upon storage. ${ }^{[1]}$ The dehydration of HMF in the presence of $p$-TSA and phosphorus pentoxide in toluene with a continuous water removal using a Dean-Stark trap provides OBMF in $76 \%$ yield. ${ }^{[133]}$ OBMF can also be obtained in $55 \%$ yield by thermal dehydration in DMSO without any acidic catalyst. ${ }^{[134]}$ Additionally, several heterogeneous solid acids were reported to catalyze this reaction (e.g., Amberlyst-15, Amberlite IR 120, Preyssler heteropolyacids, graphene oxide). ${ }^{[1,135-140]}$ Finally, OBMF could also be obtained by Williamson reaction of HMF and 5-chloromethylfurfural. ${ }^{[141]}$ 


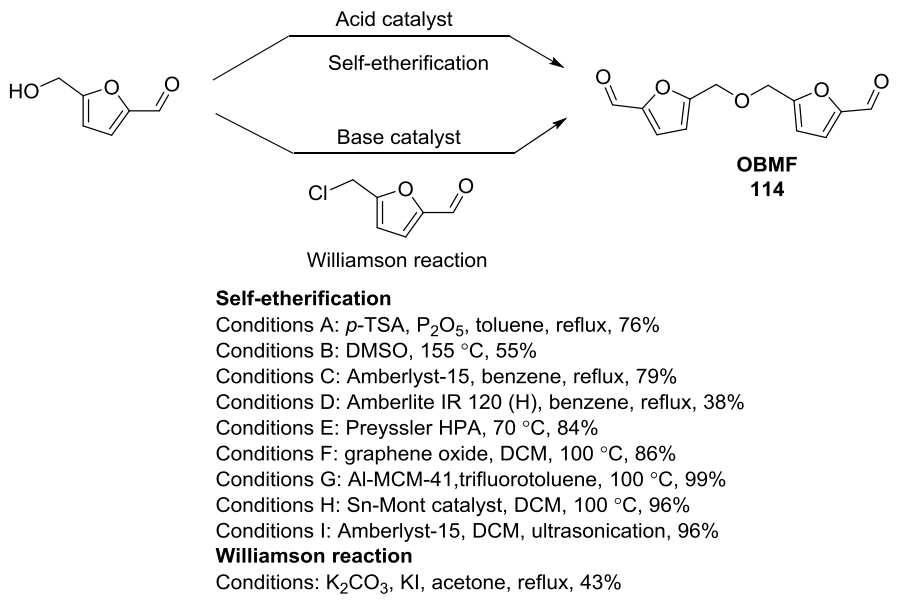

Scheme 44. Conversion HMF to OBMF

Simple alkyl ethers (e.g. 5-ethoxymethylfurfural) can be prepared by catalytic etherification of HMF and alcohols at high temperature. ${ }^{[142-143]}$ A milder alternative is the Williamson reaction between HMF and an alkyl halide. It was reported that treatment of HMF with sodium hydride/iodomethane could give the methyl ether in 94\% yield. ${ }^{[22]} \mathrm{HMF}$ reacted with benzyl bromide in the presence of $\mathrm{Ag}_{2} \mathrm{O}$ in DMF to afford 5benzyloxymethylfurfural in $72 \%$ yield. ${ }^{[135]}$ Pichiafuran $\mathrm{C}$, a monofuran metabolite isolated from Pichia membranifaciens yeast, was synthesized via $\mathrm{Yb}(\mathrm{OTf})_{3}$-catalyzed reaction of HMF with 2-phenylethanol and subsequent reduction of $\mathbf{1 1 5}$ with $\mathrm{NaBH}_{4}$ (Scheme 45). ${ }^{[144]}$

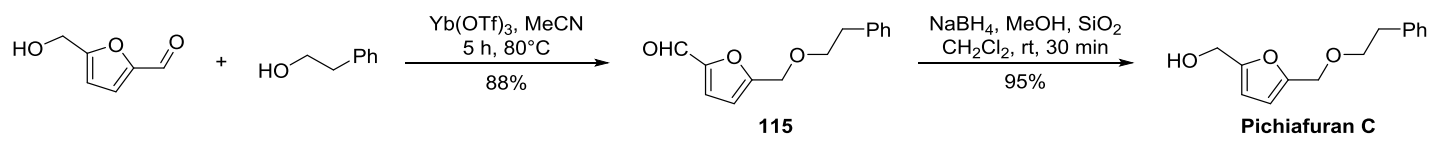

Scheme 45. Synthesis of Pichiafuran C

Sessiline, an alkaloid isolated from the fruits of Acanthopanax sessiliflorus was prepared in 54\% yield in neat conditions by reaction of 5-HMF with amidocarbinol $\mathbf{1 1 6}$ (obtained in 3 steps and 28\% yield from succinimide).$^{[145]}$ The proposed mechanism is the nucleophilic addition of HMF onto the iminium intermediate, which is in equilibrium with the amidocarbinol (Scheme 46).
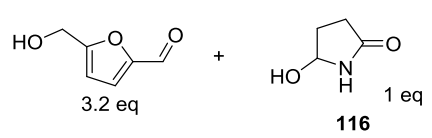

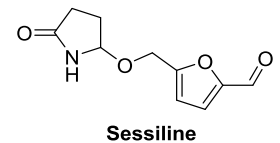

Sessiline

Scheme 46. Synthesis of Sessiline

Stevens and coworkers performed the $\beta$-alkoxylation of the in situ formed 3-imidoallenylphosphonate $\mathbf{1 1 7}$ with a range of alcohols (Scheme 47) ${ }^{[146]}$ Despite a crude yield estimated to $90 \%$, the product 118 was isolated only in $33 \%$ yield, probably due to partial degradation during reverse phase flash chromatography purification.

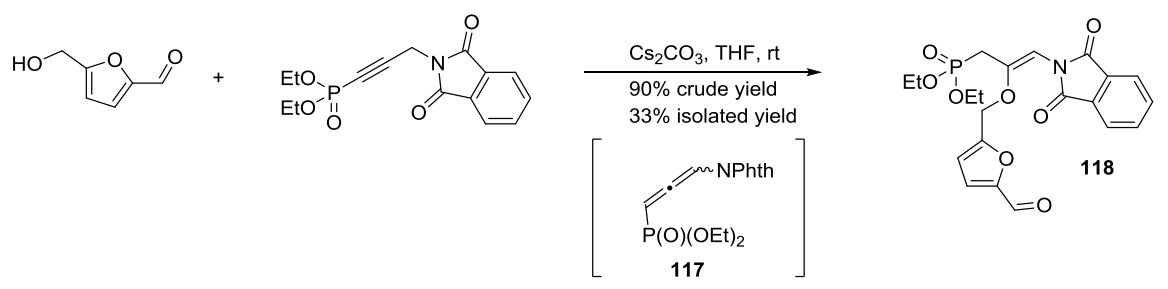

Scheme 47. Alkoxylation of 3-imidoallenylphosphonate with 5-HMF

Descotes prepared the tetrahydropyranyl ether 119 in $72 \%$ yield by reaction between HMF and dihydropyran catalyzed by pyridinium $p$-toluenesulfonate (Scheme 48). ${ }^{[147]}$ The Ferrier rearrangement of HMF and 
peracetylated glycal 120 under Lewis acid catalysis was reported by the same group in 2001 (Scheme 48). ${ }^{\text {[148] }}$ The best yield was obtained when the combination $\mathrm{LiBF}_{4} / \mathrm{SnCl}_{2}$ was employed as Lewis acid catalysts. More recently, Zhang described the transformation of various glycals including $\mathbf{1 2 0}$ with HMF in the presence of $\mathrm{FeCl}_{3} \cdot 6 \mathrm{H}_{2} \mathrm{O} / \mathrm{C}$ as a recyclable catalyst in DCE, leading to a range of 2,3-unsaturated glycosides in $67-92 \%$ yields. ${ }^{[149]}$ Other carbohydrate derivatives of HMF have also been studied. Cottier investigated several possible pathways to prepare $\beta$-glucosylmethylfurfural 123 starting from HMF and glycosyl donors such as 122. ${ }^{[116]}$ The $\mathrm{Ag}_{2} \mathrm{O}$-catalyzed coupling of $\mathrm{HMF}$ and glycosyl bromide 122a gave only $11 \%$ yield of the $\beta$ glucosylmethylfurfural. The yield was improved to $32 \%$ using the imidate $\mathbf{1 2 2} \mathbf{b}$ and boron trifluoride diethyl etherate (Scheme 48).

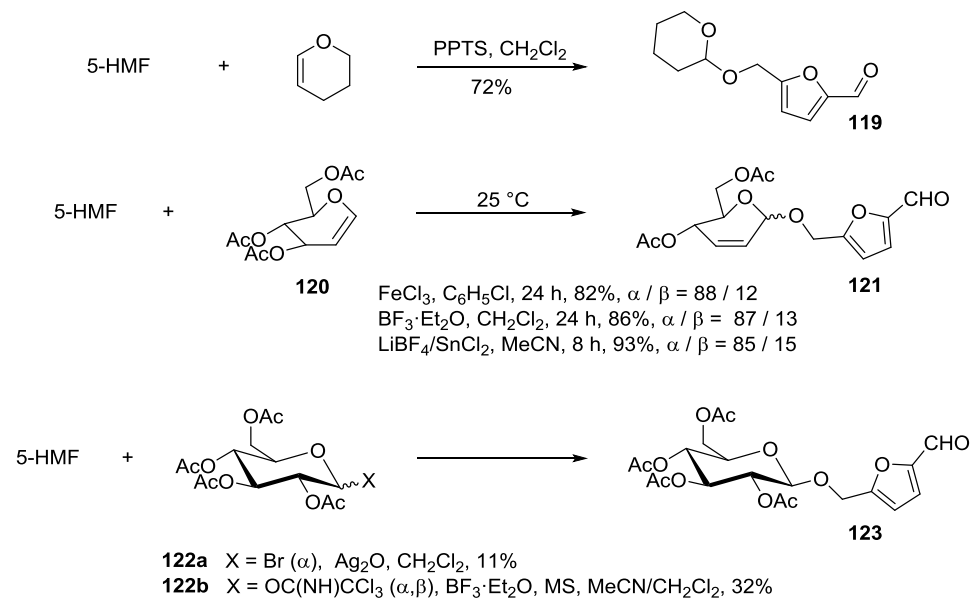

Scheme 48. Acetal formation

\subsection{Esterifications}

Classical esterification conditions were applied for the functionalization of the hydroxyl group of 5-HMF. The reaction with acetic anhydride in the presence of a base such as pyridine or sodium acetate, furnished 5acetoxymethylfurfural in up to $93 \%$ yield. ${ }^{[16,135]}$ Benzoate esters can be prepared by reaction with benzoyl halides under similar conditions. ${ }^{[150-151]}$

The esterification of 4- $O$-acetylferulic acid with HMF was performed in pyridine using DCC as coupling reagent in the presence of $p$-toluenesulfonic acid, providing the corresponding ester 124 in $40 \%$ yield (Scheme 49$).{ }^{[152]}$ The ester 125 was also prepared via DCC-promoted coupling reaction between HMF and the coumarin-derived acid, and its inhibitory activity against protein tyrosine phosphatase $1 \mathrm{~B}$ was studied. ${ }^{[153]}$
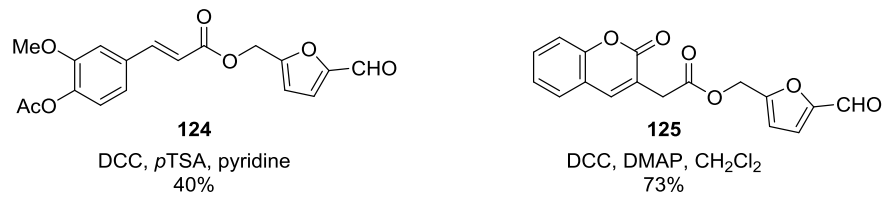

Scheme 49. DCC-promoted esterification between HMF and carboxylic acids

Tamariz's group prepared the natural product 127, isolated from the Noni fruit, by two successive esterifications: first, the esterification of HMF hydroxyl group with succinic anhydride leading to the intermediate ester-acid 126, then the alkylation of this latter with $n$-butyl bromide (Scheme 50) leading to the diester 127. The stepwise and one-pot process gave same overall yields $(85 \%){ }^{[154]}$

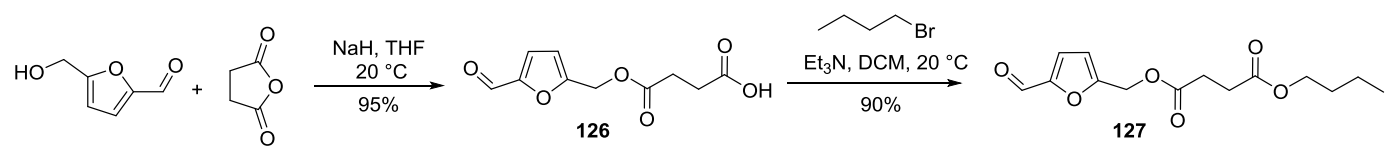

Scheme 50. Synthesis of natural succinate derivative

Mumefural, a citrate ester of 5-HMF known to improve human blood fluidity, can be prepared from malic acid 
and HMF. ${ }^{[155]}$ The intermediate $\mathbf{1 2 8}$ (prepared from malic acid) reacted with HMF in the presence of DCC and a catalytic amount of DMAP in dichloromethane to deliver the ester $\mathbf{1 2 9}$ in $91 \%$ yield (Scheme 51). Subsequent deprotection gave access to mumefural in $68 \%$ yield.

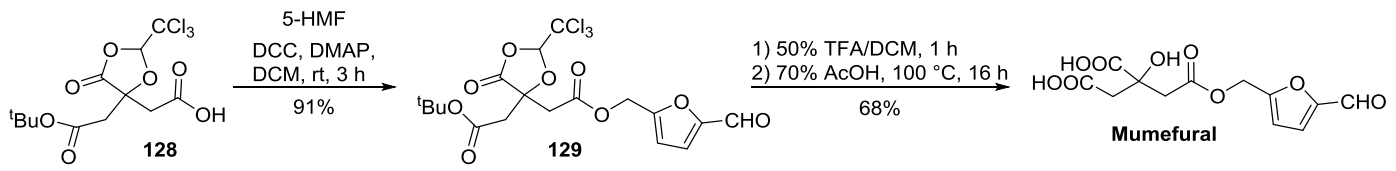

Scheme 51. Synthesis of mumefural from HMF

Biocatalytic esterification of HMF with different acyl donors such as carboxylic acids and methyl or ethyl esters has been reported (Scheme 52). ${ }^{[156]}$ Good to excellent yields of esters 130 were obtained using the lipase CAL-B as catalyst in solvent-free conditions. In the case of short-chain acids, a mixture of carboxylic acid and tertbutanol $(1: 1 \mathrm{v} / \mathrm{v})$ was used instead of solvent-free conditions to avoid the deactivation of the lipase due to the high acidity of the medium. Interestingly the same enzyme proved also to be efficient to prepare methyl carbonate $\mathbf{1 3 1}$ from dimethyl carbonate as well as HMF-esters directly from soybean oil.

The enzymatic esterification between HMF and levulinic acid to levulinate $\mathbf{1 3 2}$ was reported by Li et al. ${ }^{[157]}$ Novozym 435 was selected as the best catalyst and the reaction could proceed in alcoholic solvents such as tertbutanol, or 2-methyl-2-butanol as well as in ethereal solvents (CPME, or 2-MeTHF), with more than $90 \%$ conversion.

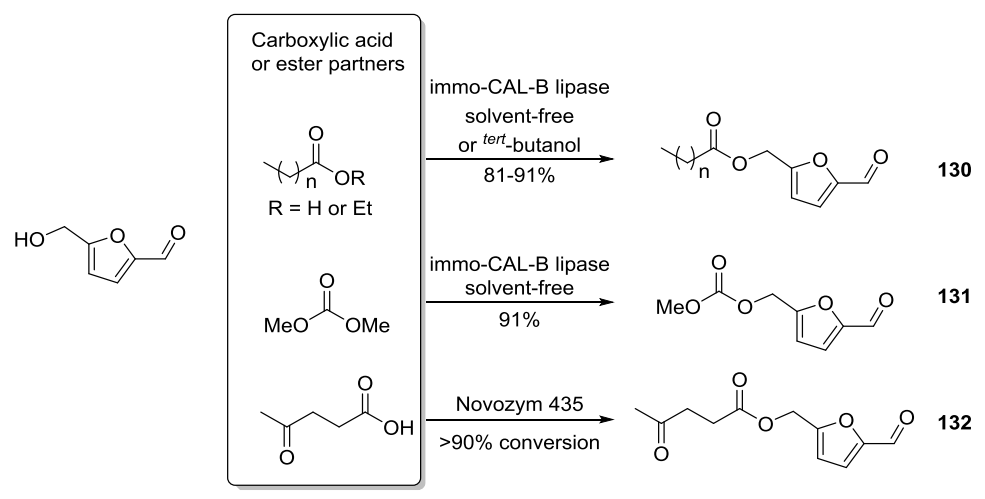

Scheme 52. Biocatalytic esterifications

\subsection{Amination reactions}

Strictly speaking, there are no examples of real amination on the OH group of HMF to make amino-deoxy-HMF. However, a few studies about the preparation of amides, hydrazines and ureas have been reported.

The group of Wierenga reported the direct preparation of hydrazine 133 under Mitsunobu conditions from 5HMF ${ }^{[158]}$ In the absence of any other nucleophile, the reduced DEAD reagent acts as a nucleophile in SN2 reaction to produce compound $\mathbf{1 3 3}$ in $\mathbf{1 2 \%}$ yield (Scheme 53). Comparatively, furfuryl alcohol or the acetalprotected HMF provided much higher yields (60\% and $86 \%$ respectively) under the same conditions.

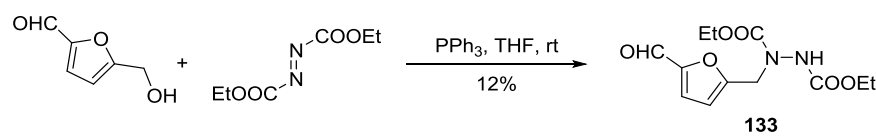

Scheme 53. Reaction between HMF and diethyl azodicarboxylate

Lewis et al. prepared the $N$-hydroxyurea derivative $\mathbf{1 3 4}$ by reacting $\mathrm{HMF}$ with $N, O$ (bisphenoxycarbonyl)hydroxylamine under Mitsunobu conditions, followed by treatment with ammonia. Subsequent reductive amination with piperazine $\mathbf{1 3 5}$ released the final product $\mathbf{1 3 6}$ (yields not reported), which exhibited antihistaminergic activity (Scheme 54). ${ }^{[159]}$ 


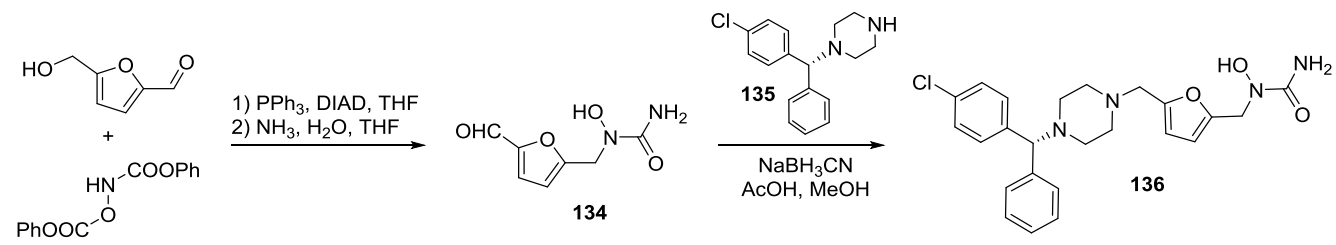

Scheme 54. Reaction between $\mathrm{HMF}$ and $\mathrm{N}, \mathrm{O}$-(bisphenoxycarbonyl) hydroxylamine

The Ritter reaction was also applied to HMF, which gave access to the corresponding amides $\mathbf{1 3 7}$ in around $50 \%$ yield by treatment with trifluoromethanesulfonic acid in acetonitrile or benzonitrile at room temperature (Scheme 55). ${ }^{[135]}$

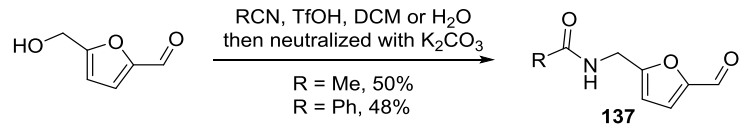

Scheme 55. Reaction between HMF and nitriles

\subsection{Construction of a C-C(Ar) bonds}

The Friedel-Crafts alkylation of arenes using HMF as the alkylating agent has been reported by different research groups. Beller et al. implemented the alkylation of $o$-xylene using $\mathrm{FeCl}_{3}(10 \mathrm{~mol} \%)$ as a catalyst providing a mixture of regioisomers in $37 \%$ yield (ratio 138/139 of 62:38) (Scheme 56). ${ }^{[160]}$ The reaction with mesitylene, either promoted by $\mathrm{FeCl}_{3}$ or nitrosonium tetrafluoroborate, provided the product 140 in excellent yield. ${ }^{[161-162]}$ Heating HMF in refluxing toluene in the presence of poly(3,4-ethylenedioxythiophene) salt gave rise to a mixture of two isomers 141 and 142 in a global $81 \%$ yield. ${ }^{[163]}$ Employing $\mathrm{Glu}-\mathrm{Fe}_{3} \mathrm{O}_{4}-\mathrm{SO}_{3} \mathrm{H}$ as a magnetic carbonaceous solid acid catalyst led to a regioisomeric mixture of $\mathbf{1 4 1}$ and $\mathbf{1 4 2}$ containing some traces of the meta isomer. ${ }^{[164]}$ Recently, Vasilyev and coworkers reported the arylation of HMF with arenes in trifluoromethanesulfonic acid medium at room temperature. ${ }^{[165]}$ 5-Arylmethylfurfurals 143 were prepared in $17-$ 91\% yields, along with by-products 2-arylmethyl-5-(diarylmethyl)furans 144 (5-37\% yield) when highly nucleophilic arenes were used. Increasing the reaction time significantly affected the yield of the by-product. The same reactions using acidic zeolites CBV-720 as catalysts at $130{ }^{\circ} \mathrm{C}$ resulted in the selective formation of 5arylmethylfurfurals (11-79\% yield).

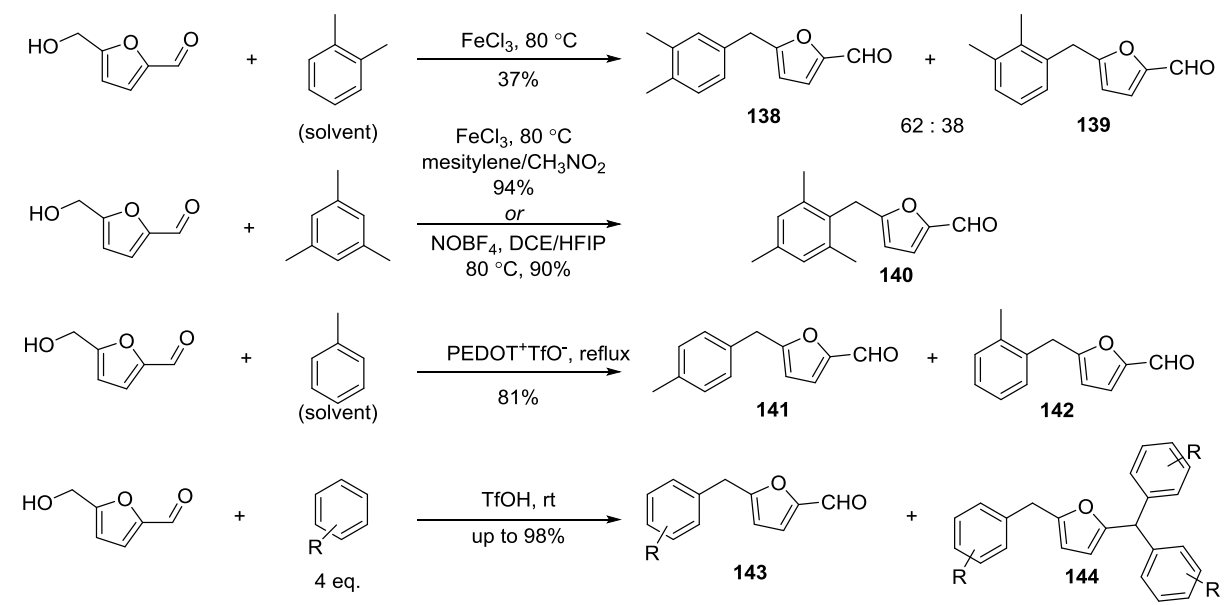

Scheme 56. Friedel-Crafts alkylation of arenes

\section{Reactions on the furan ring}

\subsection{Ring opening/rearrangement}

It is well known that HMF decomposes under acidic conditions at elevated temperature leading to the ringopening product levulinic acid. ${ }^{[2,166]}$ However, other derivatives arise from rearrangements of the furanic systems of HMF. For example, subjecting HMF to hydrothermolysis at high temperature and pressure led to 1,2,4benzenetriol 145 as the major product in yields up to $46 \%$ with $50 \%$ HMF conversion (Scheme 57). ${ }^{[167]}$ The other example is the conversion of HMF to phenols which was reported by Hashmi et al. ${ }^{[168]}$ In this reaction, 
HMF first undergoes a $O$-propargylation and the resulting aldehyde 146 is converted into trifurylmethane 147 under gold(III) catalysis. Finally, gold (I) catalysis promoted the conversion of 147 into the fused phenol 148 through ring rearrangement.

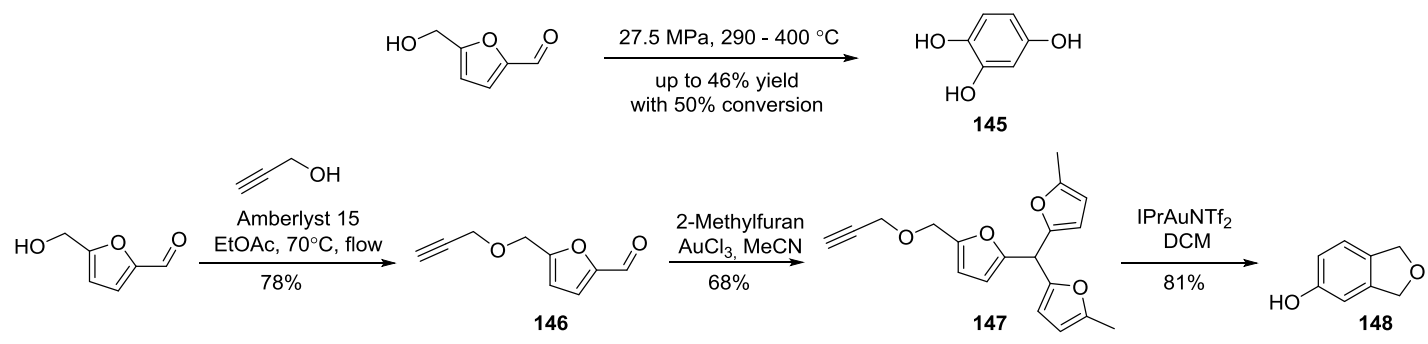

Scheme 57. Transformation of HMF and its derivatives to phenols

The hydrogenative/hydrolytic ring-opening of HMF in water provided 2,5-hexanedione (HD) ${ }^{[169-170]}$ or 1hydroxy- 2,5-hexanedione (HHD) ${ }^{[171-172]}$ depending on the catalytic conditions employed (Scheme 58). The latter was reported to be used as 1,4-diketone partner in the Paal-Knorr pyrrole synthesis. ${ }^{[173]}$ HD and HHD can be converted into cyclopentanic derivatives, respectively 3-methyl-2-cyclopent-2-en-1-one (MCO) ${ }^{[174]}$ and 2hydroxy-3-methylcyclopent-2-enone (MCP) ${ }^{[175-176]}$ via base-catalyzed intramolecular aldol reactions. Following an acid-catalyzed aldol reaction and subsequent hydrogenation sequence, HHD can be transformed into 3hydroxymethyl cyclopentanone $(\mathrm{HCPN})^{[177-178]}$. An alternative route toward cyclopentanic derivatives from HMF relies on a first catalytic reduction of the aldehyde generating 2,5-dihydroxymethylfuran (DHMF), followed by a Piancatelli rearrangement to 4-hydroxy-4-(hydroxymethyl)cyclopent-2-en-1-one (HHCPN) and further reduction of the produced cyclopentenone under the reaction conditions (Scheme 58). ${ }^{[179]}$

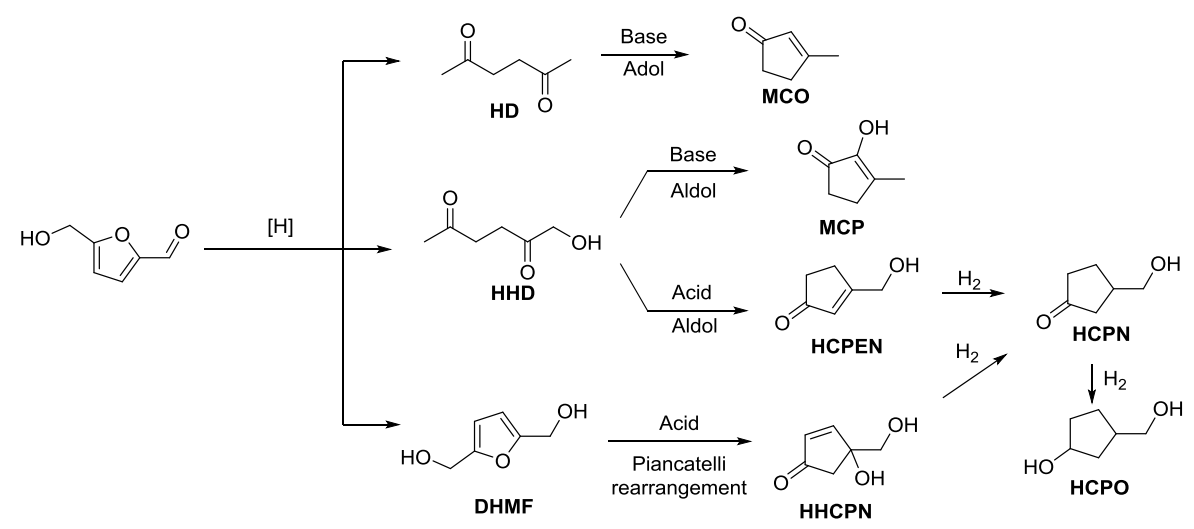

Scheme 58. Ring-opening/rearrangement of HMF derivatives

Oxidative conditions have also been employed to achieve ring opening transformations of intermediates arising from 5-HMF. Lichtenthaler and coworkers reported the preparation of various heterocycles such as the pyridazine 152, the thiophene 153 or the pyrrole 154 from HMF (Scheme 59), ${ }^{[180]}$ relying on a first reduction of the aldehyde and benzylation of the diol intermediate to produce 149. This symmetrical disubstituted furan can undergo oxidative ring opening upon treatment with $m$-CPBA to yield diketone 150. Chemoselective hydrogenation of $\mathbf{1 5 0}$ would provide diketone 151. These 1,4-diketones were rapidly converted in heterocyclic scaffolds 152-154 via diverse transformations.
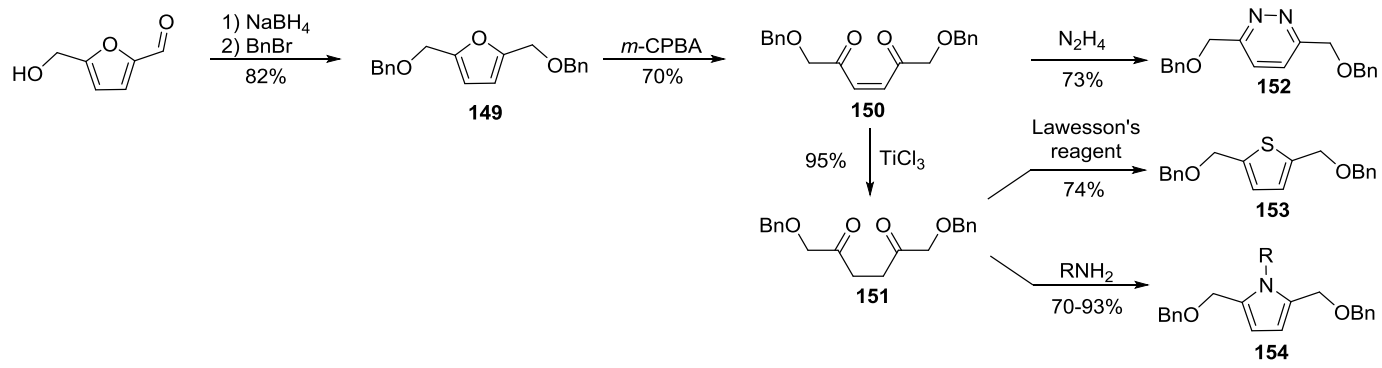
Scheme 59. Heterocycles obtained in three steps from HMF involving a furan ring-opening reactions

\subsection{Singlet oxygen oxidation}

HMF can react with singlet oxygen via [4 + 2] cycloaddition to give rise to 5-hydroxy-5-(hydroxymethyl)-furan$2(5 H)$-one $(\mathbf{1 5 6}){ }^{[135]}$ The cycloadduct 155 rearranged via a solvent-assisted decarbonylation reaction to produce efficiently the butenolide 156. The reaction was recently reinvestigated by Kappe under continuous flow conditions (Scheme 60). ${ }^{[181]}$ The best yield obtained was $93 \%$ using $1 \mathrm{mM}$ rose bengal as photosensitizer in a mixture of $i-\mathrm{PrOH} / \mathrm{H}_{2} \mathrm{O}$ as solvent with $0.5 \mathrm{~mL} / \mathrm{min}$ flow rate.

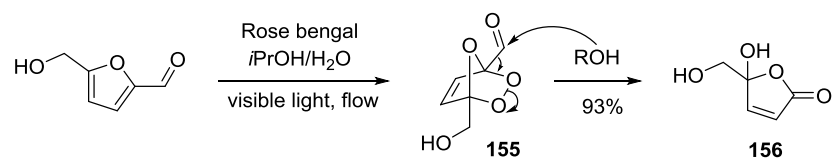

Scheme 60. Reaction of HMF with singlet oxygen

\subsection{Diels-Alder reactions}

Electron-rich furans have been widely employed as dienes in Diels-Alder reactions with electron-deficient dienophiles. In contrast to other furanic compounds, the presence of the strongly electron withdrawing aldehyde on the furan ring of HMF tends to deactivate the aromatic ring toward Diels-Alder reactions. In order to use HMF in this cycloaddition process, it usually requires chemical modification such as reduction toward 2,5dihydroxymethylfuran (DHMF) or 2,5-dimethylfuran (DMF).

Ananikov and co-workers reported the synthesis of a series of oxabicyclic compounds starting from HMF and maleimide via one-pot reduction/cycloaddition/hydrogenation sequence or in a stepwise process taking advantage of a Diels-Alder reaction as the key step (Scheme 61). ${ }^{[182]}$ Reduction of HMF to 2,5dihydroxymethylfuran followed by endo-selective Diels-Alder cycloaddition with maleimide and hydrogenation in a single pot provided the product $\mathbf{1 5 7}$ in $\mathbf{7 3 \%}$ yield (that could also be prepared in sequential-step procedure). The authors also applied the Diels-Alder reaction on HMF-derived bis(aminomethyl)furans, and bis(alkoxymethyl)furans and maleic anhydride could be employed as dienophile to prepare analogues of the anticancer drug norcantharidin. ${ }^{[183]}$

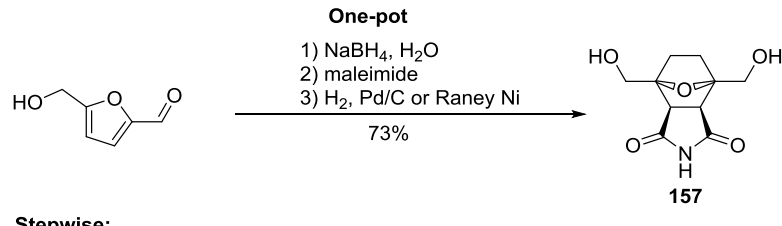

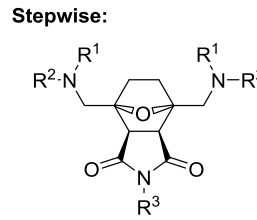

$\mathrm{R}_{1}=\mathrm{H}, \mathrm{R}_{2}=\mathrm{Ph}, \mathrm{R}_{3}=\mathrm{H}$

$\mathrm{R}_{1}=\mathrm{H}, \mathrm{R}_{2}=\mathrm{Ph}, \mathrm{R}_{3}=\mathrm{Pr}$

$R_{1}=R_{2}=E t, R_{3}=H$

$\mathrm{R}_{1}, \mathrm{R}_{2}=$ 4-Morpholinyl, $\mathrm{R}_{3}=\mathrm{H}$
RO

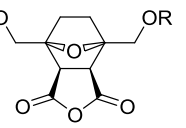

$\mathrm{R}=\mathrm{Me}$

$R=E t$
$R=B z$

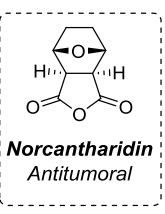

Scheme 61. Diels-Alder reaction of DHMF, bis(aminomethyl)furans and bis(alkoxymethyl)furans

Sheppard's group reported a strategy to efficiently react HMF with dienophiles, without changing the oxidation state of the aldehyde (Scheme 62). ${ }^{[184]}$ HMF was first reacted with $N$-methylhydrazine to produce the corresponding hydrazone, before reacting with maleimides providing the cycloadducts $\mathbf{1 5 8}$. The latter underwent deoxyaromatisation to produce the phthalimides 159. The reaction was carried out in water and the products were isolated in high yields by simple filtration.
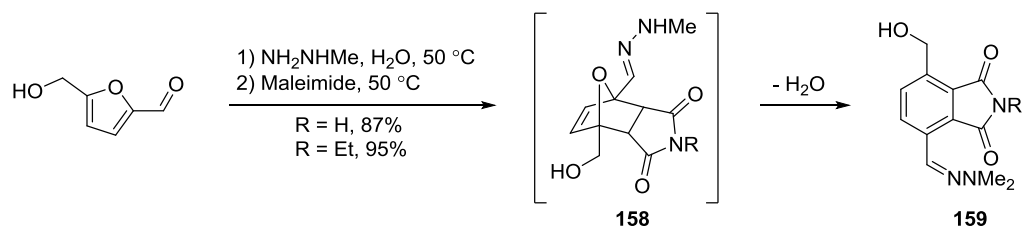
Scheme 62. Diels-Alder reaction of HMF-derived hydrazone

In addition, a range of HMF-derived furans such as 2,5-dimethylfuran (DMF) and dimethyl furan-2,5dicarboxylate have been utilized as dienes in reactions with various dienophiles (e.g., ethylene, acrolein and benzyne) to accomplish the Diels-Alder reaction. Subsequent deoxyaromatisation of the Diels-Alder adducts led to $p$-xylene or other substituted aromatic compounds. ${ }^{[185-193]}$

\section{Multi-step and multi-functionalization sequences}

As it has been shown throughout this review article, several methodological studies on the chemical modifications of HMF have been conducted, showing the high versatility of this C-6 synthon. In a synthetic perspective, 5-HMF has also been used in more complex multistep sequences, targeting complex and/or natural scaffolds.

In a study on intramolecular Diels-Alder reactions (IMDA) of furan derivatives, Sternbach used the 5-HMF as a platform for the preparation of the highly substituted keto-sulfone $\mathbf{1 6 0}$ (Scheme 63). ${ }^{[194]}$ This substrate is poorly reactive in IMDA cycloaddition, however the conversion of the ketone to a cyanohydrin group using TMSCN/ZnI 2 reactivates the furan ring, which then can undergo an IMDA reaction in good yield producing tricyclic derivative $\mathbf{1 6 1}$ and epimer 161' though with moderate diastereoselectivity.

A supported intramolecular Diels-Alder reaction was also performed on the furan ring of HMF after its coupling with a resin-bound amine (Scheme 63). ${ }^{[195]}$ The polycyclic compound $\mathbf{1 6 3}$ could be obtained from the intermediate compound 162 after IMDA reaction followed by cleavage from the resin.
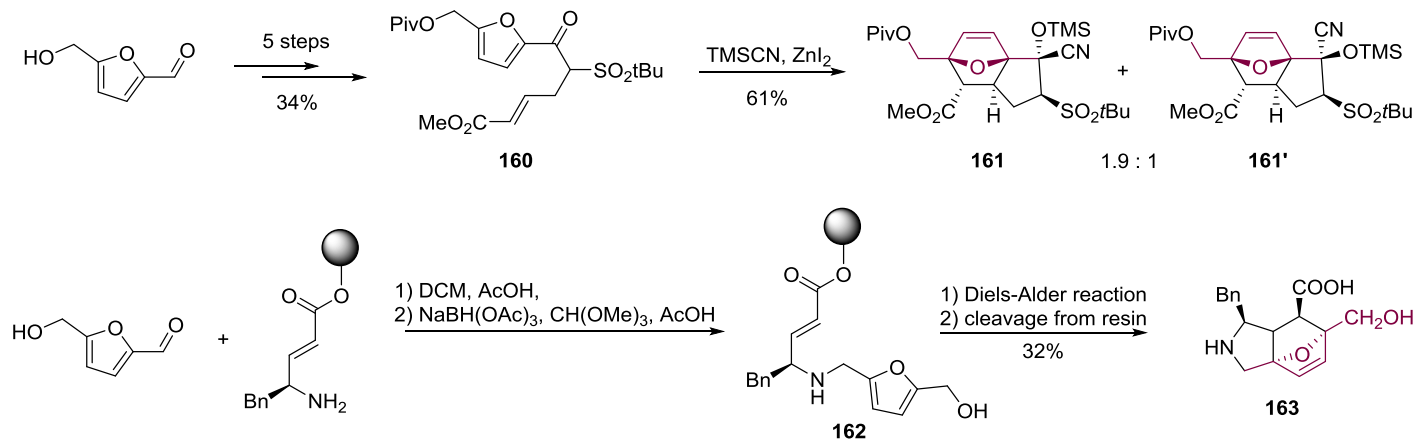

Scheme 63. Intramolecular Diels-Alder reaction on furan ring

Schinzer et al. completed the stereoselective synthesis of furano-epothilone D, analog of natural epothilone which is a powerful antitumoral molecule, using HMF as a building block (Scheme 64). ${ }^{[196]}$ Bromination of the hydroxymethyl group was the first step of functionalization. A sequence of a Negishi-type coupling and a diastereoselective aldol reaction with a chiral ketone produced the secondary alcohol 164. This advanced intermediate was then converted to the furanic analogs of epothilone D. Both furano-epothilone D and its diastereoisomer displayed only moderate effect on tubulin assembly.

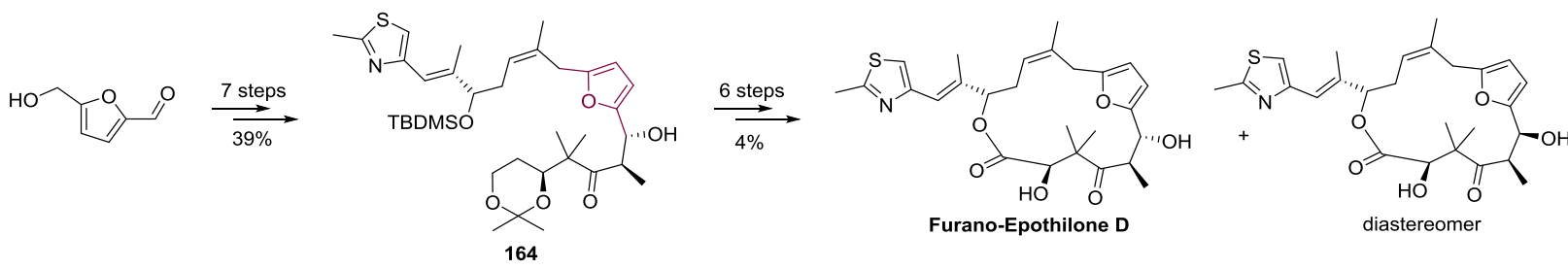

Scheme 64. Synthesis of furano-epothilone D from HMF

Loh et al. reported a synthetic route to natural products aspergillides A and B which exhibit potent cytotoxic activities towards mouse lymphocytic leukemia cell (Scheme 65$).{ }^{[197]}$ In this route, all the carbon atoms in target molecules come from biomass-derived platform chemicals such as levulinic acid and HMF. The key steps in this synthesis were a Noyori's asymmetric transfer hydrogenation to produce enantiopure alcohol 165 which was then subjected to an Achmatowicz rearrangement and subsequent reduction leading to pyranes 166 and 167, 
advanced intermediates in the preparation of the natural products aspergillides A and B.

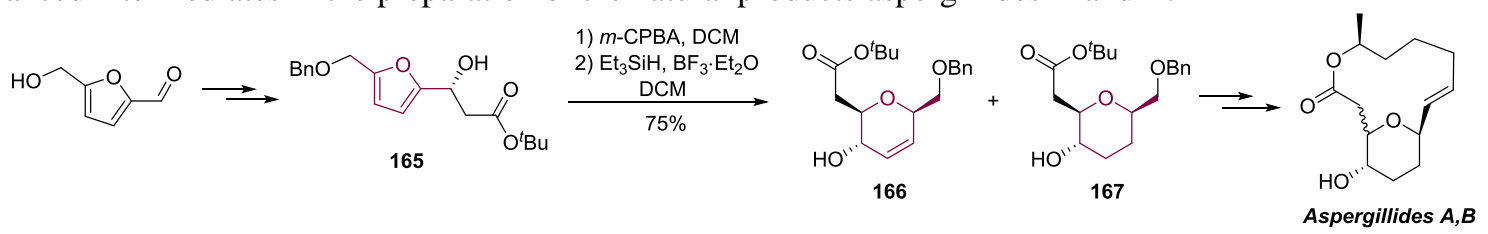

Scheme 65. Synthetic route to aspergillides A and B

A four-step process to prepare 8-oxa-3-aza-bicyclo[3.2.1]octanehydrochloride 169 starting from 5-HMF was described by Connolly et al. ${ }^{[198]}$ Reduction of 5-HMF to the corresponding saturated diol followed by double tosylation and double $\mathrm{S}_{\mathrm{N}} 2$ with benzylamine generated the bicyclic intermediate 168. The latter was hydrogenolyzed using Pearlman's catalyst in good yield to provide the final tricyclic adduct 169 (Scheme 66).

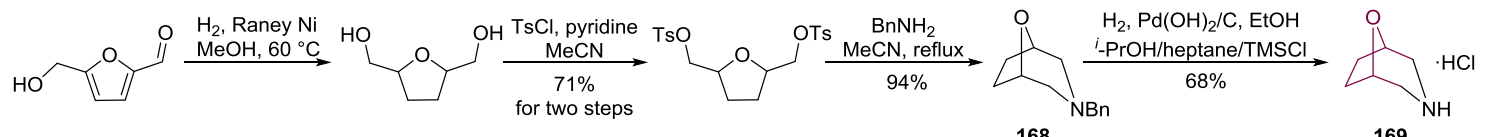

Scheme 66. Synthesis of 8-oxa-3-aza-bicyclo[3.2.1] octane hydrochloride 169

MPEG-grafted 5-HMF 170 has been used as a substrate to prepare a series of tricyclic molecules 173 (Scheme 67). ${ }^{[199]}$ The authors employed a 4-component Ugi reaction of supported HMF 170, benzyl isocyanide and various primary amines and fumaric acid mono-amides (171) to generate intermediates $\mathbf{1 7 2}$, that can undergo a tandem intramolecular Diels-Alder reaction of the furan ring followed by acidic workup to release final products 173.

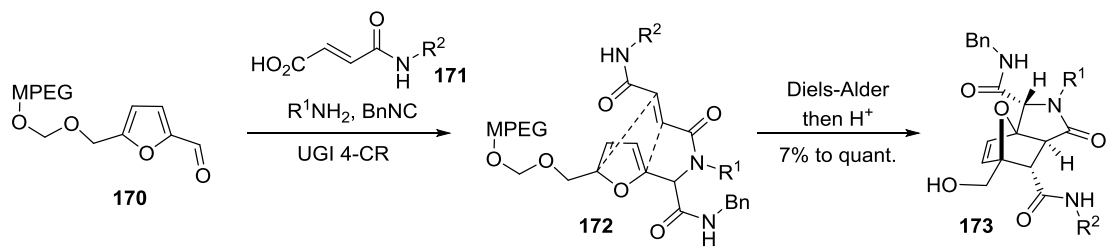

Scheme 67. Ugi/Diels-Alder tandem reaction

As illustrated above in Ugi/Diels-Alder reactions, the hydroxymethyl group present in 5-HMF offers a convenient handle for connection onto a solid support. The solid-supported HMF with a free carbonyl group could serve as a useful scaffold in combinatorial synthesis of furan-based libraries. Kundu and coworkers loaded HMF onto Sieber amide resin via the formation of amide and ester bonds using aliphatic dicarboxylic acid anhydride (Scheme 68). ${ }^{[200]}$ The resin-supported HMFs 174 could be engaged in multicomponent $\mathrm{A}^{3}$ couplings to provide, after separation from the solid support, propargylamines 175. Other multi-step transformations giving access to diverse nitrogen-containing heterocycles such as $\mathbf{1 7 6}$ and $\mathbf{1 7 7}$ were also successfully implemented using this supported synthesis strategy.

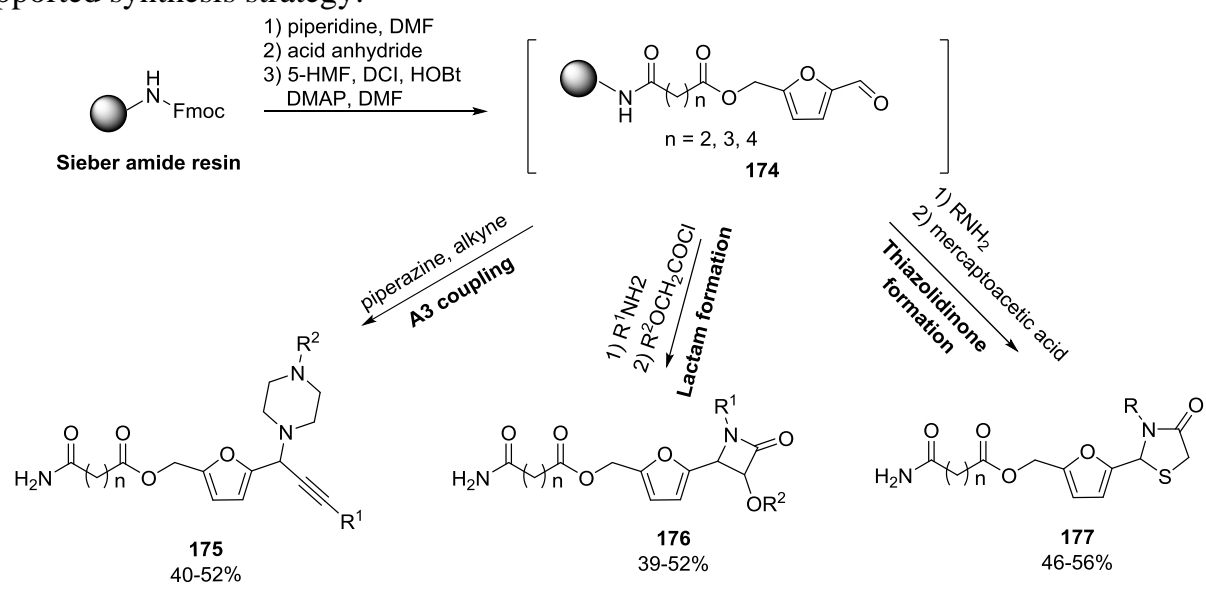

Scheme 68. Solid-phase combinatorial synthesis of HMF-based scaffolds 
In 1956, Elming reported the synthesis of 6-hydroxymethyl-3-pyridinol $\mathbf{1 7 8}$ starting with reductive amination of HMF, followed by acetylation and electrolysis (Scheme 69). ${ }^{[87]}$ The 3-pyridinol 178 could also be prepared by exposing 5-hydroxymethylfurfurylamine 179 to bromine in water/methanol at $0{ }^{\circ} \mathrm{C} .{ }^{[201]}$ Enantiopure synthesis of pyridinium salt $\left(S\right.$ )-alapyridaine $\mathbf{1 8 1}$ (a sweetness enhancer) was achieved under $\mathrm{Br}_{2} / \mathrm{MeOH} / \mathrm{H}_{2} \mathrm{O}$ conditions from the amine formed by reductive amination of HMF with L-alanine. ${ }^{[202]}$ Direct treatment of HMF with alkylamines in refluxing EtOH/ $\mathrm{H}_{2} \mathrm{O}$ under basic conditions ( $\mathrm{pH}$ adjusted $\sim 9.4$ with $\mathrm{NaOH}$ ) has been a frequently-used method to prepared pyridinium inner salts 180 in the past. ${ }^{[203-205]}$ Several pyridinium betaines derived from glycine, $\beta$-alanine and $\gamma$-aminobutyric acid proved to be potential bitter-suppressing candidates. More recently, an alternative method employing formic acid as a catalyst in $\mathrm{EtOH} / \mathrm{H}_{2} \mathrm{O}$ to synthesize pyridinium inner salts 180 from HMF was reported by Afonso. ${ }^{[206]}$

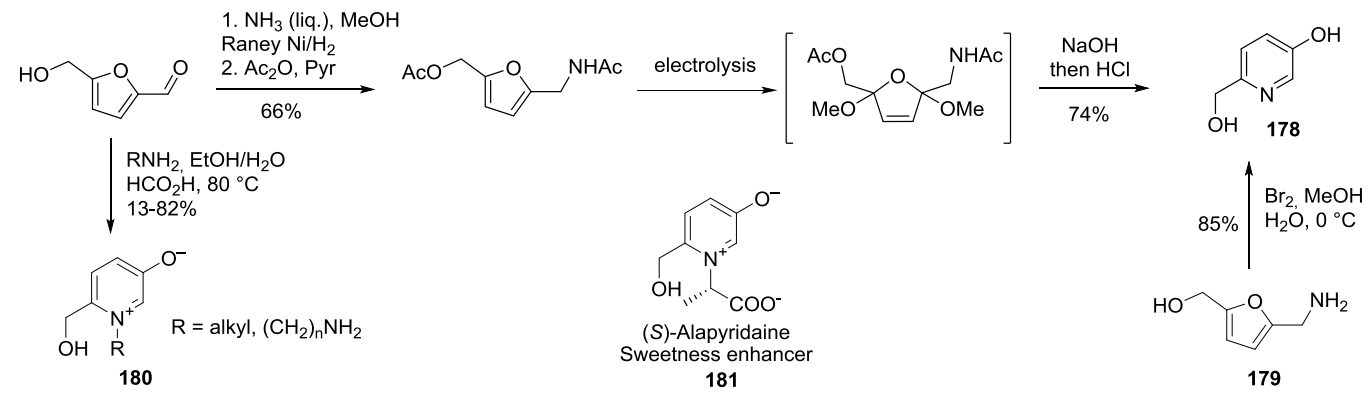

Scheme 69. Conversion of 5-HMF to pyridinol and pyridinium salt

The preparation of key intermediates of synthetic routes towards 21,23-dioxaporphyrins $\mathbf{1 8 5}$ from HMF was reported as an alternative to known but complex synthetic procedures, addressing drawbacks such as low yields and purification issues (Scheme 70). ${ }^{[207]}$ The addition of a phenyl-Grignard reagent on HMF, or the Henry reaction with nitromethane gave access to the furylcarbinol 182 and nitroalkene 183 respectively in good yields. Those intermediates were then reacted with pyrrole under indium chloride catalysis to generate diversely substituted bis-heteroarylmethanes 184, highly valuable building-blocks for the preparation of 21,23dioxaporphyrins 185 .

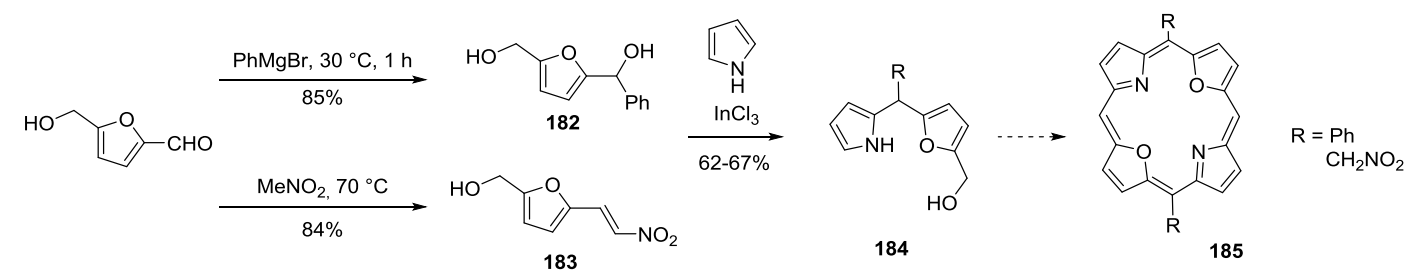

Scheme 70. Preparation of key intermediates to 21,23-dioxaporphyrin from 5-HMF

An example illustrating the usefulness of the olefination of HMF is the synthesis of trioxadispiroketal reported by Stockman. ${ }^{[208]}$ In this strategy, HMF was subjected to tandem oxidation/Wittig reaction providing the diester 186 as a 6.6:1 mixture of $(E, E)$ - and $(E, Z)$-isomers (Scheme 71). Reduction of both esters followed by hydrogenation of the two carbon-carbon double bonds on side chains afforded the corresponding diol 187. Further treatment with $N$-bromosuccinimide furnished the $[5,5,5]$-trioxadispiroketal 188. [6,5,6]Trioxadispiroketal 189 was also prepared via a similar strategy using a homologated phosphonium ylide.

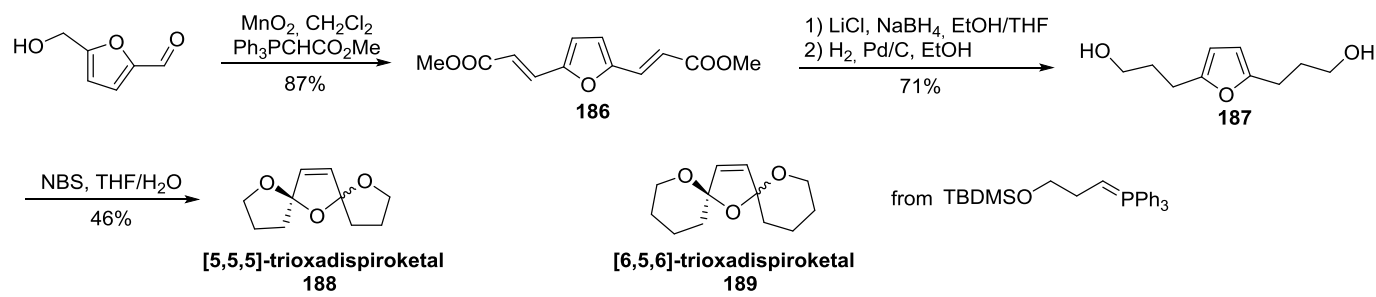


Scheme 71. Application of the olefination of HMF to the synthesis of trioxadispiroketals

\section{Conclusion}

As it has been shown throughout this review article, 5-HMF has been the object of numerous studies on its use in fine chemical synthesis. Its relatively modest stability has been shown to be overcome by choosing adequately mild reaction conditions, notably with respect to acid-catalyzed reactions. Thanks to the presence of different functional groups on this platform molecule, it proved to be an excellent starting substrate for the preparation of analogs of drugs, photo-responsive molecules or complex heterocyclic scaffolds. The use of this C-6 synthon in novel synthetic routes is appealing, as it allows the incorporation of renewable carbon-sources into the final targets. The commercial availability of HMF being now fully established, it is expected to exhibit, in a foreseeable future, a growing number of such applications toward complex chemicals.

\section{Acknowledgements}

Financial support from CNRS, UCBL, INSA Lyon and CPE Lyon is gratefully acknowledged, as well as the ANR for a post-doctoral fellowship to C. V. (FurCab project, ANR-15-CE07-0016) and the China Scholarship Council for $\mathrm{PhD}$ grants to W. F.

\section{References}

[1] Galkin, K. I.; Krivodaeva, E. A.; Romashov, L. V.; Zalesskiy, S. S.; Kachala, V. V.; Burykina, J. V.; Ananikov, V. P. Critical Influence of 5-Hydroxymethylfurfural Aging and Decomposition on the Utility of Biomass Conversion in Organic Synthesis. Angew. Chem. Int. Ed., 2016, 55 (29), 8338-8342.

[2] Girisuta, B.; Janssen, L. P. B. M.; Heeres, H. J. A kinetic study on the decomposition of 5hydroxymethylfurfural into levulinic acid. Green Chem., 2006, 8 (8), 701-709.

[3] Nikolov, P. Y.; Yaylayan, V. A. Thermal Decomposition of 5-(Hydroxymethyl)-2-furaldehyde (HMF) and Its Further Transformations in the Presence of Glycine. J. Agric. Food Chem., 2011, 59 (18), 10104-10113.

[4] Gomes, R. F. A.; Mitrev, Y. N.; Simeonov, S. P.; Afonso, C. A. M. Going Beyond the Limits of the Biorenewable Platform: Sodium Dithionite-Promoted Stabilization of 5-Hydroxymethylfurfural. ChemSusChem, 2018, 11 (10), 1612-1616.

[5] Rosatella, A. A.; Simeonov, S. P.; Frade, R. F. M.; Afonso, C. A. M. 5-Hydroxymethylfurfural (HMF) as a building block platform: Biological properties, synthesis and synthetic applications. Green Chem., 2011, 13 (4), 754-793.

[6] de Vries, J. G. Chapter Eight - Green Syntheses of Heterocycles of Industrial Importance. 5Hydroxymethylfurfural as a Platform Chemical. In Adv. Heterocycl. Chem., Scriven, E. F. V.; Ramsden, C. A., Eds. Academic Press: 2017; Vol. 121, pp 247-293.

[7] van Putten, R.-J.; van der Waal, J. C.; de Jong, E.; Rasrendra, C. B.; Heeres, H. J.; de Vries, J. G. Hydroxymethylfurfural, A Versatile Platform Chemical Made from Renewable Resources. Chem. Rev., 2013, 113 (3), 1499-1597.

[8] Kucherov, F. A.; Romashov, L. V.; Galkin, K. I.; Ananikov, V. P. Chemical Transformations of BiomassDerived C6-Furanic Platform Chemicals for Sustainable Energy Research, Materials Science, and Synthetic Building Blocks. ACS Sustainable Chem. Eng., 2018, 6 (7), 8064-8092.

[9] Liu, D.; Zhang, Y.; Chen, E. Y. X. Organocatalytic upgrading of the key biorefining building block by a catalytic ionic liquid and N-heterocyclic carbenes. Green Chem., 2012, 14 (10), 2738-2746.

[10] Liu, D.; Chen, E. Y. X. Diesel and Alkane Fuels From Biomass by Organocatalysis and Metal-Acid Tandem Catalysis. ChemSusChem, 2013, 6 (12), 2236-2239.

[11] Liu, D.; Chen, E. Y. X. Integrated Catalytic Process for Biomass Conversion and Upgrading to C12 Furoin and Alkane Fuel. ACS Catal., 2014, 4 (5), 1302-1310.

[12] Wang, L.; Chen, E. Y. X. Recyclable Supported Carbene Catalysts for High-Yielding Self-Condensation of Furaldehydes into C10 and C12 Furoins. ACS Catal., 2015, 5 (11), 6907-6917.

[13] Zang, H.; Chen, E. Y. X. Organocatalytic Upgrading of Furfural and 5-Hydroxymethyl Furfural to C10 and C12 Furoins with Quantitative Yield and Atom-Efficiency. Int. J. Mol. Sci., 2015, 16 (4), 7143-7158.

[14] Yan, B.; Zang, H.; Jiang, Y.; Yu, S.; Chen, E. Y. X. Recyclable montmorillonite-supported thiazolium 
ionic liquids for high-yielding and solvent-free upgrading of furfural and 5-hydroxymethylfurfural to C10 and C12 furoins. RSC Adv., 2016, 6 (80), 76707-76715.

[15] Donnelly, J.; Muller, C. R.; Wiermans, L.; Chuck, C. J.; Dominguez de Maria, P. Upgrading biogenic furans: blended C10-C12 platform chemicals via lyase-catalyzed carboligations and formation of novel C12 - choline chloride-based deep-eutectic-solvents. Green Chem., 2015, 17 (5), 2714-2718.

[16] Coelho, J. A. S.; Trindade, A. F.; Andre, V.; Teresa Duarte, M.; Veiros, L. F.; Afonso, C. A. M. Trienamines derived from 5-substituted furfurals: remote $\varepsilon$-functionalization of 2,4-dienals. $\mathrm{Org}$. Biomol. Chem., 2014, 12 (46), 9324-9328.

[17] Gomes, R. F. A.; Coelho, J. A. S.; Frade, R. F. M.; Trindade, A. F.; Afonso, C. A. M. Synthesis of Symmetric Bis(N-alkylaniline)triarylmethanes via Friedel-Crafts-Catalyzed Reaction between Secondary Anilines and Aldehydes. J. Org. Chem., 2015, 80 (20), 10404-10411.

[18] Yu, C.; Liu, B.; Hu, L. Efficient Baylis-Hillman Reaction Using Stoichiometric Base Catalyst and an Aqueous Medium. J. Org. Chem., 2001, 66 (16), 5413-5418.

[19] Yu, C.; Hu, L. Successful Baylis-Hillman Reaction of Acrylamide with Aromatic Aldehydes. J. Org. Chem., 2002, 67 (1), 219-223.

[20] Tan, J.-N.; Ahmar, M.; Queneau, Y. HMF derivatives as platform molecules: aqueous Baylis-Hillman reaction of glucosyloxymethyl-furfural towards new biobased acrylates. RSC Adv., 2013, 3 (39), 1764917653.

[21] Tan, J.-N.; Ahmar, M.; Queneau, Y. Bio-based solvents for the Baylis-Hillman reaction of HMF. RSC Adv., 2015, 5 (85), 69238-69242.

[22] Quiroz-Florentino, H.; Aguilar, R.; Santoyo, B. M.; Díaz, F.; Tamariz, J. Total Syntheses of Natural Furan Derivatives Rehmanones A, B, and C. Synthesis, 2008, 2008 (7), 1023-1028.

[23] Pupovac, K.; Palkovits, R. Cu/MgAl2O4 as Bifunctional Catalyst for Aldol Condensation of 5Hydroxymethylfurfural and Selective Transfer Hydrogenation. ChemSusChem, 2013, 6 (11), 2103-2110.

[24] Lewis, J. D.; Van de Vyver, S.; Román-Leshkov, Y. Acid-Base Pairs in Lewis Acidic Zeolites Promote Direct Aldol Reactions by Soft Enolization. Angew. Chem. Int. Ed., 2015, 54 (34), 9835-9838.

[25] Lee, R.; Vanderveen, J. R.; Champagne, P.; Jessop, P. G. CO2-Catalysed aldol condensation of 5hydroxymethylfurfural and acetone to a jet fuel precursor. Green Chem., 2016, 18 (19), 5118-5121.

[26] Yutthalekha, T.; Suttipat, D.; Salakhum, S.; Thivasasith, A.; Nokbin, S.; Limtrakul, J.; Wattanakit, C. Aldol condensation of biomass-derived platform molecules over amine-grafted hierarchical FAU-type zeolite nanosheets (Zeolean) featuring basic sites. Chem. Commun., 2017, 53 (90), 12185-12188.

[27] Bohre, A.; Saha, B.; Abu-Omar, M. M. Catalytic Upgrading of 5-Hydroxymethylfurfural to Drop-in Biofuels by Solid Base and Bifunctional Metal-Acid Catalysts. ChemSusChem, 2015, 8 (23), 4022-4029.

[28] Skowronski, R.; Grabowski, G.; Lewkowski, J.; Descotes, G.; Cottier, L.; Neyret, C. New chemical conversions of 5-hydroxymethylfurfural and the electrochemical oxidation of its derivatives. Org. Prep. Proced. Int., 1993, 25 (3), 353-355.

[29] Arias, K. S.; Climent, M. J.; Corma, A.; Iborra, S. Chemicals from Biomass: Synthesis of Biologically Active Furanochalcones by Claisen-Schmidt Condensation of Biomass-Derived 5hydroxymethylfurfural (HMF) with Acetophenones. Top. Catal., 2016, 59 (13), 1257-1265.

[30] Zhao, F.; Zhao, Q.-J.; Zhao, J.-X.; Zhang, D.-Z.; Wu, Q.-Y.; Jin, Y.-S. Synthesis and cdc25B inhibitory activity evaluation of chalcones. Chem. Nat. Compd., 2013, 49 (2), 206-214.

[31] Wang, Y.-H.; Dong, H.-H.; Zhao, F.; Wang, J.; Yan, F.; Jiang, Y.-Y.; Jin, Y.-S. The synthesis and synergistic antifungal effects of chalcones against drug resistant Candida albicans. Bioorg. Med. Chem. Lett., 2016, 26 (13), 3098-3102.

[32] Suryawanshi, S. N.; Chandra, N.; Kumar, P.; Porwal, J.; Gupta, S. Chemotherapy of leishmaniasis partVIII: Synthesis and bioevaluation of novel chalcones. Eur. J. Med. Chem., 2008, 43 (11), 2473-2478.

[33] Mugunthan, G.; Ramakrishna, K.; Sriram, D.; Yogeeswari, P.; Ravindranathan Kartha, K. P. Synthesis and screening of (E)-1-( $\beta$-d-galactopyranosyl)-4-(aryl)but-3-ene-2-one against Mycobacterium tuberculosis. Bioorg. Med. Chem. Lett., 2011, 21 (13), 3947-3950.

[34] Muthusamy, K.; Lalitha, K.; Prasad, Y. S.; Thamizhanban, A.; Sridharan, V.; Maheswari, C. U.; Nagarajan, S. Lipase-Catalyzed Synthesis of Furan-Based Oligoesters and their Self-Assembly-Assisted Polymerization. ChemSusChem, 2018, 11 (14), 2453-2463.

[35] Lockman, J. W.; Reeder, M. D.; Suzuki, K.; Ostanin, K.; Hoff, R.; Bhoite, L.; Austin, H.; Baichwal, V.; Adam Willardsen, J. Inhibition of eEF2-K by thieno[2,3-b]pyridine analogues. Bioorg. Med. Chem. Lett., 2010, 20 (7), 2283-2286.

[36] Meguellati, A.; Ahmed-Belkacem, A.; Yi, W.; Haudecoeur, R.; Crouillère, M.; Brillet, R.; Pawlotsky, J.M.; Boumendjel, A.; Peuchmaur, M. B-ring modified aurones as promising allosteric inhibitors of hepatitis C virus RNA-dependent RNA polymerase. Eur. J. Med. Chem., 2014, 80, 579-592.

[37] Taylor, K. M.; Taylor, Z. E.; Handy, S. T. Rapid synthesis of aurones under mild conditions using a combination of microwaves and deep eutectic solvents. Tetrahedron Lett., 2017, 58 (3), 240-241. 
[38] Witczak, Z. J.; Bielski, R.; Mencer, D. E. Concise and efficient synthesis of E-stereoisomers of exocyclic carbohydrate enones. Aldol condensation of dihydrolevoglucosenone with five-membered aromatic aldehydes Part 1. Tetrahedron Lett., 2017, 58 (43), 4069-4072.

[39] Zhao, F.; Dong, H.-H.; Wang, Y.-H.; Wang, T.-Y.; Yan, Z.-H.; Yan, F.; Zhang, D.-Z.; Cao, Y.-Y.; Jin, Y.$\mathrm{S}$. Synthesis and synergistic antifungal effects of monoketone derivatives of curcumin against fluconazole-resistant Candida spp. MedChemComm, 2017, 8 (5), 1093-1102.

[40] Liu, Q.; Zhang, C.; Shi, N.; Zhang, X.; Wang, C.; Ma, L. Production of renewable long-chained cycloalkanes from biomass-derived furfurals and cyclic ketones. RSC Adv., 2018, 8 (25), 13686-13696.

[41] Amarasekara, A. S.; Singh, T. B.; Larkin, E.; Hasan, M. A.; Fan, H.-J. NaOH catalyzed condensation reactions between levulinic acid and biomass derived furan-aldehydes in water. Ind. Crops Prod., 2015, 65, 546-549.

[42] Keskiväli, J.; Wrigstedt, P.; Lagerblom, K.; Repo, T. One-step Pd/C and Eu(OTf) $)_{3}$ catalyzed hydrodeoxygenation of branched $\mathrm{C} 11$ and $\mathrm{C} 12$ biomass-based furans to the corresponding alkanes. Appl. Catal. A: Gen., 2017, 534, 40-45.

[43] Lin, L.; Shi, Q.; Nyarko, A. K.; Bastow, K. F.; Wu, C.-C.; Su, C.-Y.; Shih, C. C. Y.; Lee, K.-H. Antitumor Agents. 250. Design and Synthesis of New Curcumin Analogues as Potential Anti-Prostate Cancer Agents. J. Med. Chem., 2006, 49 (13), 3963-3972.

[44] Martichonok, V. V.; Chiang, P. K.; Dornbush, P. J.; Land, K. M. On Regioselectivity of Aldol Condensation of Aromatic Aldehydes with Borate Complex of Acetylacetone. Synth. Commun., 2014, 44 (9), 1245-1250.

[45] Shao, W.-Y.; Cao, Y.-N.; Yu, Z.-W.; Pan, W.-J.; Qiu, X.; Bu, X.-Z.; An, L.-K.; Huang, Z.-S.; Gu, L.-Q.; Chan, A. S. C. Facile preparation of new unsymmetrical curcumin derivatives by solid-phase synthesis strategy. Tetrahedron Lett., 2006, 47 (24), 4085-4089.

[46] Tarleton, M.; Dyson, L.; Gilbert, J.; Sakoff, J. A.; McCluskey, A. Focused library development of 2phenylacrylamides as broad spectrum cytotoxic agents. Biorg. Med. Chem., 2013, 21 (1), 333-347.

[47] Tarleton, M.; Gilbert, J.; Sakoff, J. A.; McCluskey, A. Cytotoxic 2-phenyacrylnitriles, the importance of the cyanide moiety and discovery of potent broad spectrum cytotoxic agents. Eur. J. Med. Chem., 2012, 57, 65-73.

[48] Feng, Z.; Jia, J.; Liu, Y.; Wang, Z.; Zhao, X. 3-furyl-2-cyano-2-acrylamide derivative, preparation method therefor, pharmaceutical composition and use thereof US20160272604A1, 2016.

[49] Hanefeld, W.; Schlitzer, M.; Debski, N.; Euler, H. 3-(2,5-Dioxopyrrolidin-1-yl), 3-(2,6-dioxopiperidin1-yl), and 3-(1,3-dioxoisoindolin-2-yl)rhodanines. a novel type of rhodanine derivatives. J. Heterocycl. Chem., 1996, 33 (4), 1143-1146.

[50] Gregg, B. T.; Golden, K. C.; Quinn, J. F.; Tymoshenko, D. O.; Earley, W. G.; Maynard, D. A.; Razzano, D. A.; Rennells, W. M.; Butcher, J. Expedient Lewis Acid Catalyzed Synthesis of a 3-Substituted 5Arylidene-1-methyl-2-thiohydantoin Library. J. Comb. Chem., 2007, 9 (6), 1036-1040.

[51] Lukevics, E.; Ignatovich, L.; Shestakova, I. Synthesis, psychotropic and anticancer activity of 2,2dimethyl-5-[5'-trialkylgermyl(silyl)-2'-hetarylidene]-1,3-dioxane-4,6-diones and their analogues. Appl. Organomet. Chem., 2003, 17 (12), 898-905.

[52] Gomes, R. F. A.; Coelho, J. A. S.; Afonso, C. A. M. Direct Conversion of Activated 5Hydroxymethylfurfural into delta-Lactone-Fused Cyclopentenones. ChemSusChem, 2019, 12 (2), 420 425 .

[53] Nikolov, M. N.; Poneva, M. V. Spectral Determination of the Structure of 5Hydroxymethylfurfurylidene Barbituric Acid. Spectrosc. Lett., 1987, 20 (10), 821-834.

[54] Mercep, M.; Malnar, I.; Filipovic Sucic, A.; Mesic, M. Preparation of antiinflammatory conjugates of erythromycin macrolides and coumarins. WO2006092739A1, 2006.

[55] van Schijndel, J.; Canalle, L. A.; Molendijk, D.; Meuldijk, J. Exploration of the Role of Double Schiff Bases as Catalytic Intermediates in the Knoevenagel Reaction of Furanic Aldehydes: Mechanistic Considerations. Synlett, 2018, 29 (15), 1983-1988.

[56] Cummings, R. T.; DiZio, J. P.; Krafft, G. A. Photoactivable fluorophores. 2. Synthesis and photoactivation of functionalized 3-aroyl-2-(2-furyl)-chromones. Tetrahedron Lett., 1988, 29 (1), 69-72.

[57] Miller, R. Synthesis and Stereochemistry of (E)-5-(3,4,5,6-Tetrahydropyrid-3-ylidenemethyl)-2furanmethanol, a Product of the Reaction between D-Glucose and L-Lysine. Acta Chem. Scand. B, 1987, 41, 208-209.

[58] Shao, X.; Li, Z.; Qian, X.; Xu, X. Design, Synthesis, and Insecticidal Activities of Novel Analogues of Neonicotinoids: Replacement of Nitromethylene with Nitroconjugated System. J. Agric. Food Chem., 2009, 57 (3), 951-957.

[59] Lee, J.-S.; Kang, N.-y.; Kim, Y. K.; Samanta, A.; Feng, S.; Kim, H. K.; Vendrell, M.; Park, J. H.; Chang, Y.-T. Synthesis of a BODIPY Library and Its Application to the Development of Live Cell Glucagon Imaging Probe. J. Am. Chem. Soc., 2009, 131 (29), 10077-10082. 
[60] Karaguni, I.-M.; Glüsenkamp, K.-H.; Langerak, A.; Geisen, C.; Ullrich, V.; Winde, G.; Möröy, T.; Müller, O. New indene-derivatives with anti-proliferative properties. Bioorg. Med. Chem. Lett., 2002, 12 (4), 709-713.

[61] Mouloungui, Z.; Delmas, M.; Gaset, A. Synthesis of $\alpha, \beta$ Unsaturated Esters Using a Solid-Liquid Phase Transfer in a Slightly Hydrated Aprotic Medium. Synth. Commun., 1984, 14 (8), 701-706.

[62] Mouloungui, Z.; Delmas, M.; Gaset, A. Synthesis of $\alpha, \beta$-Ethylenic Esters in a Heterogenous SolidLiquid Medium. II - A Transesterification Reaction Linked to a Wittig-Horner Reaction in a Protic Medium. Synth. Commun., 1985, 15 (6), 491-494.

[63] Goodman, S. N.; Jacobsen, E. N. A Practical Synthesis of $\alpha, \beta$-Unsaturated Imides, Useful Substrates For Asymmetric Conjugate Addition Reactions. Adv. Synth. Catal., 2002, 344 (9), 953-956.

[64] Almirante, N.; Cerri, A.; Fedrizzi, G.; Marazzi, G.; Santagostino, M. A general, [1+4] approach to the synthesis of 3(5)-substituted pyrazoles from aldehydes. Tetrahedron Lett., 1998, 39 (20), 3287-3290.

[65] Fumagalli, T.; Sello, G.; Orsini, F. One-Pot, Fluoride-Promoted Wittig Reaction. Synth. Commun., 2009, 39 (12), 2178-2195.

[66] Yoshida, N.; Kasuya, N.; Haga, N.; Fukuda, K. Brand-new Biomass-based Vinyl Polymers from 5Hydroxymethylfurfural. Polym. J., 2008, 40, 1164-1169.

[67] Han, M.; Liu, X.; Zhang, X.; Pang, Y.; Xu, P.; Guo, J.; Liu, Y.; Zhang, S.; Ji, S. 5-Hydroxymethyl-2vinylfuran: a biomass-based solvent-free adhesive. Green Chem., 2017, 19 (3), 722-728.

[68] Romashov, L. V.; Ananikov, V. P. Alkynylation of Bio-Based 5-Hydroxymethylfurfural to Connect Biomass Processing with Conjugated Polymers and Furanic Pharmaceuticals. Chem. Asian J., 2017, 12 (20), 2652-2655.

[69] Sharma, U. K.; Gemoets, H. P. L.; Schröder, F.; Noël, T.; Van der Eycken, E. V. Merger of Visible-Light Photoredox Catalysis and C-H Activation for the Room-Temperature C-2 Acylation of Indoles in Batch and Flow. ACS Catal., 2017, 7 (6), 3818-3823.

[70] Ramonczai, J.; Vargha, L. Studies on Furan Compounds. III. A New Synthesis of Furyl Ketones. J. Am. Chem. Soc., 1950, 72 (6), 2737-2737.

[71] Nicklaus, C. M.; Minnaard, A. J.; Feringa, B. L.; de Vries, J. G. Synthesis of renewable fine-chemical building blocks by reductive coupling between furfural derivatives and terpenes. ChemSusChem, 2013, 6 (9), 1631-1635.

[72] Hirapara, P.; Riemer, D.; Hazra, N.; Gajera, J.; Finger, M.; Das, S. CO2-assisted synthesis of nonsymmetric $\alpha$-diketones directly from aldehydes via $\mathrm{C}-\mathrm{C}$ bond formation. Green Chem., 2017, 19 (22), 5356-5360.

[73] Cooper, W. F.; Nuttall, W. H. CXII.-Furan-2 : 5-dialdehyde. J. Chem. Soc., Trans., 1912, 101, 10741081.

[74] Middendorp, J. A. Sur l'oxyméthylfurfurol. Recl. Trav. Chim. Pays-Bas, 1919, 38 (1), 1-71.

[75] Cottier, L.; Descotes, G.; Lewkowski, J.; Skowroński, R. Synthesis and its stereochemistry of aminophosphonic acids derived from 5-hydroxymethylfurfural. Phosphorus, Sulfur Silicon Relat. Elem., 1996, $116(1), 93-100$.

[76] Fan, W.; Queneau, Y.; Popowycz, F. The synthesis of HMF-based $\alpha$-amino phosphonates via one-pot Kabachnik-Fields reaction. RSC Adv., 2018, 8 (55), 31496-31501.

[77] Amarasekara, A., S. ; Edigin, O.; Hernandez, W. Cycloaddition Reactions of 5-Hydroxymethyl-Furan2-Nitrileoxide. Lett. Org. Chem., 2007, 4 (5), 306-308.

[78] Wang, E.; Zhou, Y.; Huang, Q.; Pang, L.; Qiao, H.; Yu, F.; Gao, B.; Zhang, J.; Min, Y.; Ma, T. 5Hydroxymethylfurfural modified rhodamine B dual-function derivative: Highly sensitive and selective optical detection of $\mathrm{pH}$ and $\mathrm{Cu} 2+$. Spectrochim. Acta A, 2016, 152, 327-335.

[79] Alsaeedi, H. S.; Aljaber, N. A.; Ara, I. Synthesis and Investigation of Antimicrobial Activity of Some Nifuroxazide Analogues. Asian J. Chem., 2015, 27 (10), 3639-3646.

[80] Brown, M. L.; Cheung, M.; Dickerson, S. H.; Drewry, D. H.; Lackey, K. E.; Peat, A. J.; Thomson, S. A.; Veal, J. M.; Wilson, J. L. R. Preparation of pyrazolopyrimidines as kinase inhibitors for the treatment of type 2 diabetes. WO2004009596A2, 2004.

[81] Alturiqi, A. S.; Alaghaz, A.-N. M. A.; Ammar, R. A.; Zayed, M. E. Synthesis, Spectral Characterization, and Thermal and Cytotoxicity Studies of $\mathrm{Cr}(\mathrm{III}), \mathrm{Ru}(\mathrm{III}), \mathrm{Mn}(\mathrm{II}), \mathrm{Co}(\mathrm{II}), \mathrm{Ni}(\mathrm{II}), \mathrm{Cu}(\mathrm{II})$, and $\mathrm{Zn}(\mathrm{II})$ Complexes of Schiff Base Derived from 5-Hydroxymethylfuran-2-carbaldehyde. Journal of Chemistry, 2018, 2018, 1-17.

[82] Mohamed, O. G.; Khalil, Z. G.; Capon, R. J. Prolinimines: N-Amino-l-Pro-methyl Ester (Hydrazine) Schiff Bases from a Fish Gastrointestinal Tract-Derived Fungus, Trichoderma sp. CMB-F563. Org. Lett., 2018, 20 (2), 377-380.

[83] Cisneros, L.; Serna, P.; Corma, A. Selective Reductive Coupling of Nitro Compounds with Aldehydes to Nitrones in H2 Using Carbon-Supported and -Decorated Platinum Nanoparticles. Angew. Chem. Int. Ed., 2014, 53 (35), 9306-9310. 
[84] Pezzetta, C.; Veiros, L. F.; Oble, J.; Poli, G. Murai Reaction on Furfural Derivatives Enabled by Removable N,N'-Bidentate Directing Groups. Chem. Eur. J., 2017, 23 (35), 8385-8389.

[85] Siopa, F.; Ramis Cladera, V.-A.; Afonso, C. A. M.; Oble, J.; Poli, G. Ruthenium-Catalyzed C-H Arylation and Alkenylation of Furfural Imines with Boronates. Eur. J. Org. Chem., 2018, 2018 (44), 6101-6106.

[86] Cukalovic, A.; Stevens, C. V. Production of biobased HMF derivatives by reductive amination. Green Chem., 2010, 12 (7), 1201-1206.

[87] Elming, N.; Clauson-Kaas, N. Transformation of 2-(hydroxymethyl)-5-(aminomethyl)-furan into 6methyl-3-pyridinol. Acta Chem. Scand., 1956, 10, 1603-1605.

[88] Xu, Z.; Yan, P.; Xu, W.; Jia, S.; Xia, Z.; Chung, B.; Zhang, Z. C. Direct reductive amination of 5hydroxymethylfurfural with primary/secondary amines via Ru-complex catalyzed hydrogenation. $R S C$ $A d v ., 2014,4$ (103), 59083-59087.

[89] Chatterjee, M.; Ishizaka, T.; Kawanami, H. Reductive amination of furfural to furfurylamine using aqueous ammonia solution and molecular hydrogen: an environmentally friendly approach. Green Chem., 2016, 18 (2), 487-496.

[90] Komanoya, T.; Kinemura, T.; Kita, Y.; Kamata, K.; Hara, M. Electronic Effect of Ruthenium Nanoparticles on Efficient Reductive Amination of Carbonyl Compounds. J. Am. Chem. Soc., 2017, 139 (33), 11493-11499.

[91] Chandra, D.; Inoue, Y.; Sasase, M.; Kitano, M.; Bhaumik, A.; Kamata, K.; Hosono, H.; Hara, M. A high performance catalyst of shape-specific ruthenium nanoparticles for production of primary amines by reductive amination of carbonyl compounds. Chem. Sci., 2018, 9 (27), 5949-5956.

[92] Jagadeesh, R. V.; Murugesan, K.; Alshammari, A. S.; Neumann, H.; Pohl, M.-M.; Radnik, J.; Beller, M. MOF-derived cobalt nanoparticles catalyze a general synthesis of amines. Science, 2017, 358 (6361), 326-332.

[93] Zhu, M.-M.; Tao, L.; Zhang, Q.; Dong, J.; Liu, Y.-M.; He, H.-Y.; Cao, Y. Versatile CO-assisted direct reductive amination of 5-hydroxymethylfurfural catalyzed by a supported gold catalyst. Green Chem., 2017, 19 (16), 3880-3887.

[94] Carrillo, A. I.; Llanes, P.; Pericàs, M. A. A versatile, immobilized gold catalyst for the reductive amination of aldehydes in batch and flow. React. Chem. Eng., 2018, 3 (5), 714-721.

[95] Niphakis, M. J.; Gay, B. C.; Hong, K. H.; Bleeker, N. P.; Georg, G. I. Synthesis and evaluation of the anti-proliferative and NF- $\mathrm{BB}$ activities of a library of simplified tylophorine analogs. Biorg. Med. Chem., 2012, 20 (19), 5893-5900.

[96] Kojiri, K.; Kondo, H.; Arakawa, H.; Ohkubo, M.; Suda, H. Preparation of indolopyrrolocarbazole derivatives having glucopyranosyl group and antitumor agents containing them. US6703373B1, 2004.

[97] Plitta, B.; Adamska, E.; Giel-Pietraszuk, M.; Fedoruk-Wyszomirska, A.; Naskręt-Barciszewska, M.; Markiewicz, W. T.; Barciszewski, J. New cytosine derivatives as inhibitors of DNA methylation. Eur. J. Med. Chem., 2012, 55, 243-254.

[98] Xu, Z.; Yan, P.; Liu, K.; Wan, L.; Xu, W.; Li, H.; Liu, X.; Zhang, Z. C. Synthesis of Bis(hydroxylmethylfurfuryl)amine Monomers from 5-Hydroxymethylfurfural. ChemSusChem, 2016, 9 (11), 1255-1258.

[99] Sattler, L.; Zerban, F. W.; Clark, G. L.; Chu, C.-C. The Reaction of 2-Aminobenzenethiol with Al-doses and with Hydroxymethylfurfural. J. Am. Chem. Soc., 1951, 73 (12), 5908-5910.

[100] Koehler, A. N.; Stefan, E.; Caballero, F. Preparation of fused 1,3-azole derivatives useful for the treatment of proliferative diseases. WO2016094688A1, 2016.

[101] Takezawa, H.; Hayashi, M.; Iwasawa, Y.; Hosoi, M.; Iida, Y.; Tsuchiya, Y.; Horie, M.; Kamei, T. Substituted alkylamine derivatives. US5234946A, 1993.

[102] Forster, M.; Chaikuad, A.; Bauer, Silke M.; Holstein, J.; Robers, Matthew B.; Corona, Cesear R.; Gehringer, M.; Pfaffenrot, E.; Ghoreschi, K.; Knapp, S.; Laufer, Stefan A. Selective JAK3 Inhibitors with a Covalent Reversible Binding Mode Targeting a New Induced Fit Binding Pocket. Cell Chem. Biol., 2016, 23 (11), 1335-1340.

[103] Forster, M.; Chaikuad, A.; Dimitrov, T.; Döring, E.; Holstein, J.; Berger, B.-T.; Gehringer, M.; Ghoreschi, K.; Müller, S.; Knapp, S.; Laufer, S. A. Development, Optimization, and Structure-Activity Relationships of Covalent-Reversible JAK3 Inhibitors Based on a Tricyclic Imidazo[5,4-d]pyrrolo[2,3b]pyridine Scaffold. J. Med. Chem., 2018, 61 (12), 5350-5366.

[104] Hrast, M.; Rožman, K.; Jukič, M.; Patin, D.; Gobec, S.; Sova, M. Synthesis and structure-activity relationship study of novel quinazolinone-based inhibitors of MurA. Bioorg. Med. Chem. Lett., 2017, 27 (15), 3529-3533.

[105] Snyder, D. S.; Tradtrantip, L.; Yao, C.; Kurth, M. J.; Verkman, A. S. Potent, Metabolically Stable Benzopyrimido-pyrrolo-oxazine-dione (BPO) CFTR Inhibitors for Polycystic Kidney Disease. J. Med. Chem., 2011, 54 (15), 5468-5477. 
[106] Sachdeva, N.; Dolzhenko, A. V.; Lim, S. J.; Ong, W. L.; Chui, W. K. An efficient synthesis of 2,4,7trisubstituted pyrimido[1,2-a][1,3,5]triazin-6-ones. New J. Chem., 2015, 39 (6), 4796-4804.

[107] Matasi, J. J.; Caldwell, J. P.; Hao, J.; Neustadt, B.; Arik, L.; Foster, C. J.; Lachowicz, J.; Tulshian, D. B. The discovery and synthesis of novel adenosine receptor (A2A) antagonists. Bioorg. Med. Chem. Lett., 2005, 15 (5), 1333-1336.

[108] Bode, M. L.; Rousseau, A. L.; Gravestock, D.; Moleele, S. S.; Van der Westhuyzen, C. W. Imidazopyridines and imidazopyrimidines as HIV-1 reverse transcriptase inhibitors and their preparation, pharmaceutical compositions and use in the treatment of HIV infection. WO2010032195A1, 2010.

[109] Fan, W.; Queneau, Y.; Popowycz, F. HMF in multicomponent reactions: utilization of 5hydroxymethylfurfural (HMF) in the Biginelli reaction. Green Chem., 2018, 20 (2), 485-492.

[110] Wu, Q.; Chen, J.; Guo, X.; Xu, Y. Copper(I)-Catalyzed Four-Component Coupling Using Renewable Building Blocks of CO2 and Biomass-Based Aldehydes. Eur. J. Org. Chem., 2018, 2018 (24), 31053113.

[111] Antonio, J. P. M.; Frade, R. F. M.; Santos, F. M. F.; Coelho, J. A. S.; Afonso, C. A. M.; Gois, P. M. P.; Trindade, A. F. NHC catalysed direct addition of HMF to diazo compounds: synthesis of acyl hydrazones with antitumor activity. RSC Adv., 2014, 4 (55), 29352-29356.

[112] Baliani, A.; Bueno, G. J.; Stewart, M. L.; Yardley, V.; Brun, R.; Barrett, M. P.; Gilbert, I. H. Design and Synthesis of a Series of Melamine-based Nitroheterocycles with Activity against Trypanosomatid Parasites. J. Med. Chem., 2005, 48 (17), 5570-5579.

[113] Kashiwagi, M.; Fuhshuku, K.-I.; Sugai, T. Control of the nitrile-hydrolyzing enzyme activity in Rhodococcus rhodochrous IFO 15564: preferential action of nitrile hydratase and amidase depending on the reaction condition factors and its application to the one-pot preparation of amides from aldehydes. J. Mol. Catal. B: Enzym., 2004, 29 (1), 249-258.

[114] Ambreen, N.; Wirth, T. High-Temperature Synthesis of Amides from Alcohols or Aldehydes by Using Flow Chemistry. Eur. J. Org. Chem., 2014, 2014 (34), 7590-7593.

[115] Jia, X.; Ma, J.; Wang, M.; Ma, H.; Chen, C.; Xu, J. Catalytic conversion of 5-hydroxymethylfurfural into 2,5-furandiamidine dihydrochloride. Green Chem., 2016, 18 (4), 974-978.

[116] Cottier, L.; Descotes, G.; Soro, Y. Synthesis of Acetylated Ranunculin Diastereoisomers and $\delta-$ Glucosyloxy- $\gamma$-Oxo Esters from $\alpha$ or $\beta$ Glucosylmethylfurfural. J. Carbohydr. Chem., 2005, 24 (1), 55 71.

[117] Casanova, O.; Iborra, S.; Corma, A. Biomass into chemicals: One pot-base free oxidative esterification of 5-hydroxymethyl-2-furfural into 2,5-dimethylfuroate with gold on nanoparticulated ceria. J. Catal., 2009, 265 (1), 109-116.

[118] Kanai, S.; Nagahara, I.; Kita, Y.; Kamata, K.; Hara, M. A bifunctional cerium phosphate catalyst for chemoselective acetalization. Chem. Sci., 2017, 8 (4), 3146-3153.

[119] Kim, M.; Su, Y.; Fukuoka, A.; Hensen, E. J. M.; Nakajima, K. Aerobic Oxidation of 5(Hydroxymethyl)furfural Cyclic Acetal Enables Selective Furan-2,5-dicarboxylic Acid Formation with CeO2-Supported Gold Catalyst. Angew. Chem. Int. Ed., 2018, 57 (27), 8235-8239.

[120] Arias, K. S.; Garcia-Ortiz, A.; Climent, M. J.; Corma, A.; Iborra, S. Mutual Valorization of 5Hydroxymethylfurfural and Glycerol into Valuable Diol Monomers with Solid Acid Catalysts. ACS Sustainable Chem. Eng., 2018, 6 (3), 4239-4245.

[121] Mallesham, B.; Sudarsanam, P.; Raju, G.; Reddy, B. M. Design of highly efficient Mo and W-promoted $\mathrm{SnO} 2$ solid acids for heterogeneous catalysis: acetalization of bio-glycerol. Green Chem., 2013, 15 (2), 478-489.

[122] Garcia-Ortiz, A.; Arias, K. S.; Climent, M. J.; Corma, A.; Iborra, S. One-Pot Synthesis of BiomassDerived Surfactants by Reacting Hydroxymethylfurfural, Glycerol, and Fatty Alcohols on Solid Acid Catalysts. ChemSusChem, 2018, 11 (17), 2870-2880.

[123] Li, H.; Yang, T.; Riisager, A.; Saravanamurugan, S.; Yang, S. Chemoselective Synthesis of Dithioacetals from Bio-aldehydes with Zeolites under Ambient and Solvent-free Conditions. ChemCatChem, 2017, 9 (6), 1097-1104.

[124] Zhao, Q.; Zou, Y.; Huang, C.; Lan, P.; Zheng, J.; Ou, S. Formation of a HydroxymethylfurfuralCysteine Adduct and Its Absorption and Cytotoxicity in Caco-2 Cells. J. Agric. Food Chem., 2017, 65 (45), 9902-9908.

[125] Mascal, M. 5-(Chloromethyl)furfural is the New HMF: Functionally Equivalent But More Practical in Terms of its Production From Biomass. ChemSusChem, 2015, 8 (20), 3391-3395.

[126] Sanda, K.; Rigal, L.; Gaset, A. Synthèse du 5-bromométhyl- et du 5-chlorométhyl-2furannecarboxaldéhyde. Carbohydr. Res., 1989, 187 (1), 15-23.

[127] Bredihhin, A.; Mäeorg, U.; Vares, L. Evaluation of carbohydrates and lignocellulosic biomass from different wood species as raw material for the synthesis of 5-bromomethyfurfural. Carbohydr. Res., 
2013, 375, 63-67.

[128] Romashov, L. V.; Ananikov, V. P. Synthesis of HIV-1 capsid protein assembly inhibitor (CAP-1) and its analogues based on a biomass approach. Org. Biomol. Chem., 2016, 14 (45), 10593-10598.

[129] Sanda, K.; Rigal, L.; Delmas, M.; Gaset, A. The Vilsmeier Reaction: A New Synthetic Method for 5(Chloromethyl)-2-furaldehyde. Synthesis, 1992, 1992 (06), 541-542.

[130] Newth, F. H.; Wiggins, L. F. 80. The conversion of sucrose into furan compounds. Part III. Some amidino-furans. J. Chem. Soc., 1947, 10.1039/JR9470000396 (0), 396-398.

[131] Villain-Guillot, P.; Gualtieri, M.; Bastide, L.; Roquet, F.; Martinez, J.; Amblard, M.; Pugniere, M.; Leonetti, J.-P. Structure-Activity Relationships of Phenyl-Furanyl-Rhodanines as Inhibitors of RNA Polymerase with Antibacterial Activity on Biofilms. J. Med. Chem., 2007, 50 (17), 4195-4204.

[132] Bedjeguelal, K.; Rabot, R.; Kaloun, E. B.; Mayer, P.; Marchand, A.; Rahier, N.; Schambel, P.; Bienayme, H. Preparation of pyrazolopyridine derivatives as ALK kinase inhibitors for treating cancer. WO2011045344A1, 2011.

[133] Chundury, D.; Szmant, H. H. Preparation of polymeric building blocks from 5-hydroxymethyl- and 5chloromethylfurfuraldehyde. Ind. Eng. Chem. Prod. Res. Dev., 1981, 20 (1), 158-163.

[134] Larousse, C.; Rigal, L.; Gaset, A. Synthesis of 5,5'-oxydimethylenebis(2-furfural) by thermal dehydration of 5-hydroxymethyl-2-furfural in the presence of dimethylsulfoxide. J. Chem. Technol. Biotechnol., 1992, 53 (1), 111-116.

[135] Cottier, L.; Descotes, G.; Eymard, L.; Rapp, K. Syntheses of $\gamma$-Oxo Acids or $\gamma$-Oxo Esters by Photooxygenation of Furanic Compounds and Reduction Under Ultrasound: Application to the Synthesis of 5-Aminolevulinic Acid Hydrochloride. Synthesis, 1995, 1995 (03), 303-306.

[136] Páez, A.; Rojas, H. A.; Portilla, O.; Sathicq, G.; Afonso, C. A. M.; Romanelli, G. P.; Martínez, J. J. Preyssler Heteropolyacids in the Self-Etherification of 5-Hydroxymethylfurfural to 5,5'[Oxybis(methylene)]bis-2-furfural Under Mild Reaction Conditions. ChemCatChem, 2017, 9 (17), 3322-3329.

[137] Casanova, O.; Iborra, S.; Corma, A. Chemicals from biomass: Etherification of 5-hydroxymethyl-2furfural (HMF) into 5,5'(oxy-bis(methylene))bis-2-furfural (OBMF) with solid catalysts. J. Catal., 2010 , 275 (2), 236-242.

[138] Wang, H.; Wang, Y.; Deng, T.; Chen, C.; Zhu, Y.; Hou, X. Carbocatalyst in biorefinery: Selective etherification of 5-hydroxymethylfurfural to 5,5'(oxy-bis(methylene)bis-2-furfural over graphene oxide. Catal. Commun., 2015, 59, 127-130.

[139] Shinde, S.; Rode, C. Selective self-etherification of 5-(hydroxymethyl)furfural over Sn-Mont catalyst. Catal. Commun., 2017, 88, 77-80.

[140] Mliki, K.; Trabelsi, M. Chemicals from biomass: Efficient and facile synthesis of 5,5'(oxybis(methylene))bis-2-furfural from 5-hydroxymethylfurfural. Ind. Crops Prod., 2015, 78, 91-94.

[141] Wen, R.; Yu, F.; Dong, X.; Miao, Y.; Zhou, P.; Lin, Z.; Zheng, J.; Wang, H.; Huang, L.; Qing, D. Preparation of furfuryl compounds as antiviral agents. CN1456556A, 2003.

[142] Wang, H.; Deng, T.; Wang, Y.; Cui, X.; Qi, Y.; Mu, X.; Hou, X.; Zhu, Y. Graphene oxide as a facile acid catalyst for the one-pot conversion of carbohydrates into 5-ethoxymethylfurfural. Green Chem., 2013, 15 (9), 2379.

[143] Thombal, R. S.; Jadhav, V. H. Application of glucose derived magnetic solid acid for etherification of 5HMF to 5-EMF, dehydration of sorbitol to isosorbide, and esterification of fatty acids. Tetrahedron Lett., 2016, 57 (39), 4398-4400.

[144] Quiroz-Florentino, H.; Hernández-Benitez, R. I.; Aviña, J. A.; Burgueño-Tapia, E.; Tamariz, J. Total Synthesis of Naturally Occurring Furan Compounds 5-\{[(4-Hydroxybenzyl)oxy]methyl $\}$-2-furaldehyde and Pichiafuran C. Synthesis, 2011, 2011 (07), 1106-1112.

[145] Ilkei, V.; Faragó, K.; Sánta, Z.; Dékány, M.; Hazai, L.; Jr., C. S.; Szántay, C.; Kalaus, G. The First Synthesis of Sessiline. Int. J. Org. Chem., 2014, 4, 309-313.

[146] Berton, J. K. E. T.; Heugebaert, T. S. A.; Debrouwer, W.; Stevens, C. V. 3-Imidoallenylphosphonates: In Situ Formation and $\beta$-Alkoxylation. Org. Lett., 2016, 18 (2), 208-211.

[147] El-Hajj, T.; Martin, J.-C.; Descotes, G. Dérivés de l'hydroxyméthyl-5 furfural. I. Synthése de dérivés du di- et terfuranne. J. Heterocycl. Chem., 1983, 20 (1), 233-235.

[148] de Freitas Filho, J. R.; Srivastava, R. M.; Soro, Y.; Cottier, L.; Descotes, G. Synthesis of new 2,3unsaturated O-glycosides through Ferrier rearrangement. J. Carbohydr. Chem., 2001, 20 (7-8), 561-568.

[149] Ding, Z.; Luo, X.; Ma, Y.; Chen, H.; Qiu, S.; Sun, G.; Zhang, W.; Yu, C.; Wu, Z.; Zhang, J. Eco-friendly synthesis of 5-hydroxymethylfurfural (HMF) and its application to the Ferrier-rearrangement reaction. $J$. Carbohydr. Chem., 2018, 37 (2), 81-93.

[150] Jogia, M.; Vakamoce, V.; Weavers, R. Synthesis of Some Furfural and Syringic Acid Derivatives. Aust. J. Chem., 1985, 38 (7), 1009-1016.

[151] Bognár, R.; Herczegh, P.; Zsély, M.; Batta, G. Synthesis of 3,4-dideoxy-dl-hex-3-enopyranosides from 
5-hydroxymethyl-2-furaldehyde. Carbohydr. Res., 1987, 164, 465-469.

[152] Bakholdina, L. A.; Khlebnikov, A. I.; Sevodin, V. P. Mild reaction of primary alcohols with ferulic acid. Russ. J. Org. Chem., 2016, 52 (3), 441-443.

[153] Zhou, H.; Liu, W.; Sun, C.; Peng, C.; Wang, J.; Wang, Q.; Yang, C. Synthesis of Novel Coumarin Derivatives and in vitro Biological Evaluation as Potential PTP 1B Inhibitors. Heterocycles, 2013, 87 (8), 1711.

[154] Quiroz-Florentino, H.; García, A.; Burgueño-Tapia, E.; Tamariz, J. Total synthesis of the natural succinate derivative of 5-(hydroxymethyl)furfural isolated from the Noni fruit (Morinda citrifolia). Nat. Prod. Res., 2009, 23 (14), 1355-1362.

[155] Sugimura, H.; Kikuchi, M.; Kato, S.; Sekita, W.; Sasaki, I. Practical synthesis of mumefural, a component of Japanese apricot juice concentrate. Tetrahedron, 2016, 72 (47), 7638-7641.

[156] Krystof, M.; Pérez-Sánchez, M.; Domínguez de María, P. Lipase-Catalyzed (Trans)esterification of 5Hydroxy- methylfurfural and Separation from HMF Esters using Deep-Eutectic Solvents. ChemSusChem, 2013, 6 (4), 630-634.

[157] Qin, Y.-Z.; Zong, M.-H.; Lou, W.-Y.; Li, N. Biocatalytic Upgrading of 5-Hydroxymethylfurfural (HMF) with Levulinic Acid to HMF Levulinate in Biomass-Derived Solvents. ACS Sustainable Chem. Eng., 2016, 4 (7), 4050-4054.

[158] Dow, R. L.; Kelly, R. C.; Schletter, I.; Wierenga, W. A Direct Alcohol for Hydrazine Interchange: Scope and Stereochemistry. Synth. Commun., 1981, 11 (1), 43-53.

[159] Lewis, T. A.; Bayless, L.; Eckman, J. B.; Ellis, J. L.; Grewal, G.; Libertine, L.; Marie Nicolas, J.; Scannell, R. T.; Wels, B. F.; Wenberg, K.; Wypij, D. M. 5-Lipoxygenase inhibitors with histamine H1 receptor antagonist activity. Bioorg. Med. Chem. Lett., 2004, 14 (9), 2265-2268.

[160] Iovel, I.; Mertins, K.; Kischel, J.; Zapf, A.; Beller, M. An Efficient and General Iron-Catalyzed Arylation of Benzyl Alcohols and Benzyl Carboxylates. Angew. Chem. Int. Ed., 2005, 44 (25), 39133917.

[161] Zhou, X.; Rauchfuss, T. B. Production of Hybrid Diesel Fuel Precursors from Carbohydrates and Petrochemicals Using Formic Acid as a Reactive Solvent. ChemSusChem, 2013, 6 (2), 383-388.

[162] Bering, L.; Jeyakumar, K.; Antonchick, A. P. Metal-Free C-O Bond Functionalization: Catalytic Intramolecular and Intermolecular Benzylation of Arenes. Org. Lett., 2018, 20 (13), 3911-3914.

[163] Onorato, A.; Pavlik, C.; Invernale, M. A.; Berghorn, I. D.; Sotzing, G. A.; Morton, M. D.; Smith, M. B. Polymer-mediated cyclodehydration of alditols and ketohexoses. Carbohydr. Res., 2011, 346 (13), 1662-1670.

[164] Nale, S. D.; Jadhav, V. H. Synthesis of Fuel Intermediates from HMF/Fructose. Catal. Lett., 2016, 146 (10), 1984-1990.

[165] Ryabukhin, D. S.; Zakusilo, D. N.; Kompanets, M. O.; A.Tarakanov, A.; Boyarskaya, I. A.; Artamonova, T. O.; Khohodorkovskiy, M. A.; Opeida, I. O.; Vasilyev, A. V. Superelectrophilic activation of 5hydroxymethylfurfural and 2,5-diformylfuran: organic synthesis based on biomass-derived products. Beilstein J. Org. Chem., 2016, 12, 2125-2135.

[166] Teunissen, H. P. Velocity measurements on the opening of the furane ring in hydroxymethylfurfuraldehyde. Recl. Trav. Chim. Pays-Bas, 1930, 49 (9), 784-826.

[167] Luijkx, G. C. A.; van Rantwijk, F.; van Bekkum, H. Hydrothermal formation of 1,2,4-benzenetriol from 5-hydroxymethyl-2-furaldehyde and d-fructose. Carbohydr. Res., 1993, 242, 131-139.

[168] Tšupova, S.; Rominger, F.; Rudolph, M.; Hashmi, A. S. K. Synthesis of phenols from hydroxymethylfurfural (HMF). Green Chem., 2016, 18 (21), 5800-5805.

[169] Roylance, J. J.; Choi, K.-S. Electrochemical reductive biomass conversion: direct conversion of 5hydroxymethylfurfural (HMF) to 2,5-hexanedione (HD) via reductive ring-opening. Green Chem., 2016, 18 (10), 2956-2960.

[170] Ren, D.; Song, Z.; Li, L.; Liu, Y.; Jin, F.; Huo, Z. Production of 2,5-hexanedione and 3-methyl-2cyclopenten-1-one from 5-hydroxymethylfurfural. Green Chem., 2016, 18 (10), 3075-3081.

[171] Wu, W.-P.; Xu, Y.-J.; Zhu, R.; Cui, M.-S.; Li, X.-L.; Deng, J.; Fu, Y. Selective Conversion of 5Hydroxymethylfuraldehyde Using Cp*Ir Catalysts in Aqueous Formate Buffer Solution. ChemSusChem, 2016, 9 (10), 1209-1215.

[172] Xu, Z.; Yan, P.; Li, H.; Liu, K.; Liu, X.; Jia, S.; Zhang, Z. C. Active Cp*Iridium(III) Complex with ortho-Hydroxyl Group Functionalized Bipyridine Ligand Containing an Electron-Donating Group for the Production of Diketone from 5-HMF. ACS Catal., 2016, 6 (6), 3784-3788.

[173] Wozniak, B.; Li, Y. H.; Hinze, S.; Tin, S.; de Vries, J. G. Efficient Synthesis of Biomass-Derived NSubstituted 2-Hydroxymethyl-5-Methyl-Pyrroles in Two Steps from 5-Hydroxymethylfurfural. Eur. J. Org. Chem., 2018, 2018 (17), 2009-2012.

[174] Sacia, E. R.; Deaner, M. H.; Louie, Y. L.; Bell, A. T. Synthesis of biomass-derived methylcyclopentane as a gasoline additive via aldol condensation/hydrodeoxygenation of 2,5-hexanedione. Green Chem., 
2015, 17 (4), 2393-2397.

[175] Duan, Y.; Zheng, M.; Li, D.; Deng, D.; Ma, L.-F.; Yang, Y. Conversion of HMF to methyl cyclopentenolone using $\mathrm{Pd} / \mathrm{Nb} 2 \mathrm{O} 5$ and $\mathrm{Ca}-\mathrm{Al}$ catalysts via a two-step procedure. Green Chem., 2017, 19 (21), 5103-5113.

[176] Wozniak, B.; Spannenberg, A.; Li, Y.; Hinze, S.; de Vries, J. G. Cyclopentanone Derivatives from 5Hydroxymethylfurfural via 1-Hydroxyhexane-2,5-dione as Intermediate. ChemSusChem, 2018, 11 (2), 356-359.

[177] Ohyama, J.; Kanao, R.; Ohira, Y.; Satsuma, A. The effect of heterogeneous acid-base catalysis on conversion of 5-hydroxymethylfurfural into a cyclopentanone derivative. Green Chem., 2016, 18 (3), 676-680.

[178] Ohyama, J.; Kanao, R.; Esaki, A.; Satsuma, A. Conversion of 5-hydroxymethylfurfural to a cyclopentanone derivative by ring rearrangement over supported Au nanoparticles. Chem. Commun., 2014, 50 (42), 5633-5636.

[179] Verrier, C.; Moebs-Sanchez, S.; Queneau, Y.; Popowycz, F. The Piancatelli reaction and its variants: recent applications to high added-value chemicals and biomass valorization. Org. Biomol. Chem., 2018, 16 (5), 676-687.

[180] Lichtenthaler, F. W.; Brust, A.; Cuny, E. Sugar-derived building blocks. Part 26. Hydrophilic pyrroles, pyridazines and diazepinones from -fructose and isomaltulose. Green Chem., 2001, 3 (5), 201-209.

[181] Heugebaert, T. S. A.; Stevens, C. V.; Kappe, C. O. Singlet-Oxygen Oxidation of 5Hydroxymethylfurfural in Continuous Flow. ChemSusChem, 2015, 8 (10), 1648-1651.

[182] Kucherov, F. A.; Galkin, K. I.; Gordeev, E. G.; Ananikov, V. P. Efficient route for the construction of polycyclic systems from bioderived HMF. Green Chem., 2017, 19 (20), 4858-4864.

[183] Galkin, K. I.; Kucherov, F. A.; Markov, O. N.; Egorova, K. S.; Posvyatenko, A. V.; Ananikov, V. P. Facile Chemical Access to Biologically Active Norcantharidin Derivatives from Biomass. Molecules, 2017, 22 (12), 2210.

[184] Higson, S.; Subrizi, F.; Sheppard, T. D.; Hailes, H. C. Chemical cascades in water for the synthesis of functionalized aromatics from furfurals. Green Chem., 2016, 18 (7), 1855-1858.

[185] Lin, Z.; Ierapetritou, M.; Nikolakis, V. Aromatics from Lignocellulosic Biomass: Economic Analysis of the Production of p-Xylene from 5-Hydroxymethylfurfural. AlChE J., 2013, 59 (6), 2079-2087.

[186] Ni, L.; Xin, J.; Dong, H.; Lu, X.; Liu, X.; Zhang, S. A Simple and Mild Approach for the Synthesis of pXylene from Bio-Based 2,5-Dimethyfuran by Using Metal Triflates. ChemSusChem, 2017, 10 (11), 2394-2401.

[187] Shiramizu, M.; Toste, F. D. On the Diels-Alder Approach to Solely Biomass-Derived Polyethylene Terephthalate (PET): Conversion of 2,5-Dimethylfuran and Acrolein into p-Xylene. Chem. Eur. J., 2011, 17 (44), 12452-12457.

[188] Serum, E. M.; Sermadurai, S.; Zimmermann, N.; Sibi, M. P. Valorization of 2,5-Furandicarboxylic Acid. Diels-Alder Reactions with Benzyne. Green Chem., 2018, 20 (7), 1448-1454.

[189] Pacheco, J. J.; Labinger, J. A.; Sessions, A. L.; Davis, M. E. Route to Renewable PET: Reaction Pathways and Energetics of Diels-Alder and Dehydrative Aromatization Reactions Between Ethylene and Biomass-Derived Furans Catalyzed by Lewis Acid Molecular Sieves. ACS Catal., 2015, 5 (10), 5904-5913.

[190] Chang, C.-C.; Je Cho, H.; Yu, J.; Gorte, R. J.; Gulbinski, J.; Dauenhauer, P.; Fan, W. Lewis acid zeolites for tandem Diels-Alder cycloaddition and dehydration of biomass-derived dimethylfuran and ethylene to renewable p-xylene. Green Chem., 2016, 18 (5), 1368-1376.

[191] Song, S.; Wu, G.; Dai, W.; Guan, N.; Li, L. Diels-Alder and dehydration reactions of furan derivatives with ethylene catalyzed by liquid Brønsted acids and Lewis acids. J. Mol. Catal. A: Chem., 2016, 420, 134-141.

[192] Do, P. T. M.; McAtee, J. R.; Watson, D. A.; Lobo, R. F. Elucidation of Diels-Alder Reaction Network of 2,5-Dimethylfuran and Ethylene on HY Zeolite Catalyst. ACS Catal., 2013, 3 (1), 41-46.

[193] Pacheco, J. J.; Davis, M. E. Synthesis of terephthalic acid via Diels-Alder reactions with ethylene and oxidized variants of 5-hydroxymethylfurfural. Proc. Natl. Acad. Sci. U. S. A., 2014, 111 (23), 8363-8367.

[194] McNelis, B. J.; Sternbach, D. D.; MacPhail, A. T. Synthetic and kinetic studies of substituent effects in the furan intramolecular Diels-Alder reaction. Tetrahedron, 1994, 50 (23), 6767-6782.

[195] Sun, S.; Murray, W. V. Solid Phase Diels-Alder Reactions of Amino Acid Derived Trienes. J. Org. Chem., 1999, 64 (16), 5941-5945.

[196] Schinzer, D.; Bourguet, E.; Ducki, S. Synthesis of Furano-Epothilone D. Chem. Eur. J., 2004, 10 (13), 3217-3224.

[197] Koh, P. F.; Loh, T. P. Synthesis of biologically active natural products, aspergillides A and B, entirely from biomass derived platform chemicals. Green Chem., 2015, 17 (7), 3746-3750.

[198] Connolly, T. J.; Considine, J. L.; Ding, Z.; Forsatz, B.; Jennings, M. N.; MacEwan, M. F.; McCoy, K. 
M.; Place, D. W.; Sharma, A.; Sutherland, K. Efficient Synthesis of 8-Oxa-3-aza-bicyclo[3.2.1]octane Hydrochloride. Org. Process Res. Dev., 2010, 14 (2), 459-465.

[199] Oikawa, M.; Ikoma, M.; Sasaki, M. Parallel synthesis of tandem Ugi/Diels-Alder reaction products on a soluble polymer support directed toward split-pool realization of a small molecule library. Tetrahedron Lett., 2005, 46 (3), 415-418.

[200] Gupta, P.; Singh, S. K.; Pathak, A.; Kundu, B. Template-directed approach to solid-phase combinatorial synthesis of furan-based libraries. Tetrahedron, 2002, 58 (52), 10469-10474.

[201] Müller, C.; Diehl, V.; Lichtenthaler, F. W. Building blocks from sugars. Part 23. Hydrophilic 3pyridinols from fructose and isomaltulose. Tetrahedron, 1998, 54 (36), 10703-10712.

[202] Villard, R.; Robert, F.; Blank, I.; Bernardinelli, G.; Soldo, T.; Hofmann, T. Racemic and Enantiopure Synthesis and Physicochemical Characterization of the Novel Taste Enhancer N-(1-Carboxyethyl)-6(hydroxymethyl)pyridinium-3-ol Inner Salt. J. Agric. Food Chem., 2003, 51 (14), 4040-4045.

[203] Koch, J.; Pischetsrieder, M.; Polborn, K.; Severin, T. Formation of pyridinium betaines by reaction of hexoses with primary amines. Carbohydr. Res., 1998, 313 (2), 117-123.

[204] Frank, O.; Ottinger, H.; Hofmann, T. Characterization of an Intense Bitter-Tasting $1 \mathrm{H}, 4 \mathrm{H}-$ Quinolizinium-7-olate by Application of the Taste Dilution Analysis, a Novel Bioassay for the Screening and Identification of Taste-Active Compounds in Foods. J. Agric. Food Chem., 2001, 49 (1), 231-238.

[205] Soldo, T.; Hofmann, T. Application of Hydrophilic Interaction Liquid Chromatography/Comparative Taste Dilution Analysis for Identification of a Bitter Inhibitor by a Combinatorial Approach Based on Maillard Reaction Chemistry. J. Agric. Food Chem., 2005, 53 (23), 9165-9171.

[206] Sowmiah, S.; Veiros, L. F.; Esperanca, J. M.; Rebelo, L. P.; Afonso, C. A. Organocatalyzed One-Step Synthesis of Functionalized N-Alkyl-Pyridinium Salts from Biomass Derived 5-Hydroxymethylfurfural. Org. Lett., 2015, 17 (21), 5244-5247.

[207] Rajmohan, R.; Gayathri, S.; Vairaprakash, P. Facile synthesis of 5-hydroxymethylfurfural: a sustainable raw material for the synthesis of key intermediates toward 21,23-dioxaporphyrins. RSC Adv., 2015, 5 (121), 100401-100407.

[208] McDermott, P. J.; Stockman, R. A. Combining Two-Directional Synthesis and Tandem Reactions: Synthesis of Trioxadispiroketals. Org. Lett., 2005, 7 (1), 27-29. 